\title{
INVESTIGATING HEMODYNAMIC RESPONSES TO ELECTRICAL NEUROSTIMULATION
}

\author{
A Thesis \\ presented to \\ the Faculty of California Polytechnic State University, \\ San Luis Obispo
}

\author{
In Partial Fulfillment \\ of the Requirements for the Degree \\ Master of Science in Biomedical Engineering
}

by

Sean Youra

August 2014 
(C) 2014

Sean Youra

ALL RIGHTS RESERVED 


\section{COMMITTEE MEMBERSHIP}

TITLE:

Investigating Hemodynamic Responses to

Electrical Neurostimulation

AUTHOR:

Sean Youra

DATE SUBMITTED:

August 2014

COMMITTEE CHAIR:

Dr. Trevor Cardinal

Associate Professor of Biomedical Engineering

COMMITTEE MEMBER: Dr. Kristen Cardinal

Associate Professor of Biomedical Engineering

COMMITTEE MEMBER: Stuart Rosenberg

St. Jude Medical

COMMITTEE MEMBER: Dr. Melanie Goodman Keiser

St. Jude Medical 


\begin{abstract}
Investigating Hemodynamic Responses to Electrical Neurostimulation
\end{abstract}

\title{
Sean Youra
}

Since the 1900s, the number of deaths attributable to cardiovascular disease has steadily risen. With the advent of antihypertensive drugs and non-invasive surgical procedures, such as intravascular stenting, these numbers have begun to level off. Despite this trend, the number of patients diagnosed with some form of cardiovascular disease has only increased. By 2030, prevalence of coronary heart disease is expected to increase approximately by $18 \%$ in the United States. By 2050 , prevalence of peripheral arterial occlusive disease is expected to increase approximately by $98 \%$ in the U.S. No single drug or surgical intervention offers a complete solution to these problems. Thus, a multifaceted regimen of lifestyle changes, medication, and device or surgical interventions is usually necessary. A potential adjunct therapy and cost-effective solution for treating cardiovascular disease that has been overlooked is neurostimulation.

Recent studies show that using neurostimulation techniques, such as transcutaneous electrical nerve stimulation (TENS), can help to reduce ischemic pain, lower blood pressure, increase blood flow to the periphery, and decrease systemic vascular resistance. The mechanisms by which these hemodynamic changes occur is still under investigation. The primary aim of this thesis is to elucidate these mechanisms through a thorough synthesis of the existing literature on this subject. Neurostimulation, specifically TENS, is thought to modulate both the metaboreflex and norepinephrine release from sympathetic nerve terminals.

To test the hypothesis that TENS increases local blood flow, decreases mean arterial pressure, and decreases cutaneous vascular resistance compared to placebo, in which the electrodes are attached but no electrical stimulation is applied, a protocol was developed to test the effect of neurostimulation on healthy subjects. Implementation of this protocol in a pilot study will determine if neurostimulation causes significant changes in blood flow using the most relevant perfusion measurement instrumentation. Before conducting this study, pre-pilot comparison studies of interferential current therapy (IFC) versus TENS, low frequency $(4 \mathrm{~Hz})$ TENS versus high frequency $(100 \mathrm{~Hz})$ TENS, and electrode placement on the back versus the forearm were conducted. The only statistically significant difference found was that the application of IFC on the back decreased the reperfusion time, meaning that the time required to reach the average baseline perfusion unit value after occlusion decreased. Further pre-pilot work investigating these different modalities and parameters is necessary to ensure that favorable hemodynamic changes can be detected in the pilot study.

Keywords: neurostimulation, hemodynamics, ischemia, transcutaneous electrical nerve stimulation, interferential current therapy 


\section{ACKNOWLEDGMENTS}

I would first like to thank Dr. Melanie Goodman and Stuart Rosenberg for all the time and effort they invested into this project to provide us with continual feedback and guide us along the way. I feel so fortunate to have been a part of such an important scientific endeavor. I have learned so much more from the project alone than I could have from any one course, and I look forward to what future iterations of this project will accomplish. I would also like to thank St. Jude Medical for its gracious funding of this MEDITEC project and for providing students such as myself the opportunity to conduct cutting-edge research with "real world" implications.

Next, I would like to thank Dr. Trevor Cardinal for being such a supportive faculty advisor to my thesis. I appreciate all the time and effort you invested as well into guiding the project along and providing feedback when requested.

I would like to recognize Dr. Kristen Cardinal's efforts in helping to deal with the financial aspects of this project and for being the one to recommend me for this project in the first place. Between working in the tissue engineering lab, and taking both your and Trevor's classes throughout my college career, I have learned a tremendous amount that I hope to one day apply in the medical device industry. Cal Poly is truly lucky to have both of you teaching here.

My partner in this project, Stacey Fishman, also deserves honorable mention for all her help and support, her willingness to be one of our "guinea pig" test subjects, and serving as my own personal sanity check along the way. I would have not been able to do this without you.

Last, but certainly not least, my family and friends have been so paramount to my success in college and in life in general. Thank you all for being there when I need it most. Your love and support has not gone unnoticed, and I hope that I will be able to return the favor in days to come.

"Nothing is impossible; there are ways that lead to everything, and if we had sufficient will we should always have sufficient means. It is often merely for an excuse that we say things are impossible." - Francois de La Rochefoucauld 


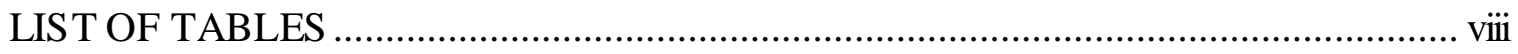

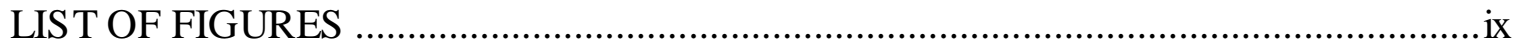

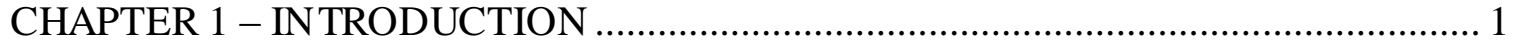

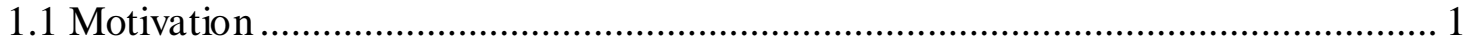

1.1.1 Peripheral Arterial Occlusive Disease ............................................................ 1

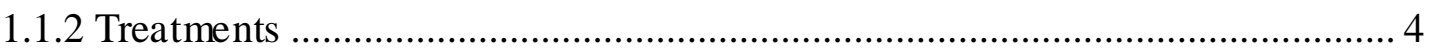

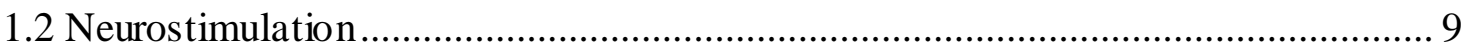

1.3 Overview and Aims of the Thesis ........................................................................... 21

CHAPTER 2 - NEUROSTIMULATION TECHNIQUES …………….......................... 24

2.1 Transcutaneous Electrical Nerve Stimulation ........................................................... 24

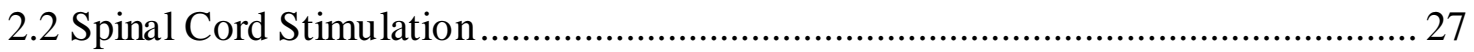

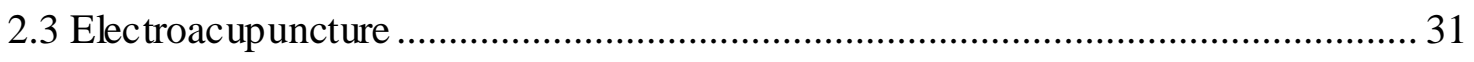

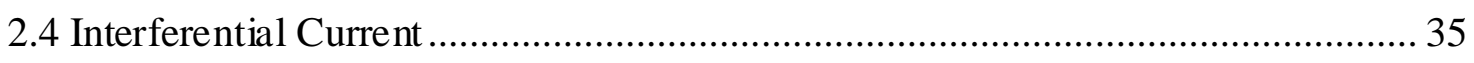

CHAPTER 3 - PERFUSION MEASUREMENT INSTRUMENTATION ...................... 39

3.1 Justification for Non-invasive Measurements of Perfusion ....................................... 39

3.2 Laser Doppler Flowmetry ………...................................................................... 40

3.3 Laser Speckle Contrast Analysis ....................................................................... 44

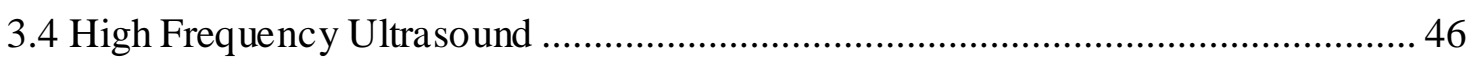

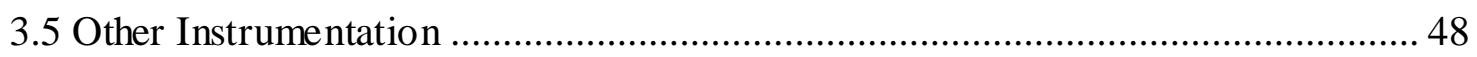

CHAPTER 4 - CLINICAL PILOT STUDY DESIGN …………………………........ 51

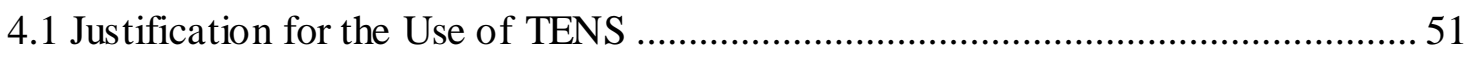

4.2 Mechanism of Action of TENS on Hemodynamics .............................................. 52

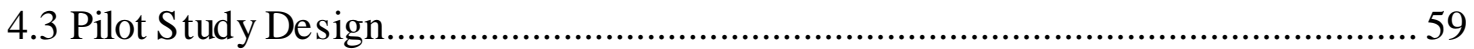

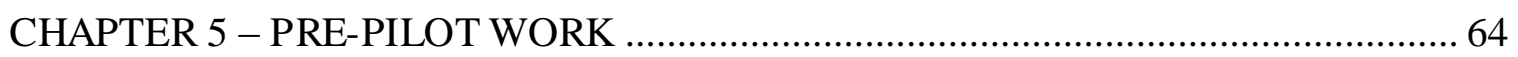

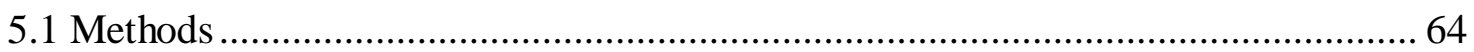

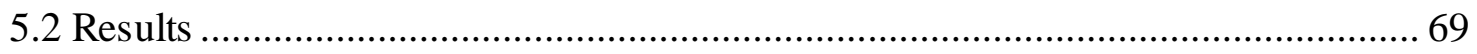

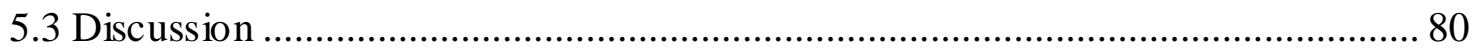

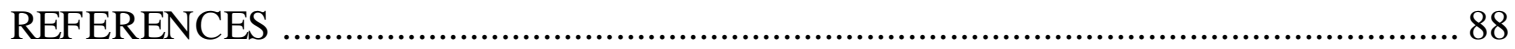

APPENDICES

Appendix A: Summary of Select Neurostimulation Studies on Hemodynamics ....... 105

Appendix B: Informed Consent Form..................................................................... 114 
Appendix C: Medical History And Screening Form............................................ 116

Appendix D: Numeric Pain Rating Scale ............................................................. 118

Appendix E: Protocol For The Pilot Study ............................................................ 119

Appendix F: Averages From Pre-Pilot Work ..................................................... 122

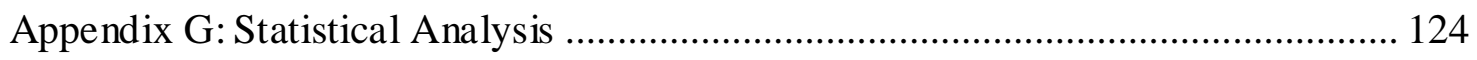




\section{LIST OF TABLES}

Table 4.1: Expected Outcomes for Systemic Hemodynamic Parameters and Pain Intensity for both Control and TENS Groups with and without PECO .................. 63

Table 5.1: Treatment Parameters for TENS and IFC Testing....................... 67

Table A.1: Summary of TENS studies..................................... 105

Table A.2: Summary of SCS studies...................................... 109

Table A.3: Summary of EA studies...................................... 111

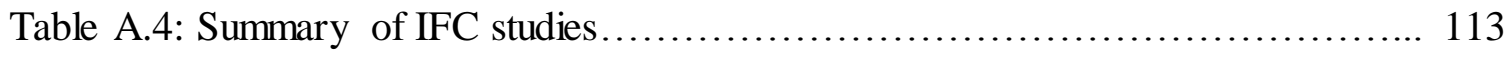

Table F.1: Average percent change for all hemodynamic parameters for each treatment condition................................................... 122

Table G.1: Two-way Repeated Measures ANOVA P-values for Hemodynamic Endpoints. 


\section{LIST OF FIGURES}

Figure 1.1: Prevalence of large-vessel PAOD (LV-PAD) in American patients

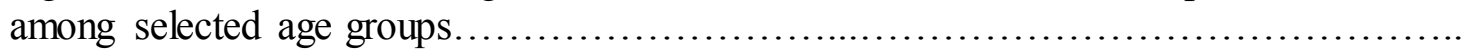

Figure 1.2: Progression of atherosclerosis. Early atherosclerosis characterized by increased plaque buildup within the vessel. Advanced atherosclerosis characterized by proliferation of smooth muscle into the tunica intima, thickening of the tunica

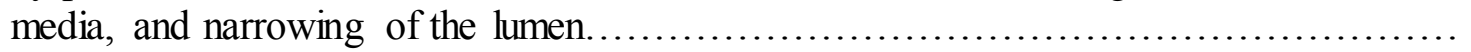

Figure 1.3: A longitudinal section view of the insertion of a stent within an artery 1) Balloon and stent are guided to the plaque location using a catheter guidewire 2) The balloon is inflated expanding the stent and pushing the plaque up against the vessel wall 3) After deflating the balloon and removing the catheter, the stent remains in place and integrates with the host tissue over time

Figure 1.4: Peripheral artery bypass circumvents the occluded areas within the lower extremities, allowing blood to reach the tissue downstream of the blockage.

Figure 1.5: Schematic diagrams of both the pattern theory and specificity theory. In the pattern theory, nonspecific receptors in the skin respond to both noxious and innocuous stimuli, which are transmitted to the dorsal root ganglion (DRG) neurons, each of which has different levels of responsiveness to stimuli; the pattern of firing determines the stimulus type. In the specificity theory, each stimulus type is encoded in its own unique pathway e.g. a noxious stimulus is transmitted to DRG nociceptors and then to dorsal horn nociceptive neurons.

Figure 1.6: Cross-section of the spinal cord at the cervical level depicting the various tracts and regions; the substantia gelatinosa is located within the dorsal horn (upper right)

Figure 1.7: Average diameters and conduction velocities for primary afferent neurons; more myelination increases conduction velocity.

Figure 1.8: Schematic of the gate control system where A-fibers and C-fibers innervate the SG and first central transmission (T) cells. The SG inhibitory effect on the $\mathrm{T}$ cells is influenced by the relative activities of the A-fibers and $\mathrm{C}$-fibers. This, combined with central control mechanisms, leads to some sensory and response output by the action system. 
Figure 1.9: Diagram of how somatosensory information travels from the periphery to the brain. All fibers travel up through the dorsal root ganglion (DRG) and synapse at the dorsal horn within different laminae as well as with the wide dynamic range (WDR) neurons; only $\mathrm{C}$-fibers and $\mathrm{A} \delta$-fibers synapse with nociceptive specific (NS) neurons. Projection neurons, shown as black arrows, innervate the periaqueductal grey (PAG), parabrachial area $(\mathrm{PB})$, and thalamus. Descending pathways, shown as yellow arrows, project from the rostral ventromedial medulla (RVM) and other brainstem regions to the dorsal horn.

Figure 2.1: A dual-channel TENS unit consisting of four electrodes positioned over different regions of the body for treating peripheral pain.....

Figure 2.2: Overview of SCS procedure showing where the electrodes and IPG are placed as well as the basic functions of each component.

Figure 2.3: Possible mechanism of action for SCS-induced hemodynamic changes. High intensity electrical stimulation in the epidural space activates both $A \delta$-fibers and $\mathrm{C}$-fibers in the dorsal root ganglion (DRG), both of which activate extracellular signal-regulated kinase (ERK) and protein kinase B (AKT) that cause activation of the transient receptor potential vanilloid receptor-1 (TRPV-1) on these neurons. Activation of TRPV-1 releases CGRP that causes systemic effects such as release of nitric oxide (NO) from ECs and SMC relaxation, leading to increased blood flow and decreased vascular resistance..............................................

Figure 2.4: Set-up of an EA unit on a patient, consisting of electrodes with leads inserted into a programmable stimulator.

Figure 2.5: Diagram showing how a dual-channel IFC unit can be applied to the skin surface to produce an AMF and potentially cause pain relief within deep tissue... 36

Figure 3.1: Light from the incident source impinges on both non-moving components within the tissue and from RBCs, which is then reflected back to a photodetector and processed.

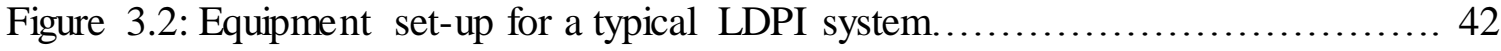

Figure 3.3: Blood perfusion map using LDPI on the hand; participant subjected to a vascular occlusion test to simulate ischemia; perfusion scale bar shown on right....

Figure 3.4: The number of publications utilizing the LDF method, either LDPM or LDPI, from 1980 through 2006 
Figure 3.5: Color Doppler image of the brain cortex showing blood flow away from the transducer in blue and blood flow toward the transducer in red.

Figure 3.6: Siemens Inveon Micro-CT/PET system capable of ultra-high resolutions down to $15 \mu \mathrm{m}$.

Figure 4.1: Diagram of the proposed mechanisms for TENS-induced changes on the cardiovascular system in PAOD patients, involving a reduction in the metaboreflex and presynaptic inhibition of NE from sympathetic neurons. GABA: Gamma-aminobutryic Acid; MAP: Mean Arterial Pressure; ROS: Reactive Oxygen Species; NE: Norepinephrine.

Figure 4.2: Dermatomes for the various regions of the human body. 60

Figure 4.3: Study flow diagram for the pilot study.

Figure 5.1: Representative data trace showing the raw breath signal in $\mathrm{mV}$, the respiratory rate in $\mathrm{BPM}$, the grip force in $\mathrm{N}$, and the blood flow measurements at the two different locations in PU

Figure 5.2: Experimental set-up for pre-pilot work A) Manual blood pressure cuff B) Hand dynamometer C) Digital blood pressure cuff D) Respiration belt E) LDF system F) PowerLab system G) Blood pressure monitor H) Stimulator I) Laptop with LabChart software

Figure 5.3: Electrode placement for: IFC on the forearm (upper left), TENS on the forearm (upper right), IFC on the back (lower left), and TENS on the back (lower right); 1) Channel 1 of the stimulator 2) Channel 2 of the stimulator

Figure 5.4: Pain intensity according to the NRS during each interval for all treatment conditions.

Figure 5.5: Blood flow in the left palm, measured as percent change from baseline reading, for all treatment conditions

Figure 5.6: Blood flow in the left anterior brachial region, measured as percent change from baseline reading, for all treatment conditions 
Figure 5.7: Average reperfusion time, which is the time from the start of hyperemia after occlusion to the first instance where blood flow reaches the average baseline value, for all treatment conditions; $* p<0.05$ compared to control.

Figure 5.8: Systolic blood pressure, measured as percent change from baseline reading, for all treatment conditions

Figure 5.9: Diastolic blood pressure, measured as percent change from baseline reading, for all treatment conditions...

Figure 5.10: Heart rate, measured as percent change from baseline reading, for all treatment conditions.

Figure 5.11: Estimated mean arterial pressure, measured as percent change from baseline reading, for all treatment conditions

Figure 5.12: Estimated cutaneous vascular resistance in the left palm, measured as percent change from baseline reading, for all treatment conditions.

Figure 5.13: Estimated cutaneous vascular resistance in the left anterior brachial region, measured as percent change from baseline reading, for all treatment conditions

Figure 5.14: Diagram detailing the pre-pilot work that still needs to be conducted and what specific parameters should be analyzed before the pilot study...

Figure D.1: TENS Electrode Placement at the C7 and T4 Regions 120 


\section{CHAPTER 1 - INTRODUCTION}

\subsection{Motivation}

\subsubsection{Peripheral Arterial Occlusive Disease}

Peripheral arterial occlusive disease (PAOD) affects 8 to 12 million Americans, which is expected to increase to about 19 million by 2050 [1-3]. PAOD affects patients greater than 65 years of age significantly more than younger patients (Figure 1.1).

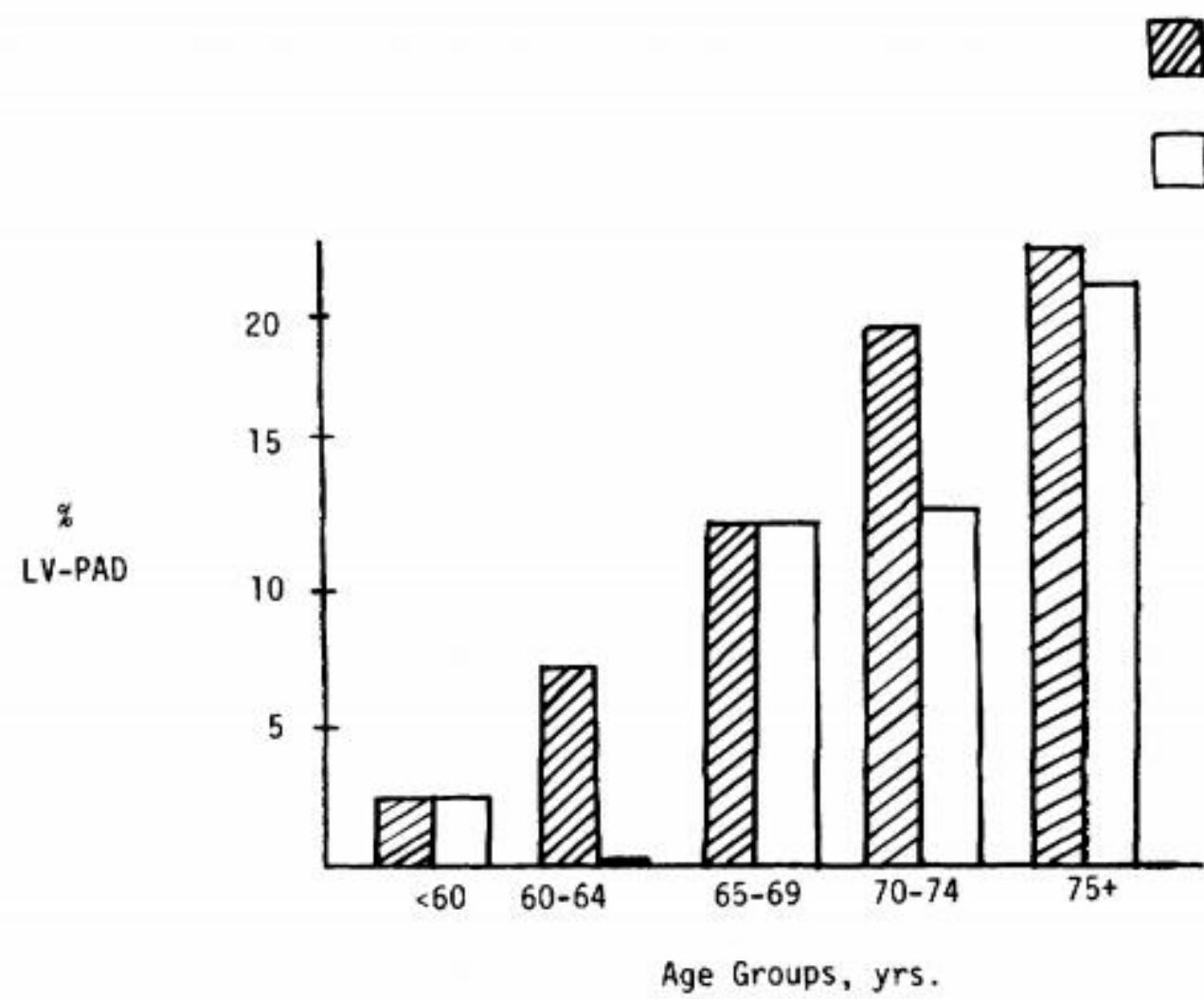

Figure 1.1: Prevalence of large-vessel PAOD (LV-PAD) in American patients among selected age groups [4]

PAOD is one of three serious forms of ischemic disease; the other two are cerebrovascular disease (CVD) and coronary artery disease (CAD). Ischemic disease is responsible for more deaths in the United States than any other condition [5]. 
The etiology behind all these forms of ischemic disease is atherogenesis, whereby plaque builds up in the artery wall causing it to thicken, which eventually manifests itself as atherosclerosis, i.e. mature, vulnerable plaques and stiffening of the vessel wall. Atherogenesis is a positive feedback mechanism induced by turbulent shear stresses within the arteries, usually at bifurcation points. Normally, changes in laminar shear is resolved by outward or inward vessel remodeling. However, turbulent shear cannot be adequately resolved at these bifurcation points, which continually activates the endothelium, i.e. the shear induces a proinflammatory and procoagulant state. The activation of the endothelium causes endothelial cells (ECs) to separate, express adhesion proteins, such as intercellular adhesion molecule-1 (ICAM-1), and secrete cytokines, such as monocyte chemoattractant protein-1 (MCP-1). MCP-1 triggers migration of leukocytes into the intima and ICAM-1 binds the leukocytes to the ECs. These leukocytes, specifically monocytes, mature into macrophages that phagocytose lipids, e.g. low-density lipoproteins (LDLs) in the subendothelial space. After ingesting enough LDLs, the macrophages transform into foam cells, which activate T-helper cells that secrete interferon- $\gamma(\mathrm{INF}-\gamma)$ and tumor necrosis factor- $\alpha$ (TNF- $\alpha)$, both of which activate the endothelium. In addition, TNF- $\alpha$ causes proliferation of smooth muscle cells (SMCs) into the intima [6]. The proliferation of SMCs is one of the few events in this whole cellular cascade that seems to have more of a reparative effect. Once in the intima, SMCs produce matrix proteins, such as collagen and elastin, that contribute to the formation of the fibrous cap over the plaque, providing structural stability to the lesion and reducing the chance of it rupturing. Plaque mainly consists of calcium hydroxyapatite, microvasculature, fibrous tissue, cholesterol, and fats, as well as inflammatory cells, such 
as $\mathrm{T}$ cells and macrophages, at the periphery of the plaque. Plaque composition and size will eventually determine clinical prognosis for PAOD patients i.e. the smaller the size and the more stable the plaque, the less severe the disease tends to be [7]. Over time, plaque buildup changes the properties and physical appearance of the artery, as illustrated in Figure 1.2.

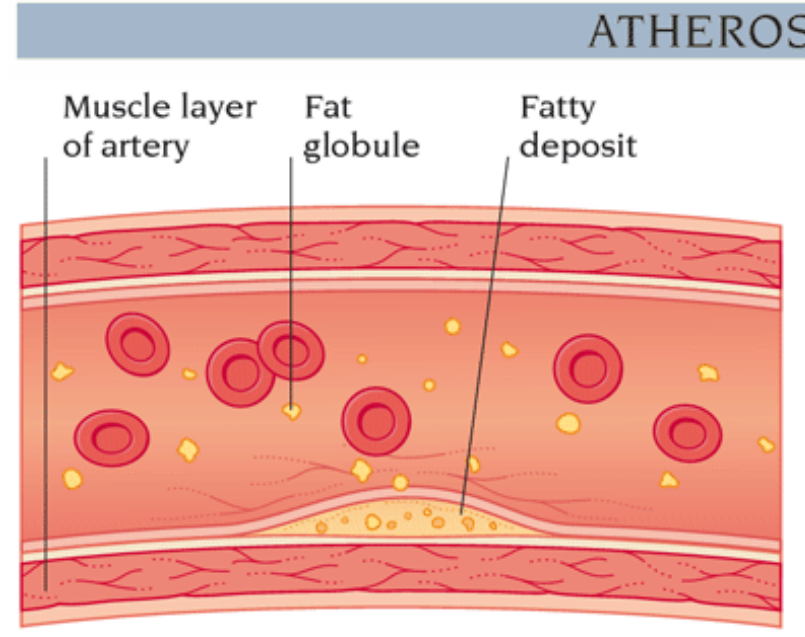

EARLY ATHEROSCLEROSIS

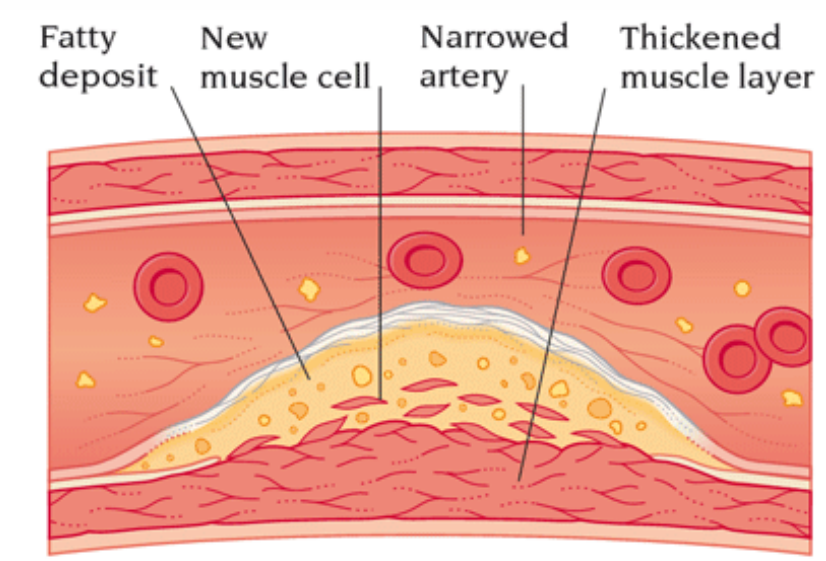

ADVANCED ATHEROSCLEROSIS

Figure 1.2: Progression of atherosclerosis. Early atherosclerosis characterized by increased plaque buildup within the vessel. Advanced atherosclerosis characterized by proliferation of smooth muscle into the tunica intima, thickening of the tunica media, and narrowing of the lumen [8]

In the case of PAOD and other ischemic diseases, endogenous revascularization is impaired, i.e. arteriogenesis and angiogenesis, as well as vasodilation of the collateral vessels [6]. The walls of the artery begin to harden and blood flow is impeded as the condition worsens, causing ischemia and hypoxia. If exacerbated through continual endothelium activation, thrombus formation may occur. Eventually, a myocardial infarction (MI) or stroke may occur if the thrombus detaches from the vessel wall and becomes an embolus that reaches the heart or brain, respectively. Both an MI and stroke 
can cause immediate death; even if they do not, the lifespan of the individual will be drastically shortened.

The symptoms of atherosclerosis may remain silent until there is a significant reduction in blood flow. If this occurs in the heart, symptoms such as angina pectoris and shortness of breath tend to develop. Worsening angina pectoris, especially at rest, may signal an imminent MI. If this occurs in the brain, a number of motor and neurological problems may result, such as speech deterioration, breathing difficulty, and bladder incontinence. As blood flow is further impeded, a stroke can occur, potentially causing significant brain damage. If this occurs in the peripheral limbs, claudication is the most common symptom, although many patients do not report this to their physician.

Claudication makes exercise and even normal daily activity difficult because of the ischemic pain. Atherosclerosis may also occur in the kidneys i.e. ischemic nephropathy, causing a host of symptoms such as uremia, dyspnea, hypertension, and kidney atrophy. If hypoperfusion occurs in both kidneys, it may lead to renal failure. There are a number of risk factors associated with ischemic disease including lack of exercise, poor nutrition, smoking, hypertension, diabetes, obesity, and a family history of heart disease [5].

\subsubsection{Treatments}

The first-line treatment option against ischemic disease is usually lifestyle changes. A patient's diet can be carefully controlled by limiting their intake of calories, fat, and sodium, so that blood pressure is reduced. Frequently, medication may also be prescribed to lower cholesterol levels. Cholesterol medication includes statins, niacin, bile-acid resins, fibric acid derivatives, and cholesterol absorption inhibitors. Many of these lower LDL and triglyceride levels while slightly raising HDL levels [9]. The rationale behind this is that lowering LDLs should cause less endothelial activation and 
raising HDLs should increase reverse cholesterol transport, whereby HDLs remove lipids from the surface of foam cells and transport them to the liver for processing [6]. Statins are the most commonly prescribed cholesterol medications to treat atherosclerosis, because they reduce all-cause mortality by about $14 \%$ and major adverse cardiac events by more than $20 \%$ [10]. Other lifestyle changes include smoking cessation and a regular exercise regimen that includes aerobic and resistance training, both of which can improve pain-free walking distance in patients with PAOD $[3,11]$. In fact, under direct supervision, maximal walking distance may improve by an estimated $120 \%$ compared to before the start of the exercise training program [12]. The mechanisms behind this improvement in walking distance are attributed to enhanced vaso-responsiveness, angiogenesis, and arteriogenesis [13, 14].

The advent of antihypertensive drugs has vastly improved our ability to control many of the symptoms associated with atherosclerosis. Numerous variants of such drugs exist on the market today including diuretics, adrenergic inhibitors such as beta-blockers, angiotensin-converting-enzyme (ACE) inhibitors, and calcium channel blockers. Diuretics have been prescribed for decades and are considered the "gold standard" of antihypertensive drugs. Diuretics inhibit sodium and chloride reabsorption, which decreases extracellular fluid volume, cardiac output, and peripheral vascular resistance. In this way, they offer protection against myocardial infarction (MI), stroke, and heart failure [15]. Beta-blockers suppress over-activity of the sympathetic nervous system (SNS) by inhibiting beta-adrenergic norepinephrine receptors, which in turn reduces heart rate $(\mathrm{HR})$, cardiac output $(\mathrm{CO})$, and blood pressure $(\mathrm{BP})$. This is especially important for both older individuals and PAOD patients who have an overactive SNS [16]. ACE 
inhibitors block the synthesis of angiotensin II in the renin-angiotensin system. Normally, renin is converted into angiotensin I via angiotensinogen, and then subsequently angiotensin I is converted into angiotensin II via ACE. Angiotensin II is a potent vasoconstrictor, so ACE inhibitors reduce vasoconstriction [15]. They are commonly prescribed to congestive heart failure (CHF) patients to lower mean arterial pressure (MAP) and decrease systemic vascular resistance (SVR), and diabetic renal disease patients to increase renal blood flow and sodium excretion rates, which improves renal functioning $[17,18]$. Calcium-channel blockers cause vasodilation by blocking L-type calcium channels on arterial SMCs, which decreases BP, especially in the case of hypertension. Calcium-channel blockers may also be combined with beta-blockers for enhanced cardioprotective effects by further increasing blood flow and reducing BP [15]. As the disease progresses, a more aggressive surgical procedure may be needed. If the plaque buildup is limited to one particular area, then balloon angioplasty combined with stenting is commonly used. In this procedure, a balloon-tipped catheter is inserted into the femoral artery and guided to the area of interest. The balloon is then inflated, pushing the plaque up against the walls of the artery, which helps to improve blood flow in the region by temporarily relieving stenosis. Another balloon with a mounted stent is guided to the blockage and expanded in the same way. The stent is a permanent fixture that is used to prevent elastic recoil of the vessel wall. The basic surgical procedure is shown in Figure 1.3. 


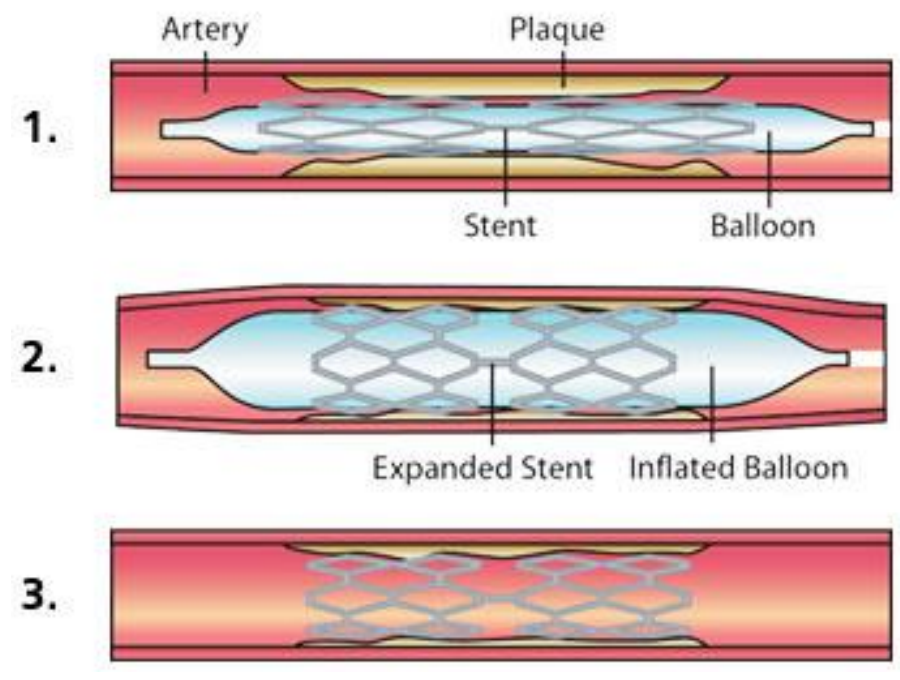

Figure 1.3: A longitudinal section view of the insertion of a stent within an artery 1) Balloon and stent are guided to the plaque location using a catheter guidewire 2) The balloon is inflated expanding the stent and pushing the plaque up against the vessel wall 3) After deflating the balloon and removing the catheter, the stent remains in place and integrates with the host tissue over time [19]

The advantage of this procedure is that it is minimally invasive, so the recovery time and risk associated with the procedure are significantly reduced. However, there are many cases in which angioplasty and stenting may not be a viable option. For example, if there are multiple sites of blockage, if the artery itself it too small, or if there is a complete blockage in the region, then peripheral artery bypass surgery may be necessary. Peripheral artery bypass utilizes autologous, healthy functioning vessels, commonly the great saphenous vein, or a synthetic graft such as Dacron or PTFE, to create a detour around the blockage, as can be seen in Figure 1.4 [20]. Higher patency rates, i.e. unobstructed and open vessel lumens, are typically seen when autologous vein grafts are used compared to synthetic grafts [21]. As compared to angioplasty and stenting, this procedure is much more invasive and expensive [22], but is associated with lower amputation rates and higher survival rates [20]. 

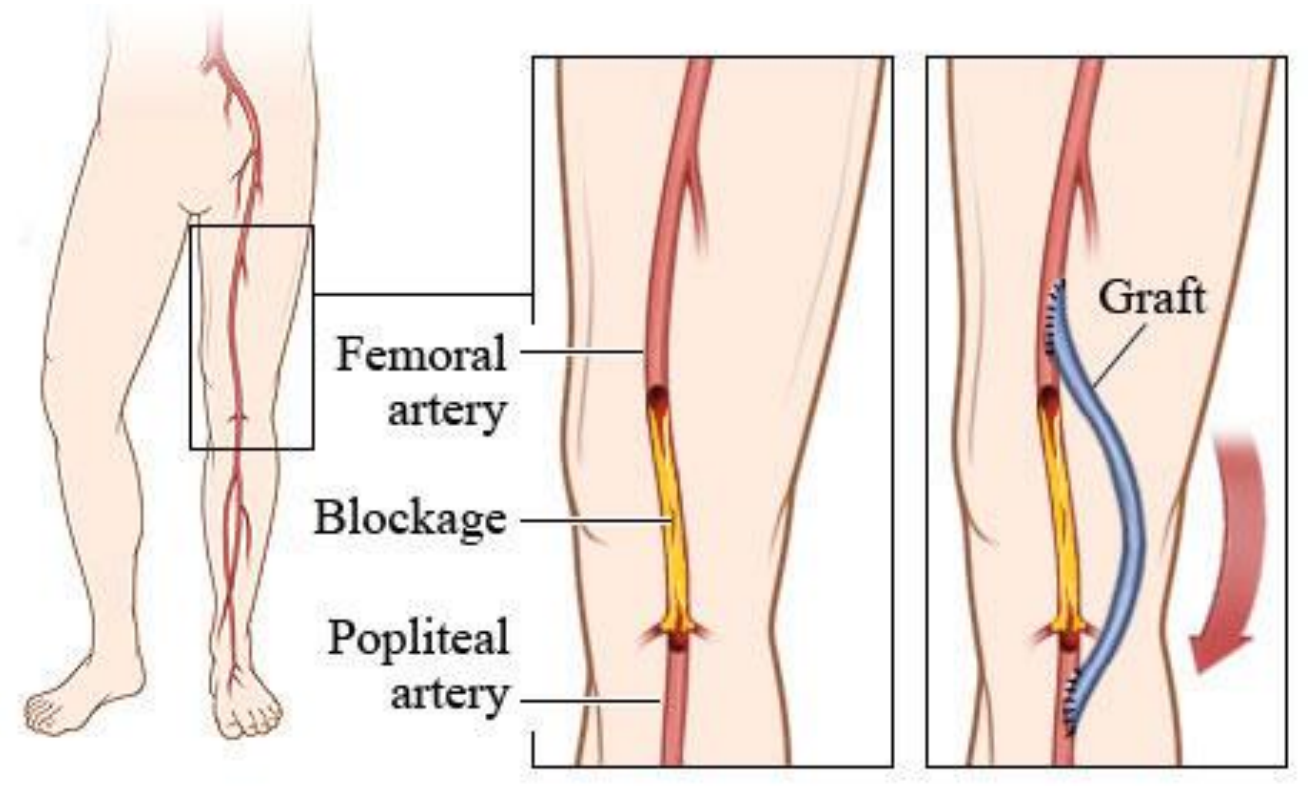

Figure 1.4: Peripheral artery bypass circumvents the occluded areas within the lower extremities, allowing blood to reach the tissue downstream of the blockage [23]

All treatments available for atherosclerosis have limited efficacy, especially longterm. In the case of lifestyle changes, such as exercise, the progression of the disease may be slowed and the quality of life may be improved, but in more severe cases, such as critical limb ischemia, this may have little to no effect [21]. Statins carry many possible side-effects including memory loss, liver damage, and hyperglycemia [9]. Both diuretics and beta-blockers may cause insulin resistance, while calcium-channel blockers, specifically Nifedipine, may provoke myocardial ischemia from reflex tachycardia [15]. Not only are peripheral bypass grafts more invasive and expensive than angioplasty and stenting, but they also exhibit lower patency rates and higher reintervention rates [24], hence stenting is now more commonly used in hospitals across the U.S. [25]. However, even with stenting, there is a risk of possible infection at the catheter insertion site and restenosis with bare-metal stents (BMS) [26]. The restenosis issue has been partially ameliorated with the advent of drug-eluting stents (DES) that prevent restenosis [27]. 
Specifically, paclitaxel-eluting stents exhibit the lowest vascular restenosis [28, 29], but in-stent thrombosis is actually higher with DES following the removal of anti-platelet agents compared to BMS [30, 31]. Because all current treatments suffer from various inadequacies, novel treatment options must be explored and implemented.

As an adjunct to these treatments, neurostimulation may be used to treat the symptoms of ischemic disease, specifically the pain caused by ischemia. Although neurostimulation has been primarily used to treat chronic pain, such as low back pain, many studies now suggest that it may also reduce ischemic pain by increasing blood flow and restoring the oxygen supply to the affected area [32-37]. The mechanisms of these effects are poorly understood, mainly because there is more than one process at work. The neurostimulation technique, stimulation parameters, and patient selection all influence the changes in blood perfusion. Nonetheless, the changes in SVR, BP, and perfusion have potentially large implications for patients suffering from ischemic diseases. For example, if neurostimulation can decrease vascular resistance and blood pressure while maintaining adequate blood flow throughout the body, the workload on the heart will be reduced and the condition may be prevented from worsening. Another potential application of neurostimulation could be saving severely ischemic limbs from being amputated by restoring some blood flow to the limbs. Thus, it would be worthwhile to investigate whether neurostimulation can provide reliable analgesic, anti-ischemic benefits to these affected patients.

\subsection{Neurostimulation}

Neurostimulation uses electrodes to stimulate excitable biological tissue, which in turn modulates some part of the nervous system. Neurostimulation is the cornerstone of neural engineering (neuroengineeering) and encompasses three subfields: 
neuromodulation, stereotactic and functional neurosurgery, and functional electrical stimulation (FES) [38]. Neuromodulation acts directly upon specific nerves or regions of the brain by sending electrical, chemical, or optical signals via implantable, or nonimplantable, devices, which are used to treat neural disorders, including sensory and motor disorders. Examples of such devices include spinal cord stimulators, deep brain stimulators, and peripheral nerve stimulators, transcranial magnetic stimulators, and implanted intraspinal drug delivery pumps [39]. About a century ago, neurosurgery primarily entailed the ablation of damaged or dysfunctional nervous tissue to treat nervous system disorders, such as Parkinson's, epilepsy, and tremors, pain from spinal disc herniation, injuries of the peripheral nerves, spinal cord or head trauma, and psychiatric illnesses, but electrical neurostimulation is now more commonly used to treat these disorders. However, neurosurgery may still selectively be used depending on the patient criteria and if the patient presents any contraindications for the particular neurostimulation device. FES pertains mostly to restoring some function in the limbs following injury or ischemia by selectively stimulating the damaged nerves; this subfield also focuses on auditory and visual prostheses [38]. Because neuromodulation and FES are used for similar applications, the two terms are commonly used interchangeably, but the procedures involved in terms of leads and electrode placement do differ. Throughout the course of this thesis, the term "neurostimulation" will be used to refer specifically to neuromodulation that utilizes electrical impulses rather than neurosurgery or FES.

There are many neurostimulation techniques available today, and most focus on pain management. Some of the most common methods are transcutaneous electrical nerve stimulation (TENS), spinal cord stimulation (SCS), electroacupuncture (EA), and 
interferential current stimulation (IFC), all of which will be discussed in much greater detail in Chapter 2. To effectively manage and reduce the patient's pain, certain parameters must be carefully adjusted to provide the maximum analgesic benefits. These parameters include stimulus intensity, pulse width, and frequency. The intensity is the relative strength of the stimulation, measured in milliamps $(\mathrm{mA})$ or volts $(\mathrm{V})$ based on the stimulation unit design, i.e. a constant current unit provides variable voltage to maintain the current and outputs intensity in $\mathrm{mA}$, while a constant voltage unit provides variable current to maintain the voltage and outputs intensity in V. This is the most variable parameter, since the intensity range varies among different stimulation units. Electrode placement is the main factor driving these difference,s e.g. different intensities will be required for treating chronic back pain depending on whether the electrodes are applied on the surface of the skin or implanted within the epidural space of the spinal cord. There is considerable individual variation with intensity as well, because of differences in sensory and motor thresholds, so this parameter should be first adjusted by the physician to avoid any pain or discomfort. The intensity "feeling" will be strongly influenced by both the pulse width and frequency. Pulse width is the duration of a pulse, measured in microseconds ( $\mu \mathrm{s})$. This parameter usually ranges between 100 and $400 \mu$ s. Frequency is the rate the pulses are transmitted, measured in hertz (Hz, cycles per second). A range of 20 to $120 \mathrm{~Hz}$ is common for this parameter, although much higher frequencies may be used for SCS for improved paresthesia, but this comes with the cost of higher power requirements $[38,40]$. The lowest possible settings for all these parameters are usually chosen to conserve battery life, especially in the case of implanted stimulators [38]. 
Comprehension of the gate control theory is required to understand how neurostimulation elicits an analgesic effect. The gate control theory was first published by Ronald Melzack and Patrick Wall in 1965. Before this time, there were two mutually exclusive theories, the specificity theory and the pattern theory, both of which attempted to explain the mechanisms underlying pain. The specificity theory stated that pain is very similar to vision or hearing in that it has its own specific central and peripheral neural pathways; these pathways are direct "transmission lines" without modulation from any other systems [41]. According to this theory, a nociceptor would only be activated by noxious stimuli and the signal would then travel along a pain fiber up to specific "pain centers" in the brain. Large afferent fibers were responsible for touch sensations while small afferent fibers were responsible for pain sensations. Evidence for this theory comes from Schiff and Woroschiloff's work in which they transected the grey matter, which effectively eliminated painful sensations but not touch. Similarly, they transected the posterior white matter, which eliminated touch sensations but not pain $[42,43]$. The specificity theory continued to evolve when Sherrington provided a framework for the specificity of neurons to touch, temperature, and pain, and described how receptors lower the excitability threshold for a given stimulus and raise it for others. This inadvertently resolved the disparity between the specificity theory and the intensity theory, another popular pain theory of the time, which stated that pain resulted from excessive somatosensory stimulation [43, 44]. The pattern theory, as proposed by Nafe, stated that sensation occurs as a result of specific patterns of neural firing. The stimulus type and intensity is encoded in the "spatial and temporal profile", i.e. where the stimulus occurs and the duration of the stimulus. This theory was substantiated by Weddell and Sinclair's 
work who observed that intense stimulation of various nerve fibers would all cause the sensation of pain $[43,45,46]$. A depiction of both the pattern theory and the specificity theory is shown in Figure 1.5.
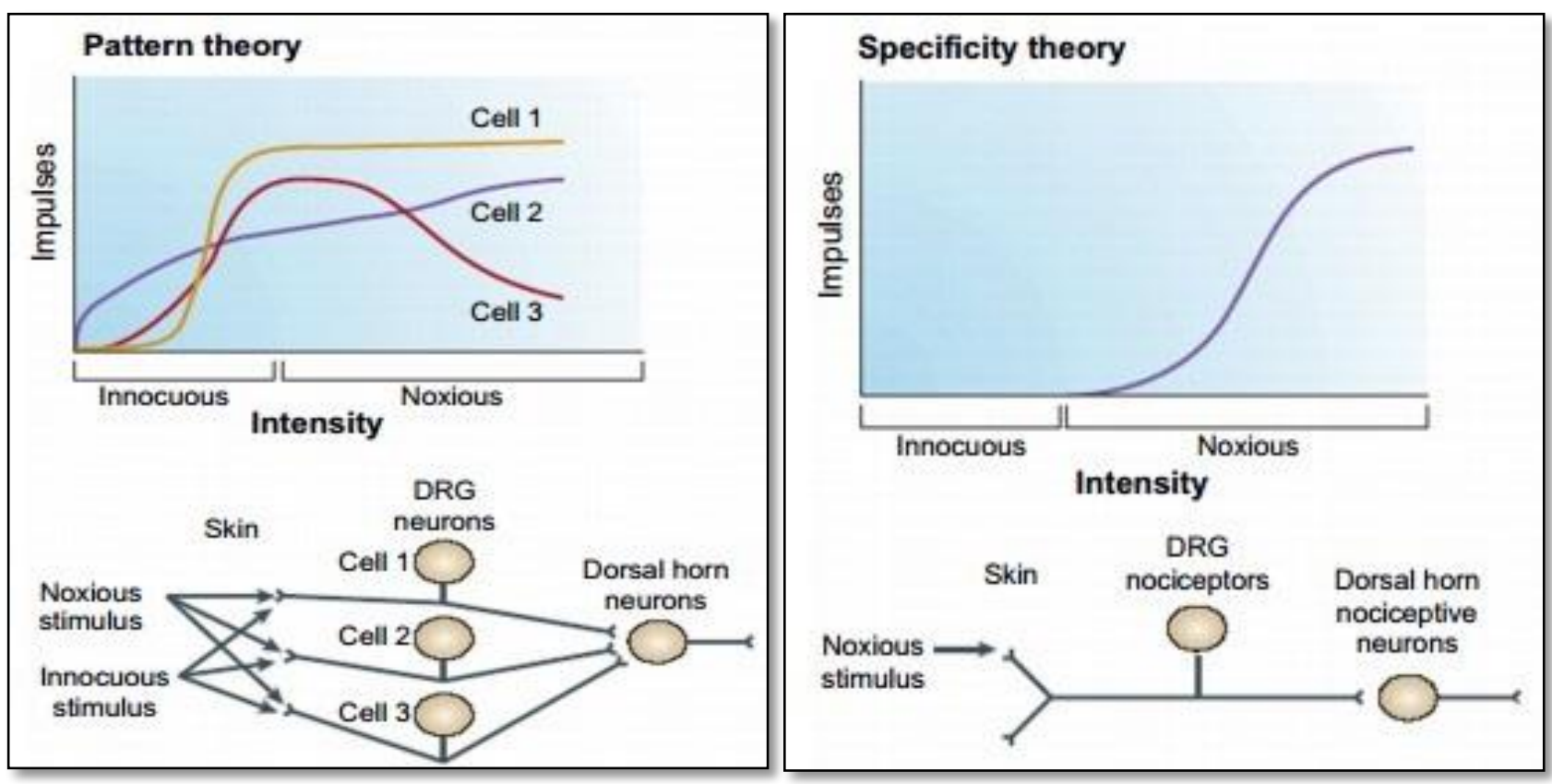

Figure 1.5: Schematic diagrams of both the pattern theory and specificity theory. In the pattern theory, nonspecific receptors in the skin respond to both noxious and innocuous stimuli, which are transmitted to the dorsal root ganglion (DRG) neurons, each of which

has different levels of responsiveness to stimuli; the pattern of firing determines the stimulus type. In the specificity theory, each stimulus type is encoded in its own unique pathway e.g. a noxious stimulus is transmitted to DRG nociceptors and then to dorsal horn nociceptive neurons [43]

However, each theory had substantial weaknesses in that they could not adequately explain the mechanisms behind certain pathological pain states, such as phantom limb pain or peripheral neuralgias, i.e. sharp pain due to irritation or injury of a nerve. The specificity theory assumed that a "pain receptor" must only sense pain and that there is a specific brain center that deals only with pain. Although it is true that $A \delta$ fibers respond to high intensity stimulation such as sharp pain, these fibers also respond to thermal and mechanical stimuli [47]. Similarly, there are many regions in the brain and spinal cord, such as the dorsal horn, thalamus, periaqueductal grey (PAG), parabrachial 
area $(\mathrm{PB})$, and rostral ventromedial medulla (RVM), that modulate and control the sensation of pain, not one single center $[48,49]$. The most glaring limitation with Nafe's pattern theory was his assumption that all fibers were alike and any type of stimulus would activate nonspecific receptors; however, there is a high degree of specialization between receptors and fibers $[50,51]$. For example, activation of transient receptor potential vanilloid receptor-1 (TRPV1), through the application of heat, selectively activates C-fibers $[47,52]$. Although reasonably sound, both theories still lacked unity and could not adequately explain the etiology behind many neuropathies and variations in pain sensation. This limitation was addressed by the gate control theory.

The gate control theory basically unites the specificity theory and the pattern theory by stating there are specific fibers and receptors, but there is also a "control center" that modulates all somatosensory stimuli before an individual experiences a sensation. This "control center" or gate control system is the substantia gelatinosa (SG) in the dorsal horn of the spinal cord, as illustrated in Figure 1.6.

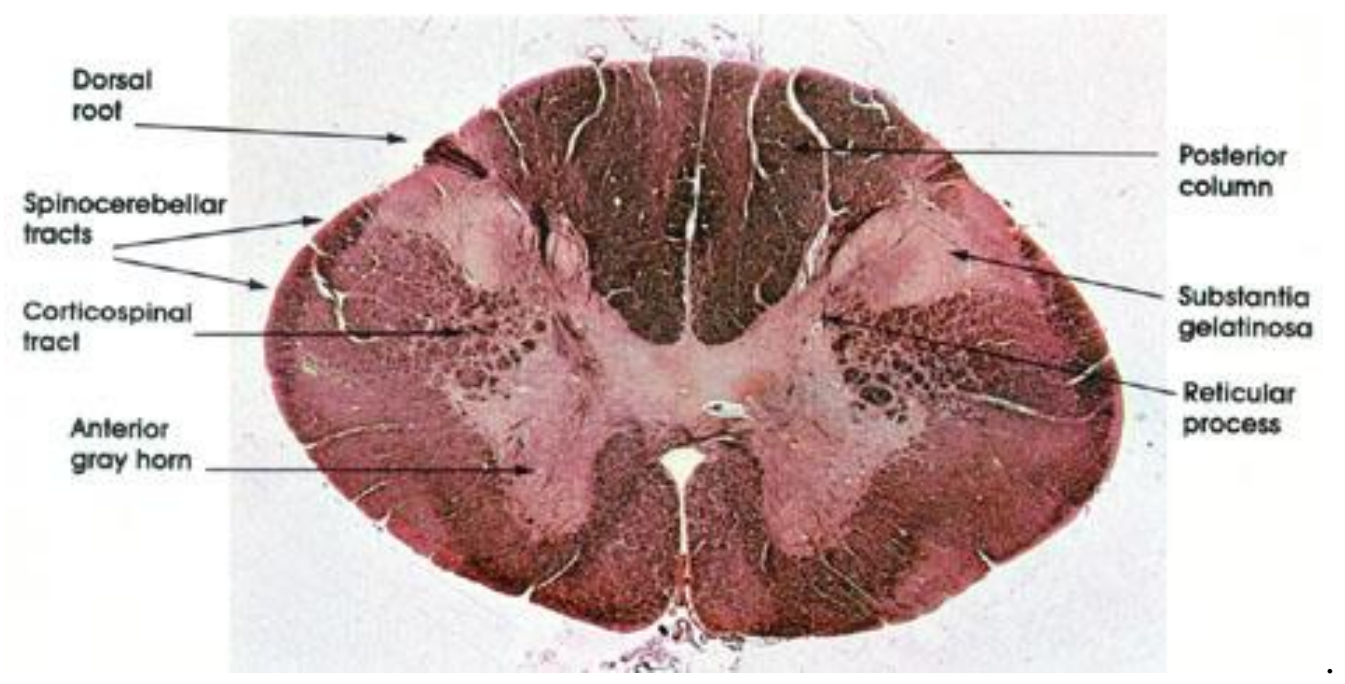

Figure 1.6: Cross-section of the spinal cord at the cervical level depicting the various tracts and regions; the substantia gelatinosa is located within the dorsal horn (upper right) [53] 
The SG modulates incoming nerve impulses before the impulse reaches the first central transmission cells ( $\mathrm{T}$ cells). Neurons in the SG have an inhibitory effect on the primary afferent terminals of the $\mathrm{T}$ cells. This inhibitory effect is enhanced by increased activity from $\mathrm{A} \alpha$-fibers and $\mathrm{A} \beta$-fibers and reduced by increased activity from $\mathrm{A} \delta$-fibers and $\mathrm{C}$ fibers [43]; depictions of these various fiber types are shown in Figure 1.7.

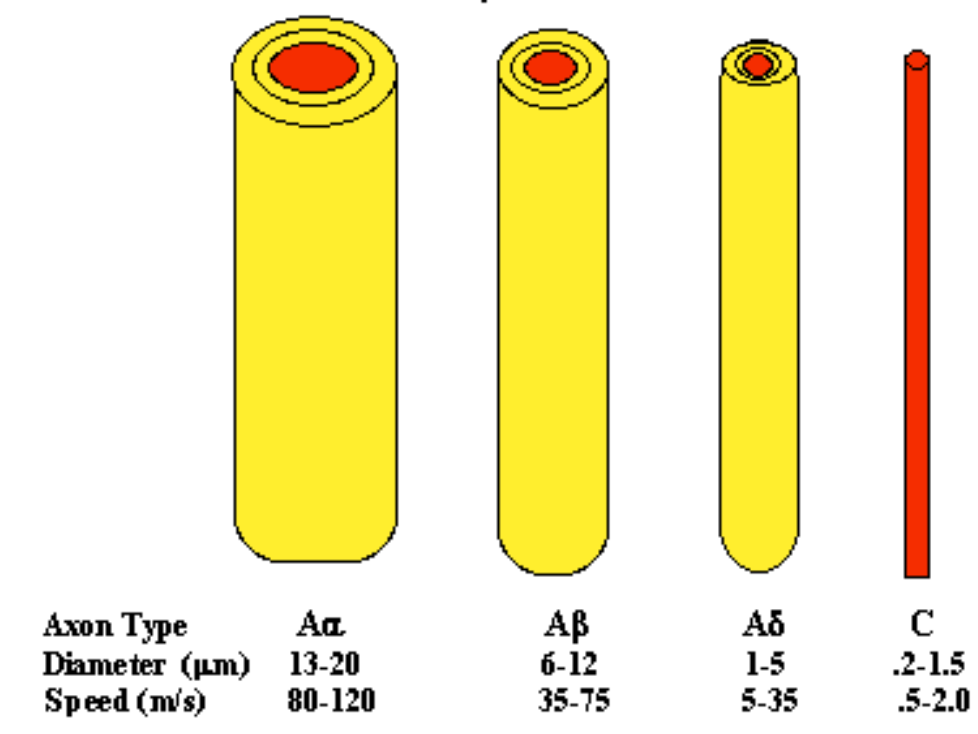

Figure 1.7: Average diameters and conduction velocities for primary afferent neurons; more myelination increases conduction velocity [54]

$\mathrm{A} \beta$-fibers have low activation thresholds and transmit tactile information. Both $A \delta$-fibers and $\mathrm{C}$-fibers have high activation thresholds and transmit nociceptive information, which may originate from thermal, chemical, or mechanical noxious stimuli [47]. C-fibers are associated with longer, throbbing pain while $A \delta$-fibers are associated with fast, sharp pain. In the absence of a stimulus or from activation of $A \beta$-fibers, the gate remains "closed", i.e. pain perception does not occur, because the inhibitory effect dominates and prevents activation of the $\mathrm{T}$ cells. The activation of $\mathrm{C}$-fibers causes the gate to "open", i.e. pain perception does occur, because the inhibitory effect is reduced, which activates the T cells, allowing the noxious stimulus to reach the "action system" that is responsible 
for painful sensations and responses. If the noxious stimulus intensity increases, the firing of the $\mathrm{T}$ cells increases slowly. If this stimulus is prolonged, the $\mathrm{A} \beta$-fibers begin to adapt while $\mathrm{C}$-fiber activity continues to increase, further increasing the firing of the $\mathrm{T}$ cells [41]. A depiction of how this gate control system works is shown in Figure $\mathbf{1 . 8}$.

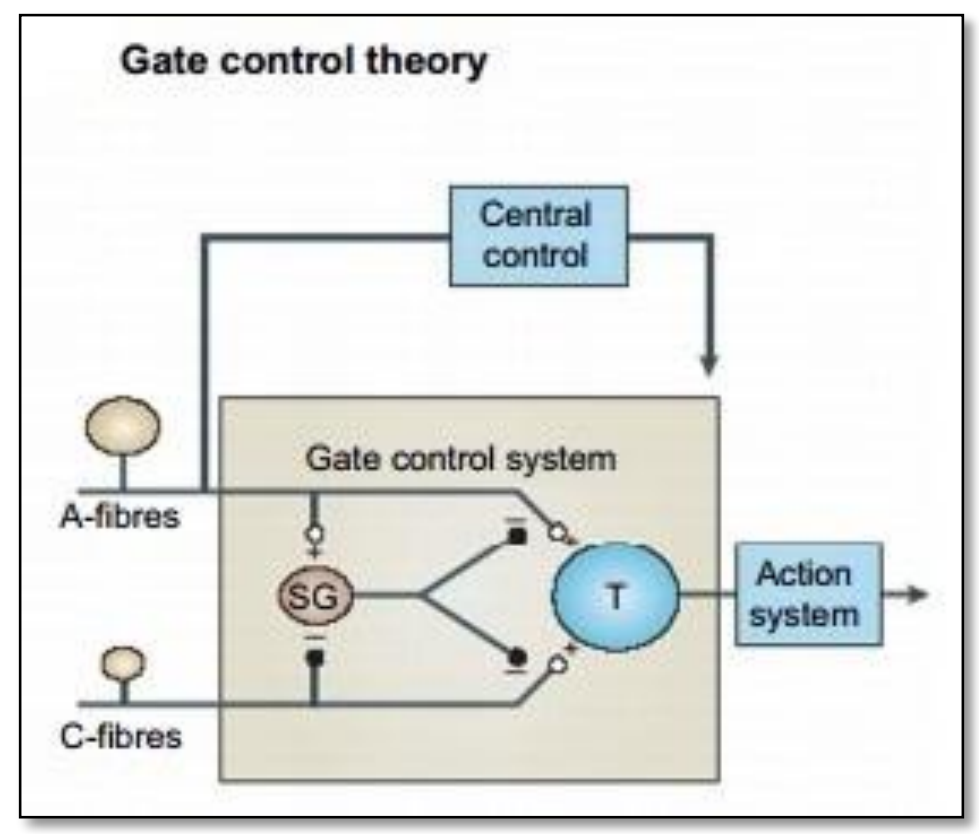

Figure 1.8: Schematic of the gate control system where A-fibers and $C$-fibers innervate the $S G$ and first central transmission $(T)$ cells. The SG inhibitory effect on the T cells is influenced by the relative activities of the A-fibers and $C$-fibers. This, combined with central control mechanisms, leads to some sensory and response output by the action system [43]

Our understanding of pain mechanisms has changed since the gate control theory was first proposed, yet many of its tenets and assumptions hold true. For example, we now know where each fiber type terminates in the different grey matter layers of the dorsal horn, i.e. the Rexed laminae of the dorsal horn. Both A $\delta$-fibers and C-fibers terminate in laminae I, II and V, while A $\beta$-fibers terminate in laminae III - V [49]. Within the dorsal horn, various neuron types exist. Nociceptive-specific (NS) neurons synapse with $A \delta$-fibers and $\mathrm{C}$-fibers, proprioceptive neurons synapse with $\mathrm{A} \beta$-fibers, and 
wide dynamic range (WDR) neurons synapse with all three fiber types. The frequency of action potentials elicited from WDR neurons is dependent upon the intensity of the stimulus, so that a noxious stimulus may be differentiated from a non-noxious stimulus based on the rate of firing of WDR neurons, i.e. noxious stimuli elicit higher rates of firing from WDR neurons. In addition, excitatory and inhibitory interneurons exist in the dorsal horn. The inhibitory interneurons release gamma-aminobutyric acid (GABA), which decreases the activity of NS and WDR neurons [47]. The excitatory interneurons primarily release glutamate, which increases activity of post-synaptic spinal neurons. Specifically, it causes depolarization of a-amino-3-hydroxy 5-methyl-4isoxazeloproprionic acid (AMPA) receptors, N-methyl-D-aspartate (NMDA) receptors, and G-protein coupled metabotropic receptors, all of which are targets for current drug and other therapeutic interventions [47, 55-57]. We also know that the "action system" that Melzack and Wall described is in fact different regions of the brain that also serve as "control centers" for pain modulation. For example, neurokinin I (NK1)-expressing neurons from lamina I, i.e. NS neurons, synapse in the thalamus, PAG, PB, and RVM [49]. Descending pathways, such as from the RVM, project back to the dorsal horn, which is where the effect of "central control" occurs [48], although these descending pathways are not activated without sufficient stimulation from afferent fibers. The limbic system is responsible for the emotional experience associated with pain, which affects the descending pathways and the response of the spinothalamic tract (STT) neurons. Projection neurons from laminae III - VI, i.e. WDR neurons, synapse primarily with the thalamus and provide the majority of the sensory information that reaches the brain. From the thalamus, somatosensory information travels to the cortex where various regions may 
be activated depending on the stimulus [47]. The anatomical projections of the primary afferent fibers and their associated innervation sites are shown in Figure 1.9. 


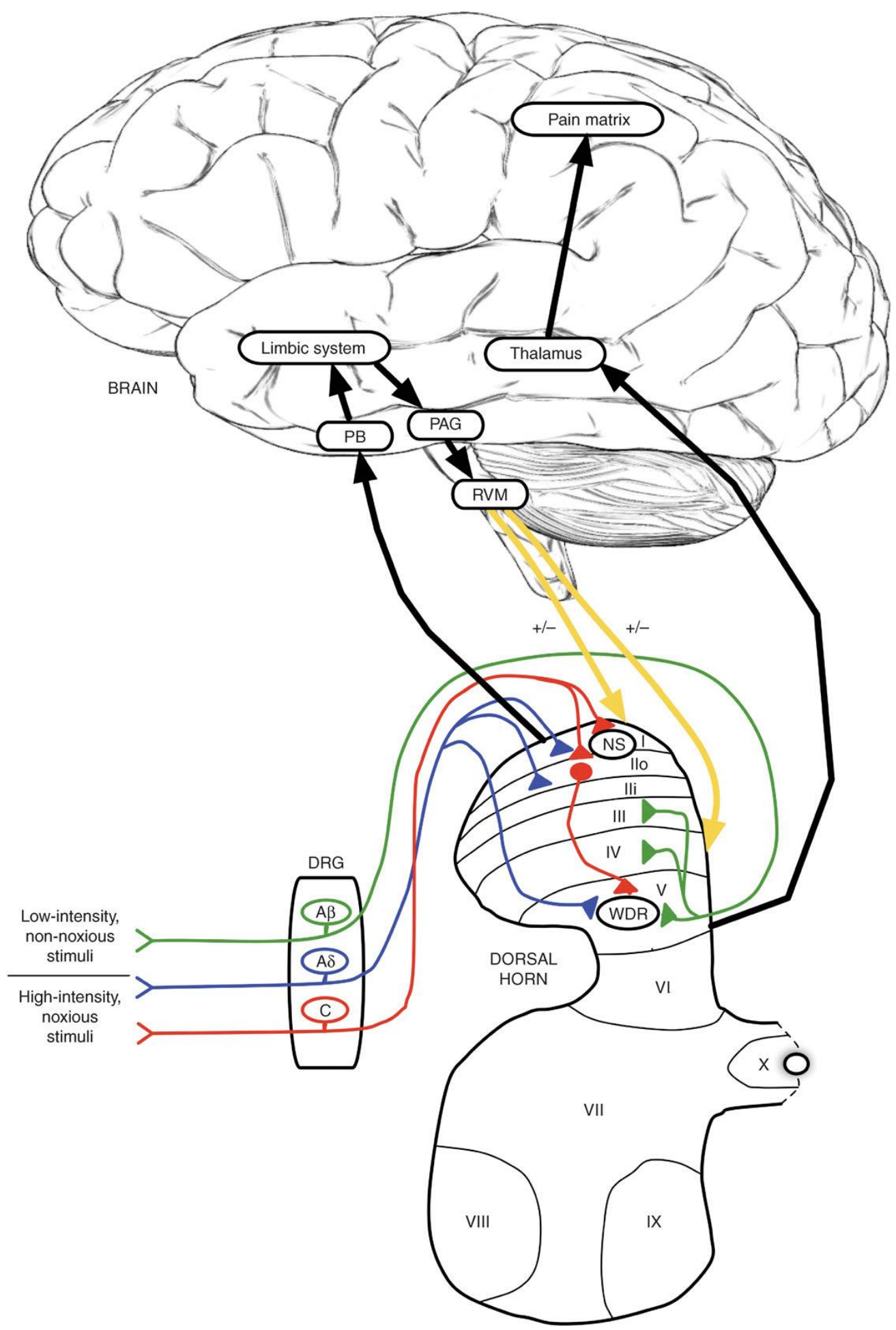

Figure 1.9: Diagram of how somatosensory information travels from the periphery to the brain. All fibers travel up through the dorsal root ganglion (DRG) and synapse at the dorsal horn within different laminae as well as with the wide dynamic range (WDR) neurons; only $C$-fibers and A $\delta$-fibers synapse with nociceptive specific (NS) neurons. Projection neurons, shown as black arrows, innervate the periaqueductal grey (PAG), parabrachial area (PB), and thalamus. Descending pathways, shown as yellow arrows, project from the rostral ventromedial medulla $(R V M)$ and other brainstem regions to the dorsal horn [47] 
The strength of the modern version of the gate control theory is that it can explain the mechanisms of many different neuropathies and provides a framework for potential therapies. In the case of hyperalgesia or allodynia, "central sensitization" occurs when the STT neurons become hyperexcitable, so that a noxious stimulus is amplified or a nonnoxious stimulus evokes pain [58]. Central sensitization is thought to occur from the activation of NMDA receptors on WDR neurons by intense stimulation of C-fibers through the release of glutamate and substance P. This depolarization temporarily eliminates the $\mathrm{Mg}^{2+}$ block on the NMDA receptors, making the WDR neurons more responsive to A $\beta$-fiber stimulation [58]. Tissue inflammation involves both central sensitization and "peripheral sensitization", where the sensitivity of C-fiber nerve terminals increases from the release of histamine, prostaglandins, and other mediators, and this increased sensitivity is responsible for triggering the spinal hyperexcitable state [59]. In chronic inflammatory diseases, the central sensitization can be sustained indefinitely as long as the noxious stimulus is present [60]. Nerve injury, from phantom limb pain, causalgia, diabetic nephropathy, etc., causes ectopic discharge at the site of injury, in the DRG, and from collateral sprouts of adjacent afferents, specifically within the cell bodies, i.e. somas, and the axons of the neurons [61]. $\mathrm{A} \delta, \mathrm{A} \beta$, and $\mathrm{C}$-fibers can all develop ectopic discharge, which evokes central sensitization, leading to allodynia [58]. This explains why amputee patients may feel pain in their residual limb if pressure is applied. Descending pathways from the brain counteract this hyperexcitability of dorsal horn neurons by releasing neurotransmitters, mainly serotonin and norepinephrine, both of which are associated with anti-nociception. Many antidepressant drugs, such as tricyclic antidepressants (TCAs) and serotonin-norepinephrine reuptake inhibitors 
(SNRIs), reduce the reuptake of one or both of these neurotransmitters, and thus can be used for analgesic purposes as well $[47,62]$. The activity of different brain regions can also be modulated through psychological interventions, e.g. hypnosis or cognitive behavioral therapy can reduce the pain sensation by influencing cognitive control from the cerebral cortex and limbic system [43]. Most importantly, electrotherapy, specifically neurostimulation, can be used to reduce chronic pain symptoms. As stated before, the gate control theory explains how a noxious stimulus carried by $\mathrm{A} \delta$-fibers and $\mathrm{C}$-fibers reaches the brain by overcoming the inhibitory effect of the dorsal horn interneurons and activating the projection neurons. Neurostimulation uses electrodes that directly stimulate the $A \beta$-fibers through electrical impulses, which blocks the noxious stimulus carried by the C-fibers, such that the inhibitory effect of the dorsal horn interneurons is enhanced, preventing the projection neurons from firing; the end result is analgesia.

\subsection{Overview and Aims of the Thesis}

Neurostimulation may offer yet another treatment option for patients suffering from ischemic disease. It possesses several advantages over current treatment methods including cost-effectiveness, ease of use, no major side-effects if applied correctly, noninvasiveness (for certain modalities), less of a need for oral medication such as analgesics, and potential for long-lasting effectiveness. However, much is still to be learned about how this stimulation actually causes hemodynamic changes. Moreover, the results from multiple studies involving neurostimulation and its effects on blood flow are conflicting $[32,36,63-68]$. To date, there is no real consensus on which neurostimulation technique offers the best treatment, mainly because the parameters used differ widely throughout the literature and most studies have not focused on direct comparisons for different disease states. Also, large-scale, multicenter studies have been conducted on 
individuals experiencing chronic pain and ischemic pain, and have found significant reductions in both using these different stimulation techniques, but have not investigated how the hemodynamics change [69-73].

In terms of hemodynamics, blood flow is the most sensitive and most difficult parameter to measure. The modality that is used to measure blood flow, calibration of the equipment, location of measurement, environmental conditions, investigator's skill with the equipment, and software that is used to acquire the data may all impact the results of the study. The application itself may warrant the use of a specific modality, such as measuring cutaneous blood flow in the periphery versus measuring myocardial perfusion. However, there are no formal guidelines established for what perfusion instrumentation works most effectively for a given application.

This thesis will take the first steps toward bridging the gap between palliative neurostimulation and hemodynamic changes. By uncovering the mechanisms underlying these changes, and the set of parameters that produce the greatest favorable changes, neurostimulation units can be utilized more efficiently to maximize the analgesia and minimize ischemia. A pilot study in healthy humans will test the hypothesis that neurostimulation provides ischemic relief through increases in cutaneous blood flow and evokes systemic changes, such as lowering blood pressure, using the most "ideal" neurostimulation technique and perfusion measurement instrumentation.

The specific aims of this thesis are as follows:

Aim 1: Outline the possible mechanisms of neurostimulation-induced hemodynamic changes, i.e. vasodilation and reduced metaboreflex, and formulate a hypothesis to test these changes 
Aim 2: Develop a protocol for a non-significant risk study in healthy volunteers

Aim 3: Optimize the study design through pre-pilot experiments

In conclusion, this thesis will provide background to perform a pilot study where neurostimulation is applied to measure both hemodynamic endpoints and ischemic pain. Before outlining the pilot study design, neurostimulation devices and perfusion measurement instrumentation that are currently available will be discussed in detail. 


\section{CHAPTER 2 - NEUROSTIMULATION TECHNIQUES}

\subsection{Transcutaneous Electrical Nerve Stimulation}

Transcutaneous electrical nerve stimulation (TENS) is a noninvasive

neurostimulation technique that uses a battery-operated unit to send electrical impulses through the skin via attached electrodes. The intensity, duration, frequency, and pulse width can all be adjusted on the TENS unit. A dual channel system with four electrodes is commonly used to stimulate different regions (Figure 2.1).

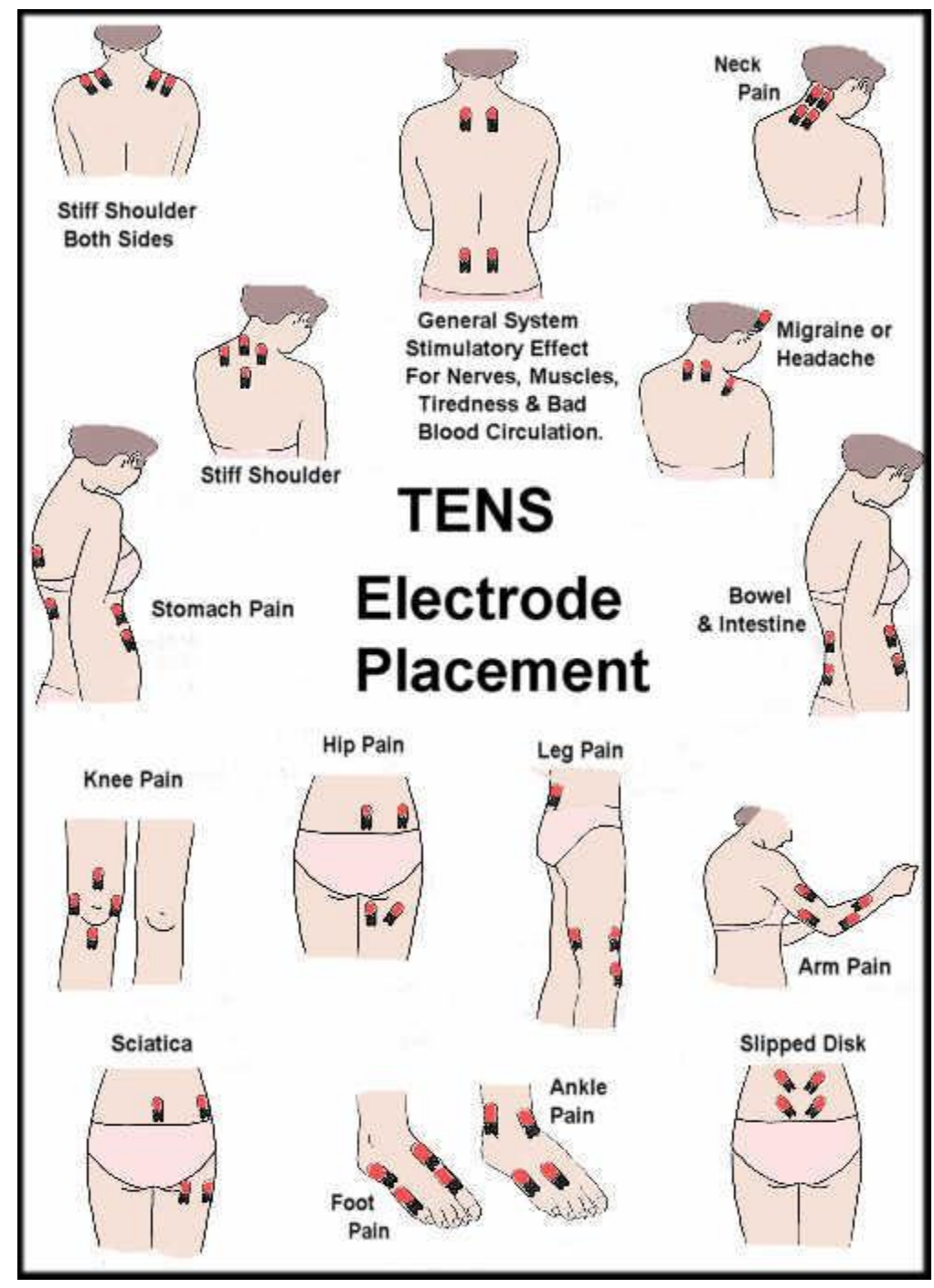

Figure 2.1: A dual-channel TENS unit consisting of four electrodes positioned over different regions of the body for treating peripheral pain [74] 
The use of TENS requires a prescription from a physician for the treatment of symptomatic pain and management of chronic pain; the indications also include postoperative and posttraumatic pain. The contraindications include undiagnosed pain, patients with implanted electronic devices such as pacemakers, patients who are currently pregnant, and patients who have a history of epilepsy [75]. Typical nerves that are stimulated with TENS include the ulnar, median, radial, tibial, and peroneal nerves, which may be stimulated directly by applying the electrodes over the desired nerve or indirectly by applying the electrodes on the back over a specific dermatome that innervates the desired region. TENS may also be combined with another neurostimulation technique such as spinal cord stimulation [76].

The mechanism of action for TENS in the mitigation of pain involves both the peripheral nervous system (PNS) and central nervous system (CNS), as discussed in Section 1.2. In addition to the gate control theory (Figure 1.8), low $(<10 \mathrm{~Hz})$ frequency TENS is associated with activation of $\mu$-opioid receptors while high (>50 Hz) frequency TENS is associated with activation of $\delta$-opioid receptors in the spinal cord and rostral ventromedial medulla. Furthermore, the fiber type that is activated by TENS depends on the level of intensity applied, i.e. sensory intensity up to and including motor threshold activates the $A \beta$-fibers, while intensities twice above motor threshold activate $A \delta$-fibers, which can also cause analgesia by activating descending inhibitory pathways, specifically the PAG and RVM $[69,77-79]$. These relative levels of intensity and the associated fibers that they activate are true for the other neurostimulation techniques that will be discussed. Sensory intensity is defined as the perception of the electrical impulses without muscle contraction, while intensity at motor threshold, i.e. motor intensity, elicits muscle 
contraction without painful sensation. If high frequency TENS is used, this is usually accompanied by sensory intensity, whereas low frequency TENS will usually be accompanied by motor intensity [69].

A summary of various studies involving TENS and its effects on the cardiovascular system are shown in Table A.1 of Appendix A. All studies were conducted on human subjects, most of them healthy. In most cases, the intensity was adjusted to sensory intensity with an average pulse width of $200 \mu \mathrm{s}$, frequency of $100 \mathrm{~Hz}$, and treatment duration of 15 minutes. The electrodes were applied either directly over the ischemic area, e.g. forearm or chest, or on the specific dermatomes that innervate the ischemic area, e.g. C2-C3. Reductions in MAP and cutaneous vascular resistance $(\mathrm{CVR})$ as well as increases in cutaneous blood flow (CBF) occurred in many of these studies $[33,63,66,67,80,81]$.

A possible mechanism of action for these hemodynamic changes may be that TENS inhibits the sympathetic nervous system (SNS), possibly through a reflex response. It may also be causing local vasodilation through release of endogenous vasodilators from DRG neurons, such as substance $\mathrm{P}$, which binds to $\mathrm{NK}-1$ receptors located throughout the central and peripheral nervous systems, or calcitonin gene-related peptide (CGRP), which binds to CGRP-1 receptors on the endothelium [82, 83], and/or decreasing arterial levels of norepinephrine/epinephrine [36]. The last study by Indergand, et. al. stands in contrast to the rest of the studies, as no changes in MAP, CVR, or CBF were found with application of TENS using similar parameters to the other studies. This contradiction is not unique for studies investigating the use of neurostimulation devices and their effects on hemodynamics; SCS, EA, and IFC also 
produce varying results [35, 84-86], making it difficult to establish whether neurostimulation induces beneficial hemodynamic changes.

\subsection{Spinal Cord Stimulation}

Spinal cord stimulation (SCS) was first used in 1967 by Dr. Norman Shealy and colleagues. It involves the implantation of electrodes in the epidural space which transmits current across the spinal cord or near the nerve roots. The electrode-containing leads are connected to an implanted pulse generator (IPG) or a radio-frequency (RF) unit, both of which serve as pulse generators that drive the current. The IPG or RF unit is usually implanted in the lower abdominal area or in the gluteal region, but can also be implanted between the shoulder blades for cervical or occipital generators [38]. The IPG has its own battery, so replacement is eventually required, even if it is rechargeable. The RF unit has an external battery that can be easily replaced. It consists of an antenna attached to the patient's skin that wirelessly communicates with the implanted receiver. An RF unit is usually preferable in cases where the patient will require high power settings for their pain treatment, although newer rechargeable IPGs are quickly replacing their use $[87,88]$. A programmer allows adjustment of the stimulation settings by the user or surgeon. The leads may be cylindrical or paddle type. In both cases, a trial is implemented to ensure that the electrically-induced paresthesia completely masks the painful region, which is referred to as concordant paresthesia [89]. A successful trial is one that provides at least a $50 \%$ reduction in pain, which can be assessed using the Visual Analog Scale for pain intensity [90, 91]. Current steering is a newer advancement in SCS lead technology, in which multiple independent current sources and sinks are used, and the current from either the source or sink is gradually decreased from one electrode and increased to another or vice versa; this allows for more efficient programming, such that 
the area of pain coverage is optimized [87, 92]. A straight percutaneous trial is used for the insertion of cylindrical leads, which involves maneuvering the lead into the posterior paramedian epidural space up to the painful location and anchoring the lead to the interspinal ligaments with nonabsorbable sutures. After the trial period, the trial lead is replaced by a new lead, which is connected to the IPG. Insertion of paddle-type leads requires a permanent lead trial, which is a more invasive and risky procedure. A laminotomy is performed, which partially removes the lamina, so that the electrodes can be slipped into the epidural space. From there, a percutaneous extension piece is tunneled from the site of incision out through the skin where it is secured with sutures. If the trial is successful, the incision is re-opened and this extension piece is cut, and new extensions are used to connect the leads to the IPG. $[38,87]$. The advantage of using paddle-type leads is that there is less risk of lead migration, where lead movement causes a loss of paresthesia over the painful region and possible stimulation of other regions, which is a serious complication associated with spinal cord stimulator implantation and requires revision surgery [93]. The basic steps involved with the implantation procedure are shown in Figure 2.2. 


\section{PARTS OF THE IMPLANT DEVICE}

PROGRAMMER or transmitter allows patients to turn the system on or off and adjust stimulation settings, including intensity, frequency, and duration

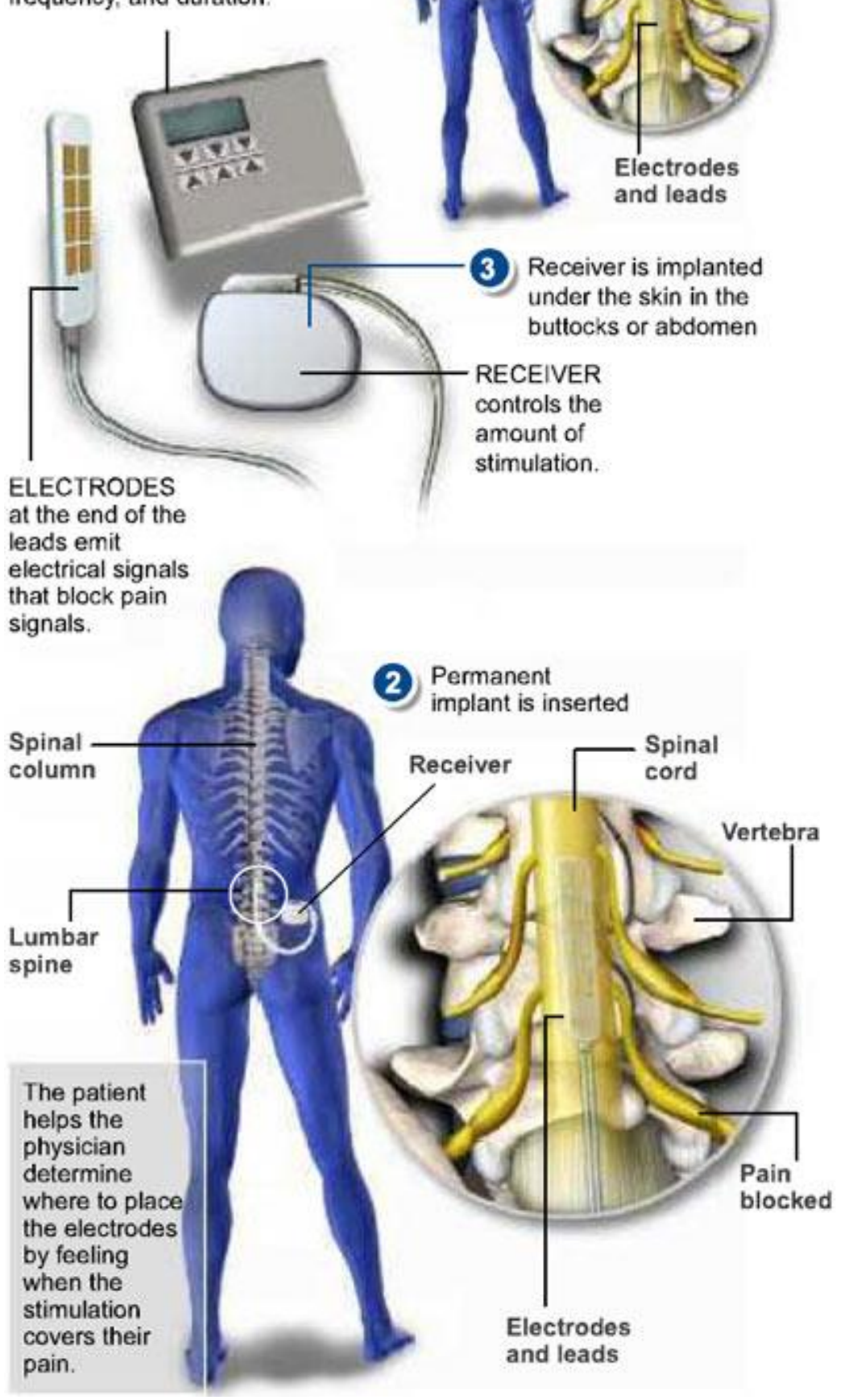

Figure 2.2: Overview of SCS procedure showing where the electrodes and IPG are placed as well as the basic functions of each component [94] 
Before deciding on SCS as a pain management therapy, the McGill Pain Questionnaire, Roland Morris Questionnaire, or other methods are used for psychological screening and pain evaluation. This is to ensure that the patient will actually be amenable to the therapy, that any prior psychiatric disorders do not interfere with the therapy, and that the therapy does not aggravate any symptoms of the disorder [87, 95]. Further patient selection criteria for SCS include unresponsiveness to standard treatments and inadvisable remedial surgery [95]. In the U.S., the most common indication for use is for failed back surgery syndrome (FBSS), while peripheral ischemia is the most common indication in Europe [87, 93]. Contraindications include failed trials with SCS, bleeding disorders, pacemakers or defibrillators, pregnancy, and severe systemic or local infections [87].

A summary of various studies involving SCS and its effects on the cardiovascular system are shown in Table A.2 of Appendix A. These studies were conducted both on rats and patients with PAOD. The pulse width was constant in all studies at $200 \mu$ s while the frequency was either adjusted to a high setting $(\sim 100 \mathrm{~Hz})$ or medium setting $(\sim 50$ $\mathrm{Hz}$ ). The treatment duration for rats was significantly shorter (on the order of minutes) compared to humans (on the order of months). This disparity in treatment duration is based on acute study design for animals versus permanent implantation in humans. One advantage to a longer treatment duration is that it allows for analys is of long-term safety and effectiveness with SCS that cannot as readily be assessed with other neurostimulation techniques. The electrode array was inserted into the epidural space using the straight percutaneous method over specific vertebral levels, depending on which limbs were affected, e.g. the electrodes were placed at the T-10 vertebral level if ischemia was 
present in the legs [32]. Reductions in MAP and vascular resistance as well as increases in blood flow were observed in these studies $[32,37,96,97]$.

A possible mechanism of action for these hemodynamic changes may be that SCS causes antidromic activation, i.e. conduction in the opposite direction of both cutaneous and muscle afferents, which releases vasodilators, such as calcitonin generelated peptide (CGRP), from the dorsal roots (Figure 2.3) [96, 97]. Through a very similar pathway, prostaglandins, specifically $\mathrm{PGE}_{2}$, may be released from the endothelium causing a reduction in sympathetic tone by inhibiting norepinephrine release from sympathetic nerve terminals [32]. In fact, when indomethacin, a prostaglandin synthesis inhibitor, was intravenously injected into cats experiencing SCS, vasodilation was significantly reduced, and in some cases, abolished [98].

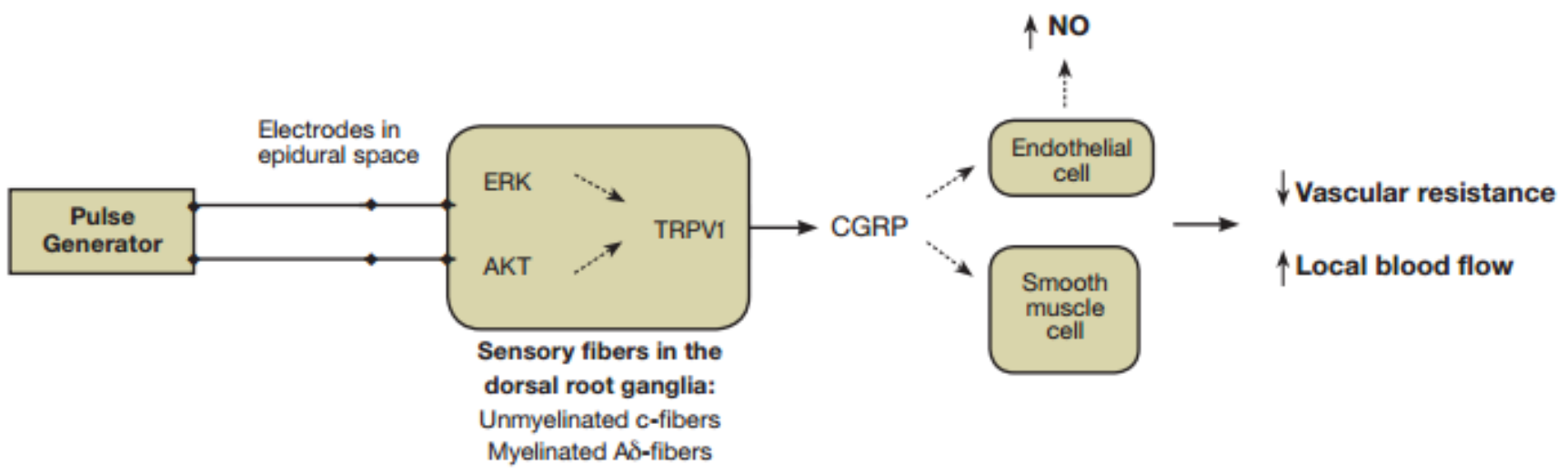

Figure 2.3: Possible mechanism of action for SCS-induced hemodynamic changes. High intensity electrical stimulation in the epidural space activates both $A \delta$-fibers and $C$-fibers in the dorsal root ganglion (DRG), both of which activate extracellular signal-regulated kinase (ERK) and protein kinase B (AKT) that cause activation of the transient receptor potential vanilloid receptor-1 (TRPV-1) on these neurons. Activation of TRPV-1 releases

CGRP that causes systemic effects such as release of nitric oxide (NO) from ECs and $S M C$ relaxation, leading to increased blood flow and decreased vascular resistance [99]

\subsection{Electroacupuncture}

Traditional acupuncture has been used for over 3000 years. This ancient Chinese therapy is based on the premise of restoring a blockage in "ch' 1 ' through a careful 
balancing of "yin and yang". This is accomplished through the application of needles at specific acupuncture points (acupoints) along the body. Although largely discredited at first for its metaphysical explanations, such as the idea of manipulating the life energy "ch'i" that flows through "meridians", i.e. channel networks within the body, by stimulating acupoints that run along these meridians, it has become a very popular form of therapy for chronic pain in the past several decades [100]. In 1975, it was found that by adding electricity to the needles, the pain modulation was $100 \%$ more effective over traditional needles [101]. Thus, electroacupuncture (EA) was born.

Both traditional acupuncture and EA have now found widespread use in the U.S. In a National Health Statistics Report, the number of Americans actively using electroacupuncture as an adjunct treatment for chronic pain was estimated at 3 million [102]. The rise in popularity for EA mirrors the rise in alternative medicine use in general over more conventional forms of medicine, part of this owing to its ease of use. Small alligator-clip electrodes are attached to each needle, each with an associated lead that plugs into the electrotherapy device. The downside of EA and traditional acupuncture is that a licensed practitioner must perform the procedure each time. However, there are newer forms of EA that do not utilize needles and instead use adhesive electrodes very similar to those used for TENS, which then allows the user to perform the procedure themselves. Around 30 minutes of continuous stimulation is usually recommended [103]. An example of a typical EA configuration using needles is shown in Figure 2.4. 


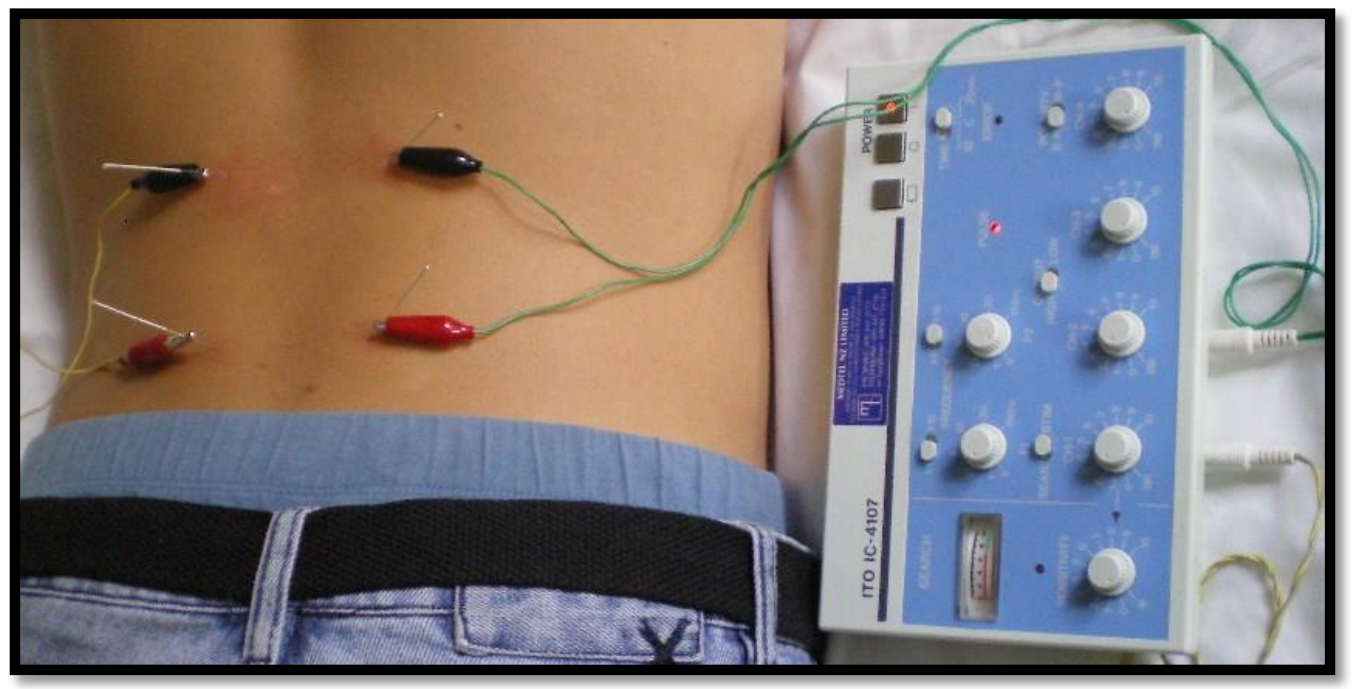

Figure 2.4: Set-up of an EA unit on a patient, consisting of electrodes with leads inserted into a programmable stimulator [104]

Unfortunately, there is not a substantial body of evidence to support the efficacy of EA as a pain management therapy and the mechanisms of action are still poorly understood [105-108]. For this reason, EA is not commonly prescribed by physicians for pain treatment. Nevertheless, it is increasingly being used by the general public, and more clinical trials are underway to investigate both the mechanisms and potential treatments for this neurostimulation technique; in fact, there are currently 36 clinical trials involving EA that are actively recruiting according to the National Institutes of Health (NIH) [109]. Furthermore, when EA is combined with conventional medication, such as prednisone, the clinical effectiveness is even greater in reducing pain compared to medication alone [109-111]. Although specific indications for use have not been established yet, EA is generally used as an analgesic for muscle spasms, neurological disorders, chronic pain, injuries, and paralysis [107]. The main contraindications include patients with a history of seizures, heart disease, stroke, or epilepsy, as well as patients with implantable electrical devices such as pacemakers [103]. 
A summary of various studies involving EA and its effects on the cardiovascular system are shown in Table A.3 of Appendix A. Very few of these studies involved humans; most used rats and dogs. Very high intensities ( $\sim \mathrm{x}$ above sensory intensity) were used in all these studies, which appears to be necessary to alter blood flow. Wider pulse widths $(>250 \mu$ s) and lower frequencies $(<20 \mathrm{~Hz})$ were used compared to the TENS and SCS studies. The electrodes were applied at acupoints specific to the ischemic area. The effect of electrode placement was commonly investigated in these studies, as stimulation of different acupoints may cause very different changes within the cardiovascular system, e.g. stimulation of the hand caused decreased BP and blood flow while stimulation of the tibial and saphenous nerves caused increased BP and blood flow $[112,113]$, although these results may also be attributable to differences in animal and human hemodynamics.

A possible mechanism of action for these hemodynamic changes may be that EA decreases or increases sympathetic tone depending on where stimulation is applied. A decrease in sympathetic tone may result from a similar pathway as presented in Figure 2.3, in which vasodilation occurs from the release of CGRP $[68,114]$. Changes in activity of different brain regions in response to EA may also be responsible for the decrease in SNS activity, e.g. modulation of RVM neurons responsible for the maintenance of arterial BP, increased expression of nitric oxide synthase in the hypothalamus, or activation of nucleus ambiguus (NAmb) neurons responsible for the regulation of autonomic functions [115] In contrast, an increase in sympathetic tone may result from a reduction in prostaglandin release $[116,117]$; it may also be attributed to increases in 
muscle sympathetic nerve activity (MSNA), which may possibly occur from a modulatory effect on PAG and arcuate neurons that control BP $[115,118]$.

\subsection{Interferential Current}

Interferential Current (IFC) stimulation is a noninvasive neurostimulation technique that is very similar to TENS in terms of its application and use. It utilizes the same type of adhesive skin electrodes connected via leads to a stimulator unit. The main difference with IFC, as compared to TENS, is the frequency used. Alternating-current (AC) sine waves or square waves at two different carrier frequencies superimpose to produce an interference, i.e. interferential current, otherwise known as an alternating modulation frequency (AMF). Typically, one current is held at $4000 \mathrm{~Hz}$ while the other is held at $4100 \mathrm{~Hz}$ to produce an AMF of $100 \mathrm{~Hz}$ [75]. One advantage of this approach is that IFC can penetrate into deeper tissues because skin impedance decreases with increasing frequency, which is important for stimulating both cutaneous and muscle afferents $[75,119]$. The duration of stimulation for IFC is usually around 30 minutes, similar to that of other neurostimulation techniques [119].

Although more commonly used in other countries, IFC is increasingly used in the U.S. because of its reported effectiveness and ease of use [71, 120, 121]. However, its use normally requires oversight by a trained practitioner to ensure that modulation of the currents is properly performed. An example of how this modulation is accomplished clinically is shown in Figure 2.5. 


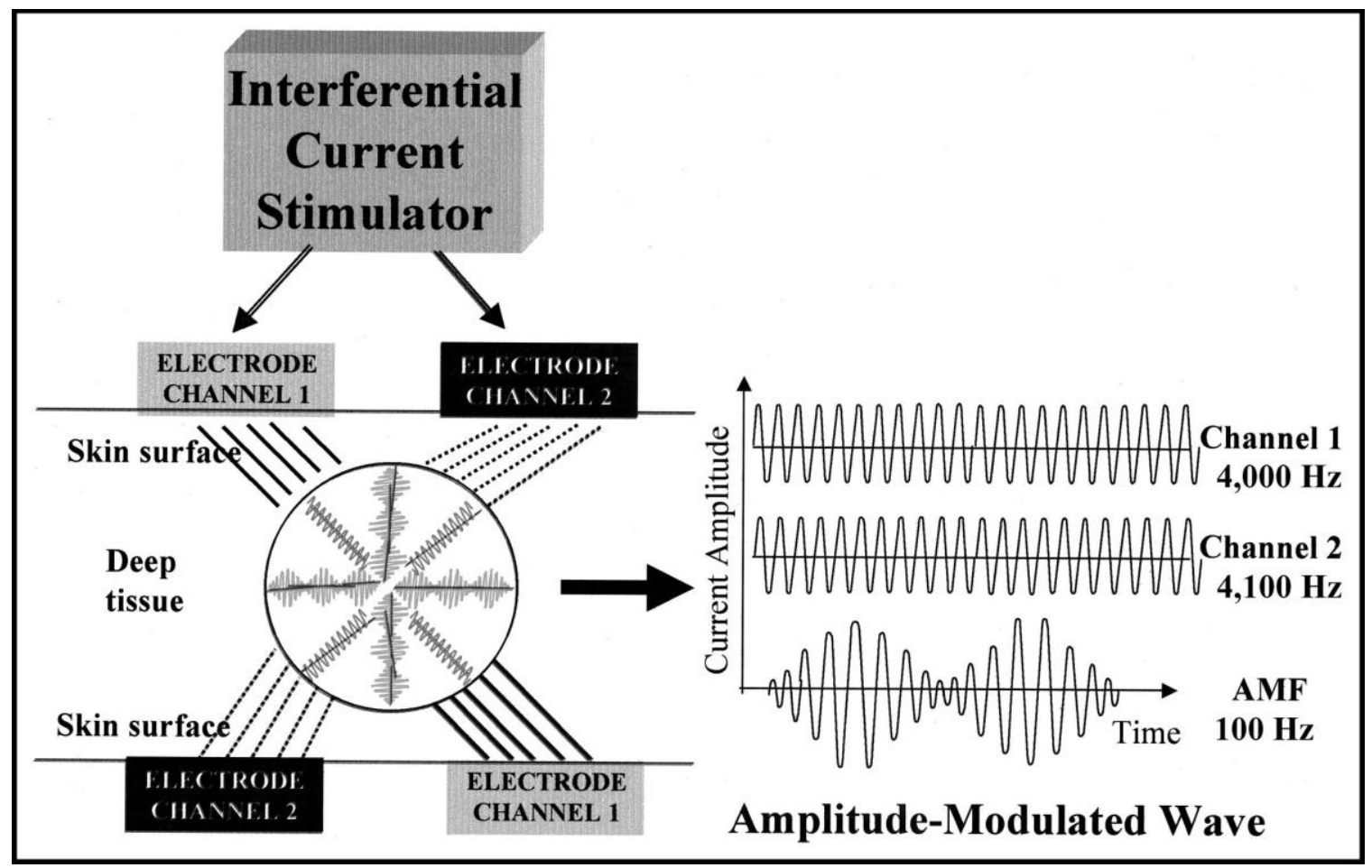

Figure 2.5: Diagram showing how a dual-channel IFC unit can be applied to the skin surface to produce an AMF and potentially cause pain relief within deep tissue [119]

Most IFC devices tend to be more expensive and less portable than TENS devices, making their widespread use further limited [119]. More portable units have been developed recently, including multi-functional units capable of both IFC and TENS, making this intervention more cost-effective [75]. IFC is indicated for use in chronic pain, post-traumatic pain, and post-surgical pain. However, the clinical use of IFC over TENS has come into question, as some studies have shown that it is no more effective at relieving pain than TENS $[122,123]$. The contraindications for IFC include undiagnosed pain, infections or inflammation in the stimulation region, patients with implanted pacemakers or defibrillators, and patients who have a history of epilepsy [75].

A summary of various studies involving IFC and its effects on the cardiovascular system are shown in Table A.4 of Appendix A. All these studies were conducted on healthy human subjects. In all cases, the intensity level was adjusted to sensory intensity 
with an average pulse width of $160 \mu \mathrm{s}$, frequency of $100 \mathrm{~Hz}$, and treatment duration of 20 minutes. The electrodes were applied on specific dermatomes e.g. C7 and T4, the thigh, or the forearm. Reductions in MAP, CVR, and ischemic pain, as well as increases in CBF were witnessed in these studies [124-126].

A possible mechanism of action for these hemodynamic changes may be that IFC inhibits SNS activity and causes local vasodilation based on very similar mechanisms as discussed in Section 2.1 involving TENS. Whether the inhibition in SNS activity and local vasodilation is more pronounced with IFC compared to TENS is still to be determined, but it seems likely that this would be the case, since IFC stimulates deeper muscle afferents in addition to cutaneous afferents [119]. This idea will be further explored in Chapters 4 and 5.

In all these neurostimulation studies, perfusion was measured in a variety of ways including laser Doppler flowmetry, laser speckle contrast analysis, venous occlusion plethysmography, and photoplethysmography, among others. The accurate interpretation of perfusion is crucial to fully understanding the mechanisms underlying hemodynamic responses to neurostimulation. This interpretation can be biased by a number of factors, such as motion artifact caused by movement of the subject or the connecting cables, calibration method (every manufacturer calibrates the equipment differently), temperature fluctuations, and inherent differences in the way each system measures perfusion. For example, laser speckle contrast analysis uses spatial averaging when scanning over a tissue region, which leads to a loss of resolution and an underestimation of the actual perfusion within this region [127]. Commonly used perfusion measurement 
systems will be discussed in Chapter 3, including each system's inherent advantages and disadvantages. 


\section{CHAPTER 3 - PERFUSION MEASUREMENT INSTRUMENTATION}

\subsection{Justification for Non-invasive Measurements of Perfusion}

Before discussing the theory and practical use of these perfusion measurement systems, the reasoning for why noninvasive perfusion systems are capable of providing accurate measures of both cutaneous and muscle blood flow will be explained. During a resting state, partition of blood flow to the muscle and skin is nearly equivalent with a slightly higher percentage of blood flow in the muscle. In a diseased state, such as CHF, blood flow in both vascular beds is reduced compared to healthy subjects. During exercise, both cutaneous and muscle blood flow decrease in non-active vascular beds and increase in active vascular beds [128]. A change in skin temperature can also be correlated with changes in cutaneous blood flow, since heat is a by-product of cellular metabolism [129]. Based on these correlations between cutaneous and muscle blood flow, measurements of cutaneous blood flow using noninvasive methods, such as laser Doppler flowmetry (LDF), can be used to estimate muscle blood flow, and perfusion in other vascular beds such as coronary and renal. This has important applications in the diagnosis and treatment of cardiovascular diseases. For example, cutaneous microangiopathy is associated with diabetic retinopathy and renal microvascular disease, in which cutaneous blood flow decreases as a function of the severity of the disease [130]. Cutaneous microcirculatory dysfunction has also been implicated in CAD patients who exhibit impaired post-ischemic capillary perfusion, i.e. reactive hyperemia, but normal perfusion during resting conditions [131]. This is in accordance with PAOD patients who also exhibit impaired reactive hyperemia [132]. Most importantly, noninvasive measurements of perfusion can provide relative measures of ischemia and reperfusion, which correlate well with more traditional, invasive measurements of 
perfusion, such as the hydrogen clearance, Xenon clearance, fluorescent dye studies, and photoplethysmography $[133,134]$. For the pre-pilot work (Chapter 5) and eventual pilot study (Chapter 4), LDF was chosen to measure cutaneous blood flow, because of its high sensitivity to local microcirculatory changes, ability for continuous, real-time measurements, noninvasiveness, and ease of use.

\subsection{Laser Doppler Flowmetry}

Laser Doppler flowmetry (LDF) was developed in 1984, when Allan Holloway unveiled the first noninvasive blood perfusion monitoring system capable of continuous, real-time measurements. Utilizing a Helium-Neon laser source and an optical fiber, light is transmitted at $632.8 \mathrm{~nm}$ from the system to the skin. Depending on the particular probe configuration, a penetration depth of $1-1.5 \mathrm{~mm}$ is possible. The light that is transmitted to the skin is reflected back to a photodetector through "receiving" optical fibers. For nonmoving components within the skin, this light is reflected back at the same frequency as the incident source. For moving components, such as red blood cells (RBCs), the light is Doppler shifted or scattered, such that the frequency changes when it hits the photodetector. This frequency shift or beat frequency is directly proportional to the velocity of the RBCs or other moving components, i.e. higher velocities cause greater frequency shifts compared to the incident frequency [127, 135]. A diagram of this phenomenon is shown in Figure 3.1. The measured output of LDF systems is in flux, measured in perfusion units (PU), which is calculated as such:

Flux $=$ Number of RBCs moving in the tissue sampling volume $\times$ RBC mean velocity 


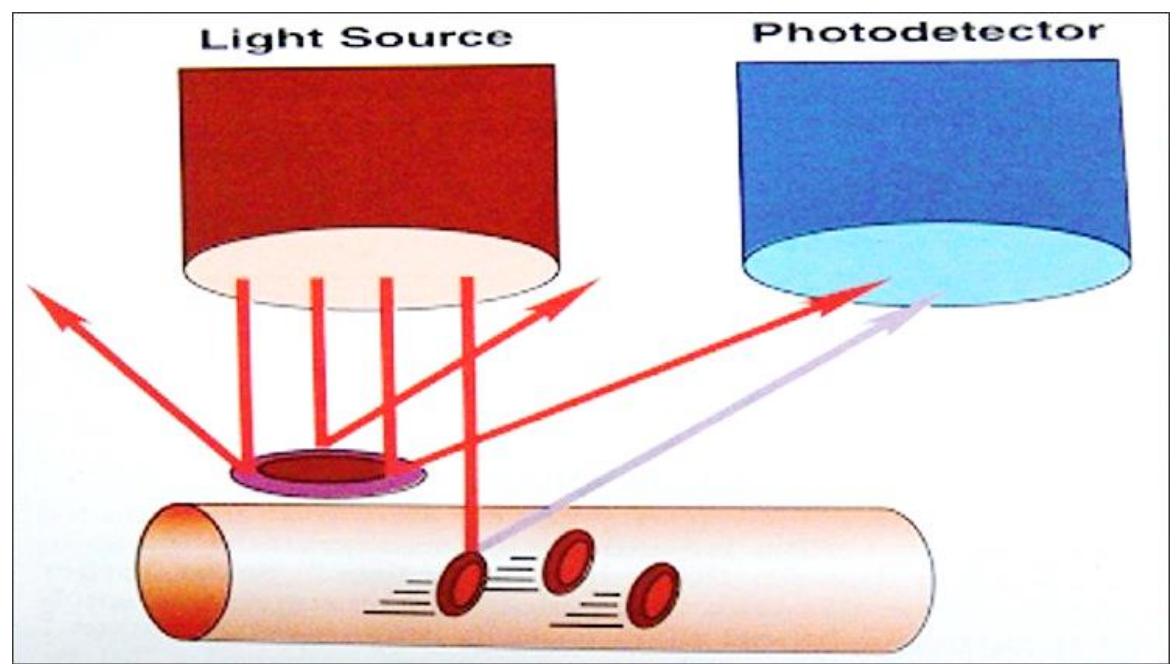

Figure 3.1: Light from the incident source impinges on both non-moving components within the tissue and from RBCs, which is then reflected back to a photodetector and processed [136]

Within the practice of LDF, laser Doppler perfusion monitoring (LDPM) and laser Doppler perfusion imaging (LDPI) systems are used. LDPM systems measure perfusion within a very small region or point, usually the equivalent of $1 \mathrm{~mm}^{3}$ in terms of tissue volume, which may vary based on site of observation and concentration of RBCs at the time of measurement [136]. LDPI systems measure perfusion in much larger areas, upwards of $1000 \mathrm{~cm}^{2}$ [137]. The larger spatial field of view is accomplished via a complementary metal-oxide semiconductor (CMOS) camera (Figure 3.2). In this case, the reflected or backscattered light from the tissue is focused onto a detector array within the camera. Each pixel in the array is used to calculate a perfusion value for that specific pixel dimension within the tissue. With these CMOS cameras, the entire image is illuminated and acquired simultaneously. Average perfusion values can then be calculated for specific regions within the field of view using specially designed software. This is a distinct advantage over earlier versions of the LDPI systems, which scanned the area point by point, making the whole process take significantly longer [127]. Both 
LDPM and LDPI systems have been used in a variety of applications including burn and wound assessment, quantification of microcirculatory disorders, amputation level determination, and dentistry, among others [127, 136, 137]. LDPM tends to be more useful in quantifying temporal changes within cutaneous vasculature, such as during vascular occlusion tests or in response to electrical stimulation [138]. LDPI serves better as a clinical diagnostic tool, e.g. ulcer or diabetic microangiopathy assessments [127]. An example of a blood perfusion map using LDPI in the case of induced ischemia is shown in Figure 3.3.

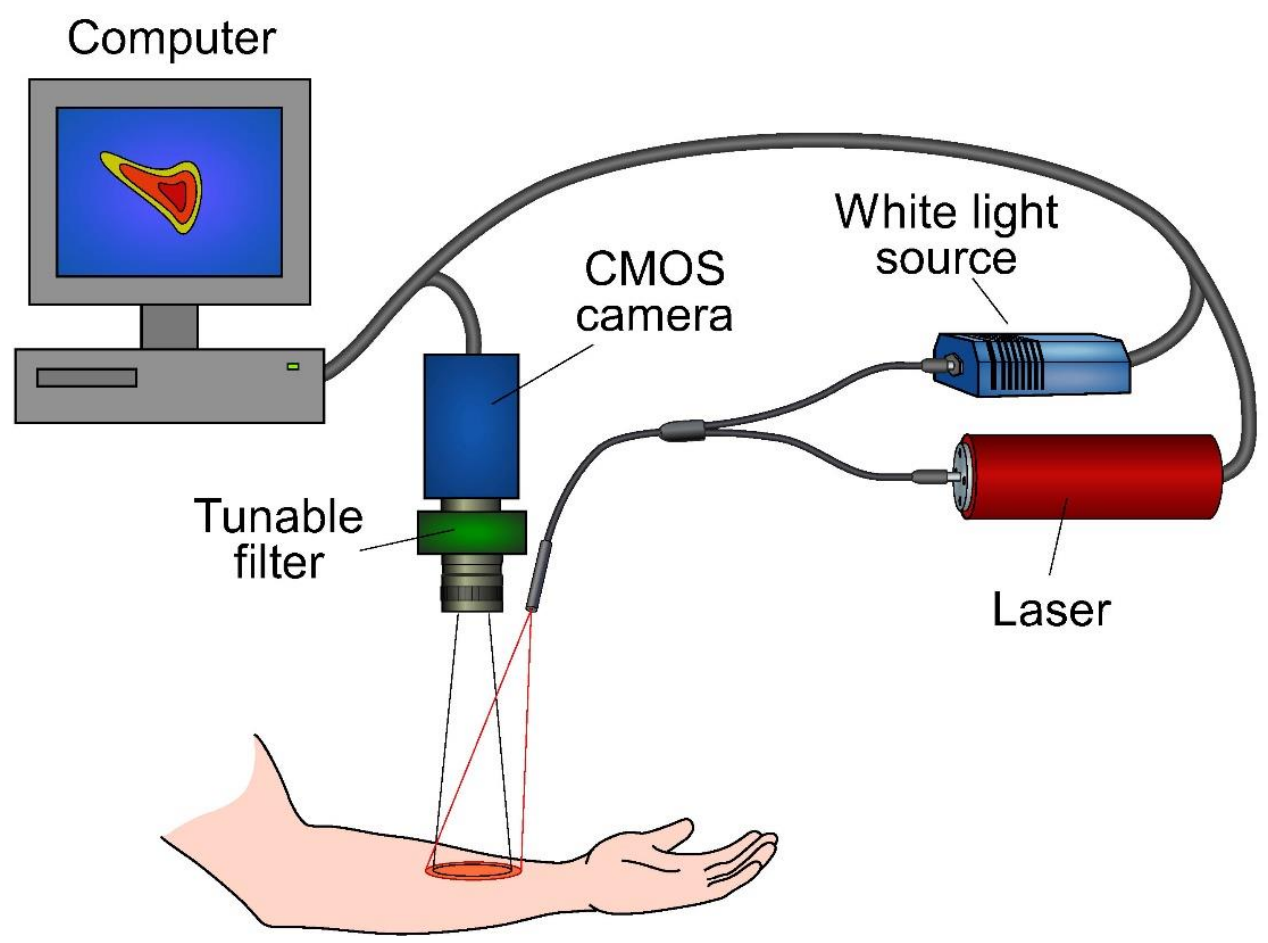

Figure 3.2: Equipment set-up for a typical LDPI system [139] 

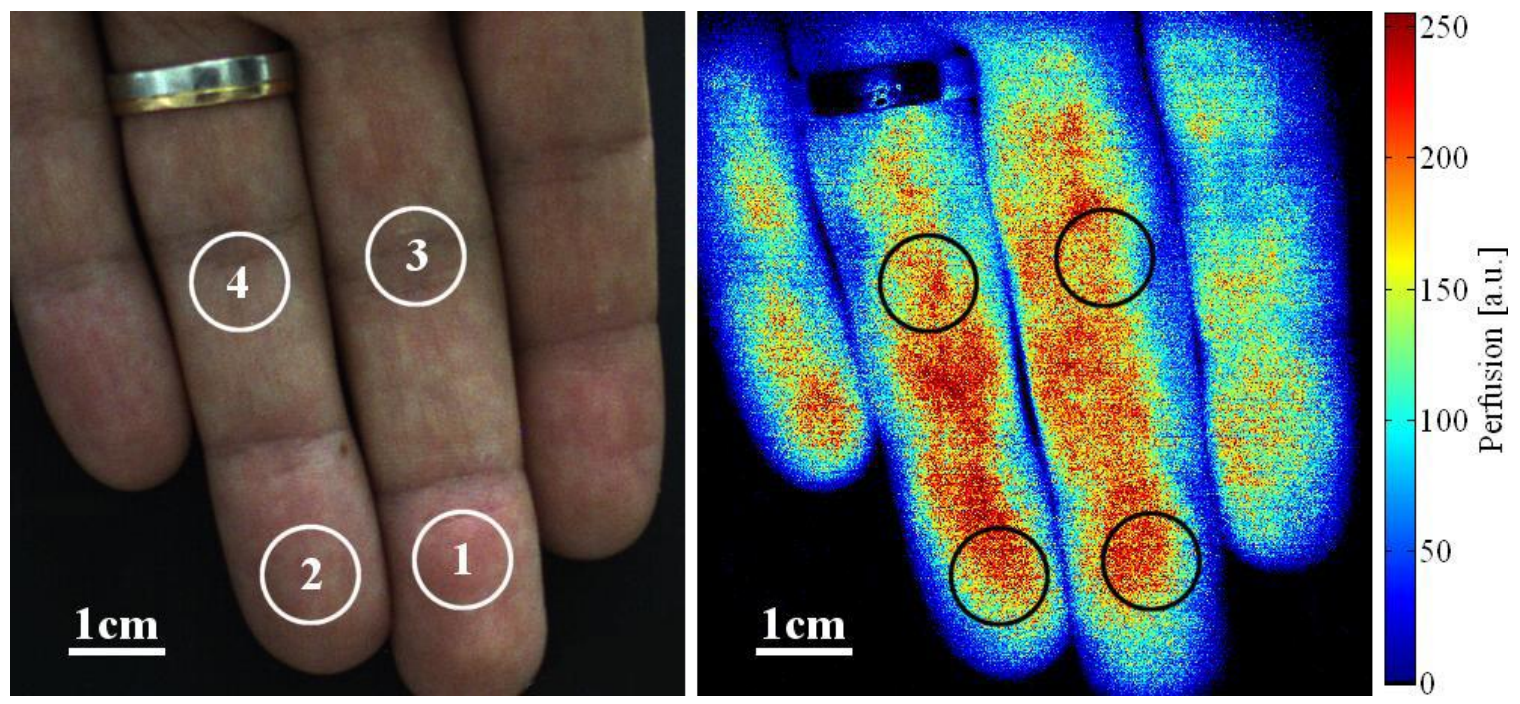

Figure 3.3: Blood perfusion map using LDPI on the hand; participant subjected to a vascular occlusion test to simulate ischemia; perfusion scale bar shown on right [137]

Although LDF is being used more often in research and clinical settings, as indicated in Figure 3.4, there are still a number of drawbacks that limit its widespread use and applicability. For one, there is significant inter-individual variability in the measurements obtained, because of differing hematocrit levels and physiological states of each subject, as well as variability introduced by several environmental factors including ambient temperature and humidity. Absolute calibration of the LDF system is difficult and each manufacturer tends to go about it in a different way. The variability in both calibration and among individuals make standardization and repeatability problematic [127]. Probe placement with LDPM systems is subjective, considering that the volume of tissue that is measured is very small and most tissue types exhibit heterogenous blood flow, even within the same relative location. This usually prevents comparison of results to other studies [140]. However, microvascular reactivity, such as in the case of occlusion tests, can be compared readily to other studies by calculating a percentage change from an initial baseline value [141]. Even with newer CMOS cameras, LDPI systems aren’t fast enough to capture the frequency content of the Doppler signal in its entirety. A 
normal Doppler power spectrum has frequency components up to $15 \mathrm{kHz}$, so the sampling frequency of the LDPI system must be at least double that [127]; even with some of the newest systems on the market today, this sampling frequency is still not yet achievable [137, 142]. This lower sampling frequency tends to lead to underestimation of the actual perfusion values [127]. In more recent years, there have been concerted efforts to create internationally standardized protocols for data recording and for various diagnoses, making the LDF method a more useful and reliable tool for monitoring the microcirculation [143].

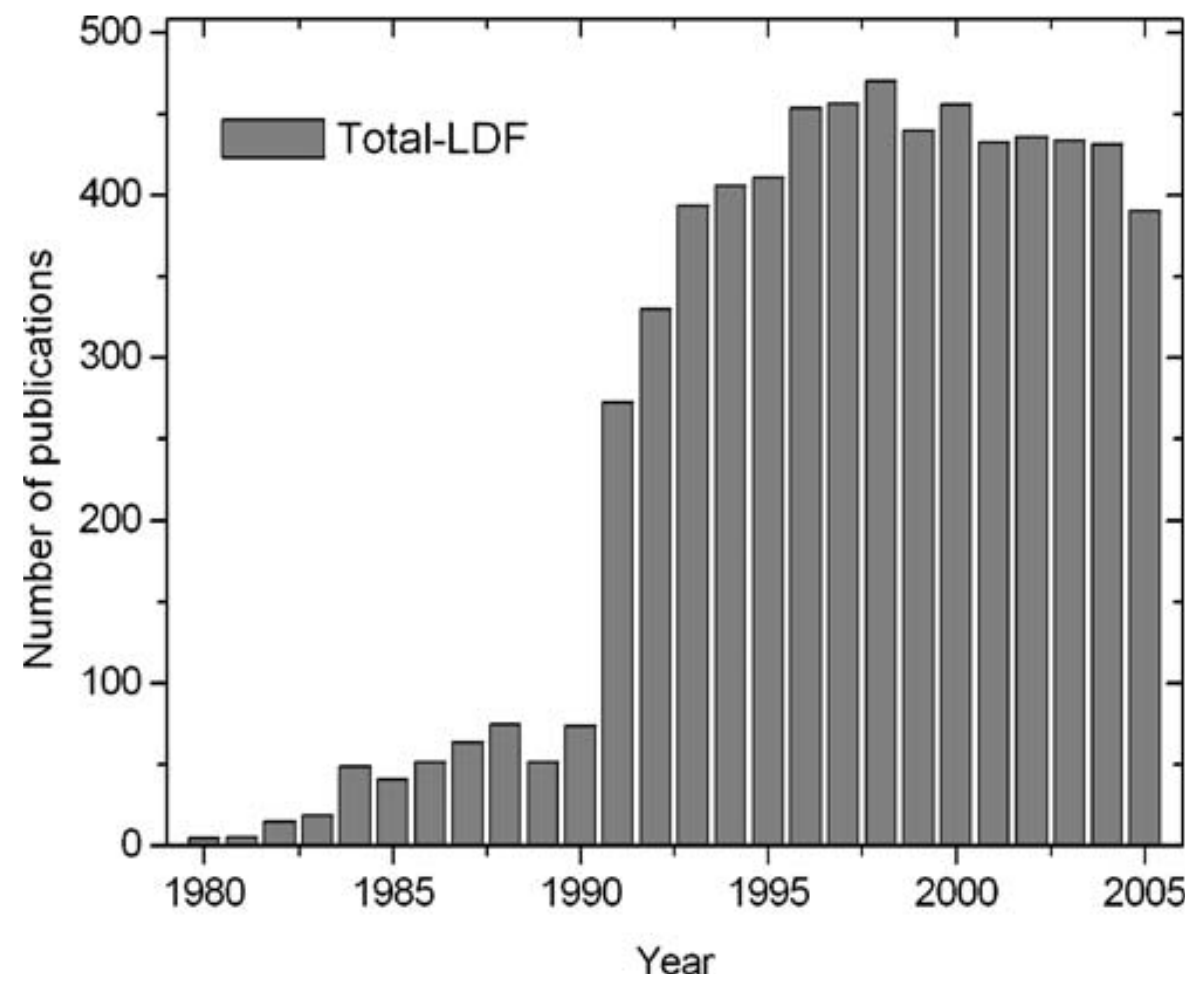

Figure 3.4: The number of publications utilizing the LDF method, either LDPM or LDPI, from 1980 through 2006 [144]

\subsection{Laser Speckle Contrast Analysis}

Laser speckle contrast analysis (LASCA), otherwise known as laser speckle contrast imaging (LSCI) or simply laser speckle imaging (LSI), utilizes very similar methodology as LDF in measuring microcirculation. "Laser speckle" is an interference 
pattern produced from light beams of the same frequency. This is in contrast to LDF where the superimposed waves have different frequencies. However, in both cases, identical equations are used to correlate the random fluctuations caused by changes in optical path lengths of the light beams to the velocity distribution of the moving components, i.e. RBCs within a given tissue. If the object is static, no change in optical path length will occur, and thus the speckle pattern will remain stationary. To scan a given area, a set-up very similar to Figure $\mathbf{3 . 2}$ for an LDPI system is typically used. A number of parameters can be manipulated with the resulting contrast map including the exposure time, number of pixels, scaling, and color coding. The number of pixels is important, because with too few pixels, proper statistical analysis cannot be performed to analyze the image, and with too many pixels, the spatial resolution is significantly diminished [127].

LASCA was originally only used for measuring perfusion in the skin, but has now become extremely important for monitoring cerebral blood flow [127, 145-147]. The increase in use for LASCA is partially because it has quicker response times than LDPI, which helps to improve patient comfort since they must remain perfectly still during the scan [148]. The LASCA method is capable of near real-time imaging (capture and processing takes less than a second on average), which is important when evaluating mechanical or pharmacological interventions on the microcirculation. However, LASCA, unlike LDF methods, does not measure the frequency spectrum; it only measures the velocity distribution. Therefore, only an average velocity of RBCs can be obtained rather than flux, i.e. perfusion. Furthermore, the velocity distribution within a given tissue must be assumed to use the equations associated with this technique [149]. The most 
significant disadvantage is the loss of resolution caused by the spatial averaging used in the analysis [127]. However, more recent developments in LASCA technology and the algorithms used have ameliorated many of these disadvantages and made this technique more comparable to LDPI $[127,140,148]$.

\subsection{High Frequency Ultrasound}

Ultrasound has been around since the late 1940s, when it was first used in sonar technology during World War II. Then, in 1955, Shigeo Satomura and Yasuhara Nimura developed the first Doppler ultrasound device, specifically for monitoring blood flow. It is now commonly utilized as a diagnostic imaging modality in medicine [150].

Ultrasound, as the term implies, is a sound wave that can be affected by properties of the medium such as density, as well as environmental factors such as temperature. However, it has a much higher frequency (> $20 \mathrm{kHz})$ than normal sound waves, but still behaves like a wave in that it transmits energy from one source to another. In ultrasound imaging systems, ultrasonic waves from a transducer propagate through a tissue and interact with mechanical discontinuities, e.g. planar interfaces between the skull and brain or between fat and liver. An echo is created from this interaction, which is a reflection or scattering of the original ultrasonic wave; ultrasonic images are then formed from these echoes $[127,150]$. The acoustic impedance of the ultrasound system is the primary factor that determines the amplitude of a given echo. As an example, blood vessels are mainly composed of connective tissue, and connective tissue exhibits impedance; thus, blood vessels tend to be more "echogenic", i.e. reflect more of the sound waves because of their higher acoustic impedance [150]. In terms of measuring blood flow, the Doppler effect is utilized in the exact same manner as with LDF. Moving components, such as RBCs, 
scatter the ultrasonic wave, which leads to a shift in frequency of the reflected waves, and this frequency shift is directly proportional to the velocity of the moving components.

Although ultrasound has been used to monitor blood flow for decades, it wasn't until the early 2000s that the microcirculation could be properly imaged. The reason for this was the limitation in imaging frequency and resolution. Before this time, maximum imaging frequencies were between $12-15 \mathrm{MHz}$ with a resolution of about $300 \mu \mathrm{m}$. With the development of micro-ultrasound, imaging frequencies are now in the $15-80 \mathrm{MHz}$ range with resolutions in the $40-200 \mu \mathrm{m}$ range [127]. The output of these systems can be displayed in a number of ways including pulsed Doppler, color Doppler, and power Doppler. Pulsed Doppler measures blood velocity with respect to time at one point in space, so it outputs the hemodynamics of that location. If vessel cross-sectional area can be determined, then flow rate in milliliters per minute can be calculated. Color Doppler presents a cover overlay of mean $\mathrm{RBC}$ velocity on top of a grayscale image of the anatomy, and can be used to distinguish arterial versus venous blood flow (Figure 3.5). However, it is only capable of providing relative flow velocities, unlike pulsed Doppler. Power Doppler computes the integral of the Doppler power spectrum, which is a representation of relative blood volume, assuming constant hematocrit. Therefore, it can provide a morphological image of the microvasculature in the region of interest (ROI). Vessels that are smaller than $50 \mu \mathrm{m}$ cannot usually be detected by power Doppler, and this modality is more prone to motion artifact than the others [151]. 


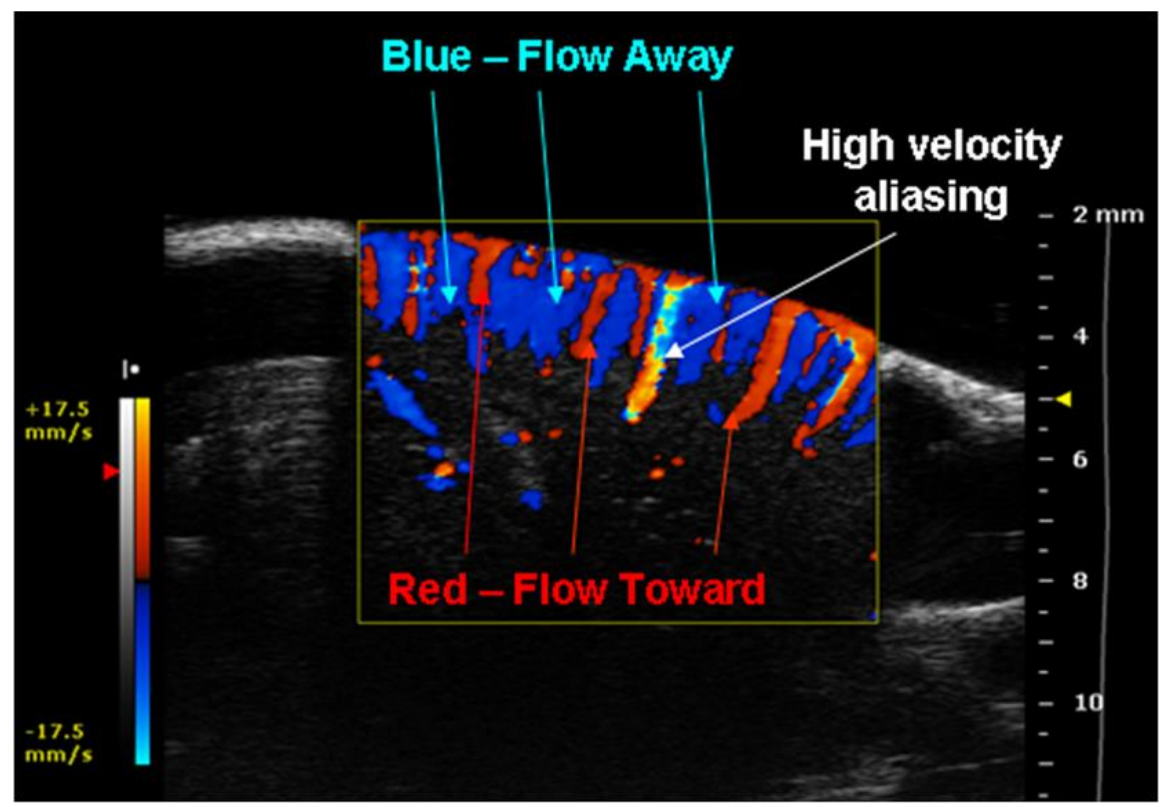

Figure 3.5: Color Doppler image of the brain cortex showing blood flow away from the transducer in blue and blood flow toward the transducer in red [151]

\subsection{Other Instrumentation}

A full review of current microcirculation monitoring techniques is beyond the scope of this work and a more comprehensive and detailed review can be found in Microcirculation Imaging by M.J. Leahy [127]. A brief description of some of these other imaging modalities will be discussed here. These include photoplethysmography (PPG), nuclear magnetic resonance imaging (NMRI), and micro-positron emission tomography (micro-PET).

PPG has been used to measure skin blood flow since the late 1940s. It utilizes electromagnetic radiation, which is transmitted from an infrared light-emitting diode (LED) source to the skin. The backscatter is measured in terms of hemoglobin absorption by a phototransistor, which indicates the relative volume of blood in the ROI. After signal processing, the output is displayed on a chart recorder. The measurement depth is around $1-1.5 \mathrm{~mm}$ for most probes, which are noninvasive like the LDPM probes. PPG is used in the assessment of skin ulcers and flap viability, in the evaluation of PAOD and CVD, 
and in measuring the pharmacodynamic response of various drugs on the circulation [135].

NMRI is capable of quantifying blood flow within the entire size range of the vasculature, i.e. large diameter arteries and small diameter capillaries. This is accomplished either through arterial spin labeling (ASL) or dynamic susceptibility contrast (DSC). ASL uses magnetically-'labeled' water protons that function as a tracer, which is similar to other imaging modalities such as single-photon emission computed tomography (SPECT), PET, and CT, except that there is no injection of a contrast agent; it instead labels the "blood magnetization". DSC uses an injection of a contrast agent called Gadolinium (Gd) encapsulated in a chelate molecule for dynamic imaging. Although DSC is a more clinically viable option in terms of high signal-to-noise ratios and simple acquisition procedures, ASL is completely non-invasive, can be operatorindependent, and is intrinsically more quantitative; hence its popularity in research and the clinical setting is increasing [152]. In ASL, blood flow causes a shift in magnetization that is displayed on the resulting image, which is subtracted from a "control" image where there is no magnetization [127]. There are numerous ways of labeling this magnetization, most commonly continuous or pulsed ASL is used, as well as numerous ways of acquiring the image signal and quantifying the blood flow. However, recently the ASL Network was established to assimilate the many different procedures and theories used in this technique in the hopes of increasing its clinical utility [152].

PET systems have been in use since the 1960s and have served as a powerful clinical diagnostic tool in terms of noninvasively studying human physiology and biochemistry. Starting in the 1990s, PET systems were scaled down to produce 
resolutions of around $2 \mathrm{~mm}$, which is when the term micro-PET became popular. MicroPET uses a radioactive substance that decays by positron emission when it collides with an electron. This annihilation causes high-energy photons to be emitted, which are collected by the micro-PET detectors. By collecting a multitude of photon pairs, a topographic image is created. This technique has the advantages of being very sensitive, having high signal-to-noise ratios, and having the capability of imaging any type of target from metabolic substrates to nanoparticles. Thus, absolute measurements of blood flow are possible [127]. However, it is still limited in terms of its spatial resolution because of the finite distance that the positron can travel in any given tissue before collision. In addition, many of the radioisotopes used in perfusion monitoring have short half-lives, although newer agents such as $\left[{ }^{11} \mathrm{C}\right] \mathrm{DMDPA}$ have helped mitigate this pitfall [153]. The combination of micro-PET with micro-computed tomography (micro-CT) scanners has vastly improved the spatial resolution as well; this type of dual modality imaging system is shown in Figure 3.6.

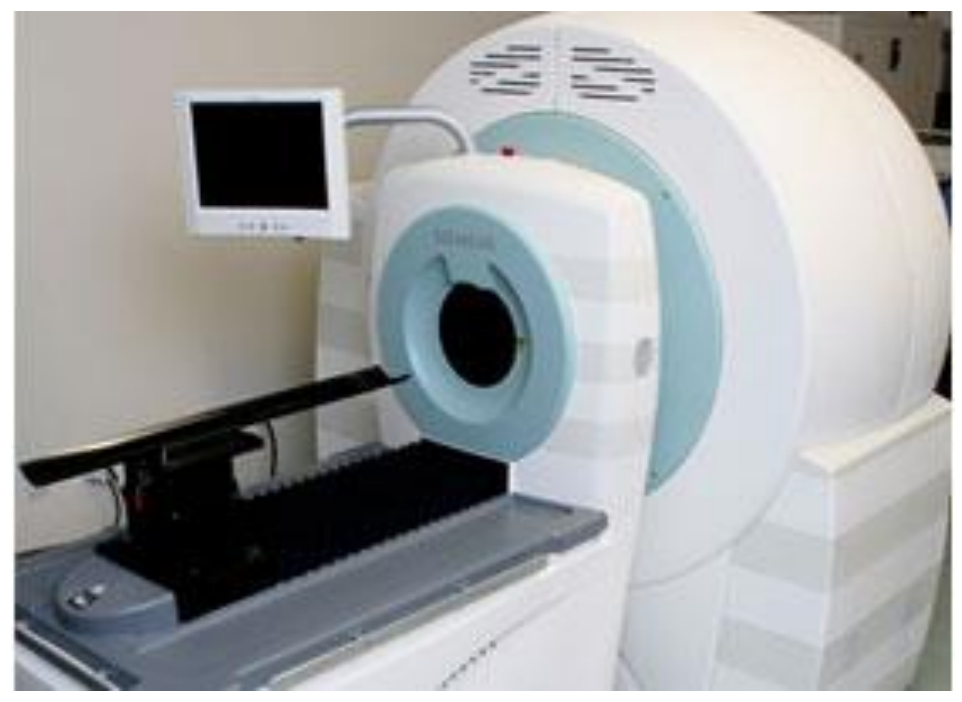

Figure 3.6: Siemens Inveon Micro-CT/PET system capable of ultra-high resolutions down to $15 \mu \mathrm{m}$ [154] 


\section{CHAPTER 4 - CLINICAL PILOT STUDY DESIGN}

\subsection{Justification for the Use of TENS}

The use of TENS for the pilot study was chosen because of its low cost, wellestablished parameters for safe and effective use, and its favorable impact on hemodynamics and pain reduction in humans. Since this was a pilot study in healthy subjects, SCS was not chosen due to its invasiveness. EA and TENS have similar effects on cutaneous blood flow and skin temperature in the hand [65]. However, EA use is limited by the need for a licensed acupuncturist to properly place the electrodes at the correct acupoints. In addition, most of the research involving EA has been conducted on animals, and with mixed results $[64,68,113,155]$. For the pilot study, we compared our results to other healthy, human subject studies using similar protocols with TENS. There is no difference between TENS and IFC in terms of treating chronic back pain, but both are still more effective than no treatment, i.e. both treatments caused reductions in the Visual Analog Scale (VAS) and Roland-Morris Disability Questionnaire (RMDQ) with regards to pain intensity, consumption of pain medications, and disability [70]. Even with ischemia-induced pain, both techniques are nearly equivalent in their analgesic effects when comparing reductions in pain intensity using the VAS and McGill Pain Questionnaire (MPQ) [119]. As far as we know, there have been no direct comparisons of the effect of IFC and TENS on the cardiovascular system, although separate studies of IFC and TENS using almost identical protocols have been conducted, but the authors only mentioned that similar results were obtained, i.e. reductions in MAP and calf vascular resistance with simultaneous increases in calf blood flow $[81,126]$. One of the goals of this study was to investigate these two neurostimulation techniques and 
determine which elicited greater hemodynamic changes, which will be discussed in more detail in Chapter 5.

\subsection{Mechanism of Action of TENS on Hemodynamics}

The gate control theory has been used for decades to explain how neurostimulation effectively mitigates pain, but it has not been used to explain the changes that are witnessed within the cardiovascular system, i.e. increased blood flow, decreased blood pressure (BP), and decreased vascular resistance. Specifically, TENS seems to modulate the gate control system by stimulating large diameter, $A \beta$-fibers and Group I - II muscle afferents, causing an increased inhibitory effect of GABA on NS and WDR neurons. This effectively reduces the transmission of pain signals carried by small diameter, C-fibers and Group III - IV muscle afferents to the dorsal horn neurons. Thus, the original noxious stimulus still reaches the brain, but the painful sensation and response that occurs is reduced $[47,156,157]$.

Simultaneous to the reduced pain sensation, the metaboreflex may be reduced. Normally, the metaboreflex (muscle chemoreflex) is triggered by ischemic by-products, e.g. lactic acid, hydrogen ions, adenosine, prostaglandins, bradykinin, and potassium, with potassium being the most potent stimulator of intramuscular chemoreceptors located on group III - IV muscle afferents [158-161]. The metaboreflex causes an increase in sympathetic activity, which in turn increases cardiac output (higher HR and SV) and vasoconstriction in nonactive tissues [162]. At the same time, there is a blunted vasoconstrictive effect on active tissues (due to functional sympatholysis), leading to a net increase in blood flow and oxygen to these tissues [163]. Although this process is imperative in healthy individuals to redistribute blood flow to active tissues during exercise, it can actually worsen the symptoms in PAOD patients who have increased 
reactive oxygen species (ROS) production as a result of the disease, which also stimulates Group IV muscle afferents, [164, 165]. This is evidenced by greater changes in MAP in response to exercise and more sympathetic activation, which is related to disease severity, i.e. the more severe the disease state, the greater the metaboreflex activation will be and the more sympathetic activation that will occur [165]. Thus, there is likely to be a more pronounced effect when TENS is used on PAOD patients compared to on healthy individuals. Specifically, it should reduce BP but should not affect HR substantially, because TENS at sensory intensity does not affect descending control mechanisms from the brain, and it is these central mechanisms that influence $\operatorname{HR}[156,166]$. Furthermore, the effect of TENS on HR has produced inconclusive results [33, 67, 81].

The reduction in the metaboreflex, in theory, should not cause local vasodilation, yet in many studies, an increase in blood flow still occurs with application of TENS [33, $36,66,167]$. Therefore, an additional mechanism must be at work to explain this local vasodilatory effect. A few studies have investigated how catecholamine metabolism increases in response to TENS and the findings suggest that it may be inhibiting norepinephrine (NE) release $[33,36,79,168]$. This inhibition of NE release may occur if TENS causes serotonin release. As stated in Section 2.1, high frequency (> $50 \mathrm{~Hz}$ ) TENS activates $\delta$-opioid receptors and low frequency TENS $(<10 \mathrm{~Hz})$ activates $\mu$-opioid receptors in the RVM and the spinal cord $[69,169]$. This activation may occur through release of $\beta$-endorphins that selectively bind to $\mu$-opioid receptors [170] or the release of enkephalins that selectively bind to $\delta$-opioid receptors [171]. A complex presynaptic synergistic interaction between opioid receptors and serotonin $(5-\mathrm{HT})$ receptors is responsible for some of the anti-nociceptive effects of electrical stimulation, possibly 
through a decrease in GABA release in spinal interneurons, although this is not fully understood $[172,173]$. TENS stimulates release of serotonin from the raphe nuclei into the spinal cord, which then activates $5-\mathrm{HT}_{1}, 5-\mathrm{HT}_{2}$, and 5- $\mathrm{HT}_{3}$ receptors $[174,175]$. Serotonin can either have a depressor effect if neurogenic vasoconstriction is present, as in the case of PAOD patients, or can have a pressor effect if neurogenic vasoconstriction is absent [176]. In the case of this depressor effect, presynaptic inhibition of NE from sympathetic nerve terminals occurs [177]. Normally, electrical stimulation, such as TENS, stimulates a vasoconstrictor response through the release of NE and ATP from postganglionic sympathetic neurons $[178,179]$. NE activates $\alpha_{2}$ adrenergic receptors, which are part of a larger class of adrenergic receptors that mediate smooth muscle contraction, i.e. vasoconstriction. The $\alpha_{2}$ receptors exist on SMCs, sympathetic nerve terminals, peripheral nerve terminals of primary afferent neurons, around injured peripheral nerves, the dorsal horn of the spinal cord, central terminals of primary afferent neurons, and in the RVM, locus coeruleus, and other brain regions [180]. They are also the only adrenergic receptors that are associated with presynaptic inhibition, specifically of NE, and provide negative feedback to stimulated NE release. Depolarization-induced release of neurotransmitters, such as NE, from nerves is dependent on the influx of calcium through voltage-gated calcium channels. N-type calcium channels, which are coupled to $\alpha_{2}$ receptors via G-proteins, mediate calcium influx responsible for norepinephrine release. Serotonin decreases the calcium current through the channels. As a result, cytosolic levels of calcium decrease, causing inhibition of NE release from the sympathetic nerve terminal $[177,181]$. In addition, both serotonin and activation of $\alpha_{2}$ receptors have both been implicated in presynaptic and postsynaptic inhibition on 
nociceptive afferents and dorsal horn neurons, resulting in analgesia [182, 183].

Supporting this idea, TENS-induced analgesia was reduced in mice with dysfunctional $\alpha_{2 \mathrm{~A}}$ receptors, i.e. the hypotensive action of these receptors was completely ablated, but not in mice with deleted $\alpha_{2 \mathrm{C}}$ receptors [79]. In this same study, spinal and supraspinal blockade of $\alpha_{2}$ receptors in wild-type (WT) mice did not affect the antihyperalgesia of TENS, while blockade of $\alpha_{2}$ receptors at the site of application of TENS reduced the antihyperalgesia. In addition, $\alpha_{2 \mathrm{~A}}$ receptors are expressed more on primary afferent neurons than $\alpha_{2 \mathrm{C}}$ receptors, suggesting that $\alpha_{2 \mathrm{~A}}$ receptors are mainly responsible for the antihyperalgesic effects. In this case, reductions in pain intensity, metaboreflex activation, and vasoconstriction could all occur through electrical stimulation of both cutaneous and muscle afferents.

Although this explanation for TENS-induced vasodilation and subsequent increases in blood flow seems plausible, other possible receptors, paracrine factors, and hormones may play some role. For example, TENS-induced vasodilation may result from activation of $\beta$-adrenergic receptors and/or release of acetylcholine, histamine, adenosine, dopamine, prostaglandins or plasma kinins; however, antagonists for all of these vasodilators still do not reduce the vasodilatory effect of TENS [184]. TENS does stimulate release of nitric oxide (NO) from the pedal ganglia of blue mussels (Mytilus edulis) by activating opioid receptors, as opioid receptor blockade with naloxone prevented NO release [185]. However, NO does not seem to be responsible for the induced vasodilation in humans as only the analgesic effects of TENS were blocked with naloxone [186]. Upregulation, i.e. higher mRNA and protein levels, of CGRP, which is the most potent of the vasodilators in the DRG, in response to TENS is another 
possibility for the induced vasodilation; this would further stimulate NO release from the endothelium and cause SMC relaxation [187, 188]. Lastly, TENS increases plasma levels of vasoactive intestinal polypeptide (VIP), another potent vasodilator, within the circulation, which the authors believed may be a secondary action attributable to a decrease in sympathetic activity, possibly as a result of the serotonergic pathway discussed earlier [189]. Evidence of TENS-induced vasodilation from any other possible mechanisms is currently unknown.

Multiple mechanisms may underlie the hemodynamic changes induced by TENS, but it seems that a dual, synergistic mechanism is most likely responsible for these changes, as shown in Figure 4.1. Specifically, stimulating the $A \beta$ cutaneous afferents and Group I and II muscle afferents not only closes the "gate" and reduces noxious stimulus transmission as previously thought, but also reduces the metaboreflex causing a decrease in SNS activity. In addition, TENS stimulates release of serotonin that inhibits NE release from sympathetic nerve terminals causing vasodilation. Through this cascade of neural events, the end result is a reduction in MAP with a simultaneous increase in local blood flow. 


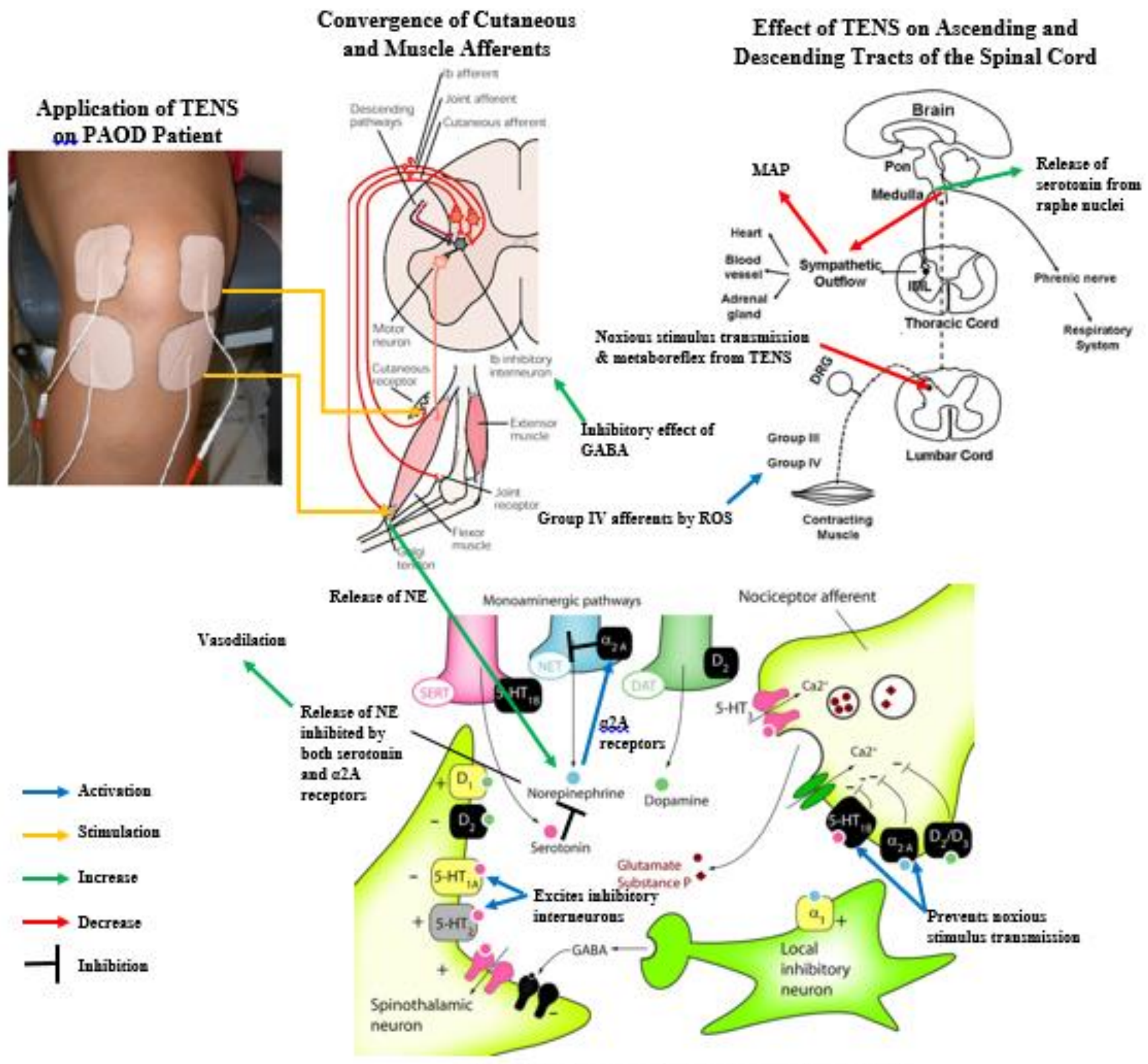

Effect of TENS on Neurotransmitter Release

Figure 4.1: Diagram of the proposed mechanisms for TENS-induced changes on the cardiovascular system in PAOD patients, involving a reduction in the metaboreflex and presynaptic inhibition of NE from sympathetic neurons. GABA: Gamma-aminobutryic Acid; MAP: Mean Arterial Pressure; ROS: Reactive Oxygen Species; NE:

Norepinephrine 
This proposed dual mechanism of action for application of TENS on PAOD patients should also apply to healthy individuals who experience induced ischemia. In healthy participants, i.e. no past or current history of any cardiovascular, musculoskeletal, or neural conditions, who experienced induced ischemia through the inflation of a blood pressure cuff wrapped around their forearm, MAP and vascular resistance decreased, while blood flow increased with TENS applied on the C7 and T4 dermatomes; this effect on the hemodynamics was more pronounced in younger individuals $(25 \pm 1.3$ years of age) [81]. This may be surprising considering that plasma levels of NE are higher in older individuals [190,191], and there is greater endothelial dysfunction and increased sympathetic tone $[192,193]$; TENS has a greater effect when increased SNS activity is present, such as during isometic exercise [80]. However, the metaboreflex may be attenuated by age, and with reduced metaboreflex activation, the effect of TENS on SNS activity will also be reduced [194]. Specifically, sympathetic reactivity to isometric hand exercise is reduced in older individuals, meaning there is a smaller percentage increase in sympathetic tone with exercise as compared to young individuals [195]. This could be explained by the increase in oxidative fibers in skeletal muscle with age, which could attenuate BP and muscle sympathetic nerve activity (MSNA), i.e. less of a change with exercise, since glycolytic fibers exhibit a greater exercise reflex response [196]. For example, in mice, there is a change in muscle myosin heavy chain (MHC) isoforms from fast, glycolytic Type II fibers to slower, oxidative Type I fibers [197]. Since glycolytic muscle evokes greater metaboreflex activation than oxidative muscle [196], and if there is a slow transformation of muscle fibers to a more oxidative phenotype with age [195], 
then it seems reasonable that younger individuals would experience a greater effect from TENS on the metaboreflex.

Although application of TENS may have a favorable impact on PAOD patients, the same may not be true of patients with other forms of cardiovascular disease, such as congestive heart failure (CHF) and hypertensive patients. In CHF patients, the metaboreflex is reduced, which is evidenced by a blunted increase in systolic blood pressure (SBP) and calf vascular resistance in the non-exercised limb [161]. This may be due to impaired left ventricular contractility, which limits cardiac output (CO). In this case, heart rate (HR) would increase, but stroke volume (SV) would decrease, so CO would not increase as much during exercise. The SV decrease is related to impaired contractility and increased ventricular afterload sensitivity, whereby the ventricles become more sensitive to pressure changes [198, 199]. An attenuation of the metaboreflex has also been found in hypertensive patients [200]. Thus, the effect of TENS may not only depend on the age of the individual, but also if that individual exhibits different forms of cardiovascular disease.

\subsection{Pilot Study Design}

To test the proposed mechanisms of TENS and its effects on hemodynamics, a pilot study will be performed after some pre-pilot work is conducted to optimize the study design, which will be discussed in Chapter 5; what follows is an "expected" study design based on a pre-approved protocol submitted to the Institutional Review Board (IRB) at Cal Poly.

For this pilot study, young, healthy, college-aged students between the ages of 18 and 24 will be recruited through department emails, fliers, and "word of mouth". Volunteers will complete an informed consent document (Appendix B) and a short 
medical history questionnaire to ensure that they do not present any of the contraindications for TENS and are free of any symptoms or signs of cardiovascular disease (Appendix C). In qualifying subjects, C7 and T4 dermatomes on the back will be stimulated; these dermatomes innervate the arms and hands as well as the thoracic region over the pectorals (Figure 4.2).

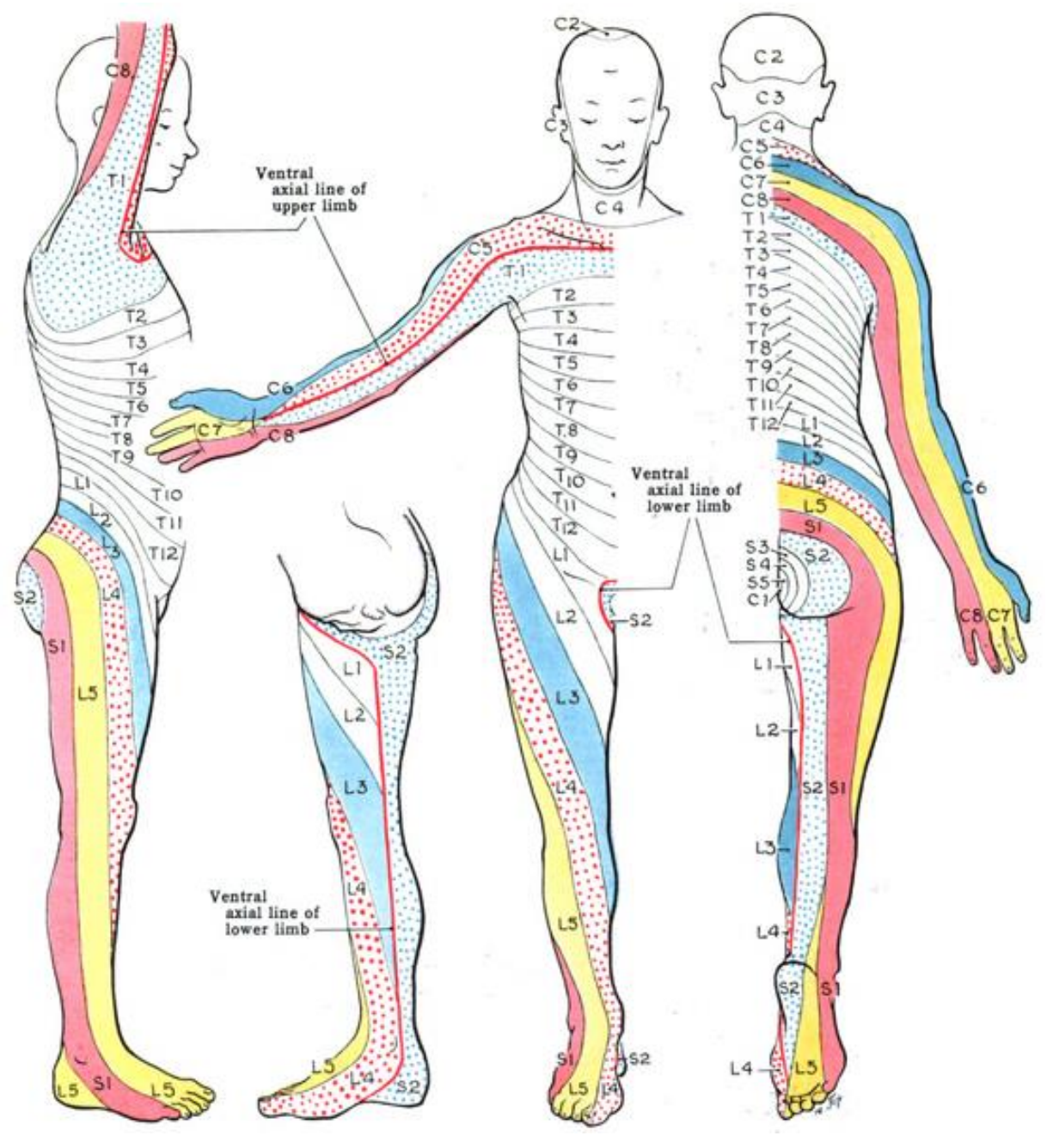

Figure 4.2: Dermatomes for the various regions of the human body [201]

TENS will be applied to these dermatomes to investigate its effectiveness in increasing blood flow to the limb, decreasing $\mathrm{BP}$, and reducing ischemic pain, using previously established parameters for frequency, pulse duration, treatment duration, and intensity 
$[33,36,63,67,80,81]$. Ischemic pain in the forearm will be induced with a blood pressure cuff $[81,119,192]$. CBF will be measured with a non-invasive laser Doppler flow system (moorVMS-LDF2), BP and HR will be measured with a digital blood pressure monitor (Life Source UA-767 Plus), and pain intensity will be measured using the Numerical Pain Rating Scale (NPRS) (Appendix D).

During one of the two treatment days, the participant will undergo the postexercise without circulatory occlusion (PECO-) protocol. On the other treatment day, the post-exercise with circulatory occlusion (PECO+) protocol will be followed. Therefore, all participants will undergo all treatment conditions. The order of these protocols will be randomized for each participant using a given code on the medical history form. The first 15 minutes will be allocated either to the placebo condition or TENS condition, a 30minute break will be given, and then 15 minutes will be allocated to the other condition (Figure 4.3). Thus, the order of placebo and treatment conditions will also be randomized. During the placebo condition, subjects will have the electrodes attached to the upper back just as during the treatment condition, but no current will be applied from the TENS unit. 


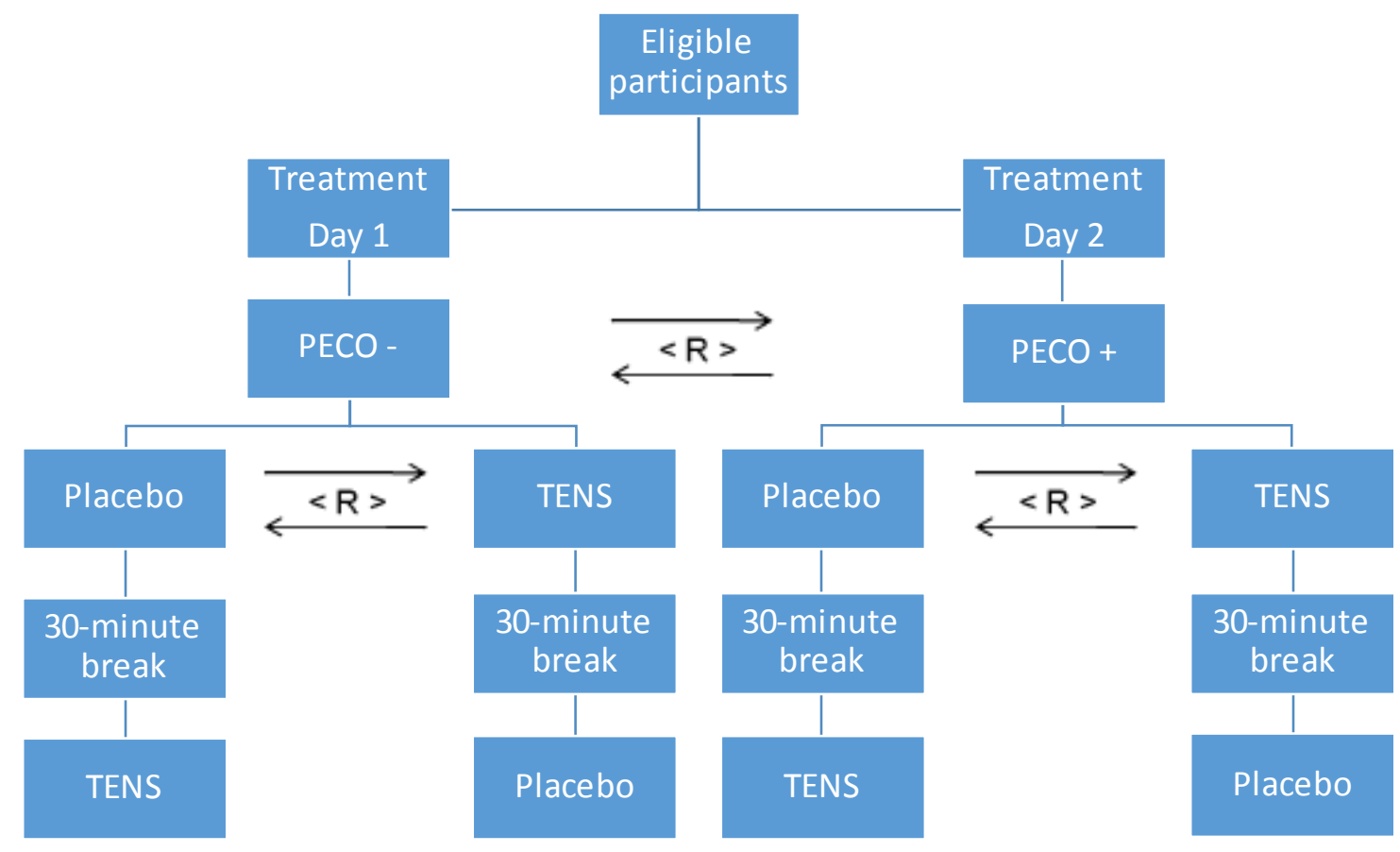

Figure 4.3: Study flow diagram for the pilot study

We hypothesize that ischemia-induced individuals who receive TENS will exhibit an increase in cutaneous blood flow $(\mathrm{CBF})$ and decreases in cutaneous vascular resistance (CVR), BP, and pain intensity compared to those who do not receive TENS.

Furthermore, the application of TENS will cause a greater decrease in BP in ischemiainduced individuals compared to non-ischemia-induced individuals; CVR and CBF responses in non-ischemia-induced individuals with TENS will be more pronounced than in those same individuals who do not receive TENS, i.e. CVR will decrease and CBF will increase. Table 4.1 shows these expected changes for the control and treatment with TENS groups with and without post-exercise circulatory occlusion (PECO). 
Table 4.1: Expected Outcomes for Systemic Hemodynamic Parameters and Pain Intensity for both Control and TENS Groups with and without PECO*

\begin{tabular}{ccccc}
\hline & \multicolumn{2}{c}{ Control } & \multicolumn{2}{c}{ TENS } \\
\hline Heart Rate & PECO- & PECO+ & PECO- & PECO+ \\
Blood Pressure & $\downarrow$ & - & $\downarrow$ & - \\
Blood Flow & $\downarrow$ & - & $\downarrow$ & $\downarrow \downarrow$ \\
Vascular Resistance & $\uparrow$ & - & $\uparrow \uparrow$ & $\uparrow$ \\
Pain Intensity & $\downarrow$ & - & $\downarrow \downarrow$ & $\downarrow \downarrow$ \\
& $\downarrow$ & - & $\downarrow$ & $\downarrow \downarrow$ \\
\hline
\end{tabular}

${ }^{*} \mathrm{PECO}+=$ Post-exercise with Circulatory Occlusion; PECO- = Post-exercise without Circulatory Occlusion; Arrows indicate change from baseline reading 


\section{CHAPTER 5 - PRE-PILOT WORK}

\subsection{Methods}

To optimize the future pilot study design, comparison studies between IFC and TENS, and two different areas of application (forearm and back) were investigated to determine which combinations produced the greatest hemodynamic changes. These studies were run over the course of three weeks on both myself and my partner in this project. The protocol, as described in Appendix E, was followed, except for the following deviations: there was only a 10 minute break in between sessions instead of 30 , pain was assessed every 3 minutes instead of every minute, blood flow was measured in the left palm and anterior brachial region of the left arm instead of in the left and right palms, and the control condition always preceded the TENS or IFC condition instead of being randomized. Ischemia was induced using a manual blood pressure cuff (CVS Pharmacy Model \#BPAG1-20CVS) wrapped around the subject's left forearm. Isometric exercise was performed using a hand dynamometer. Electrical stimulation was provided by an InTENSity Select Combo TENS/IF/MIC/EMS Stimulator. CBF and skin temperature were monitored using a Moor Instruments VMS-LDF2 and VP1T/7 skin probes attached just distal to the elbow and wrist creases. BP and HR were assessed halfway through each treatment interval, i.e. baseline, occlusion, exercise, and recovery, using a Life Source digital blood pressure monitor (Model \#UA-767 Plus) with the cuff wrapped around the subject's right arm. MAP was calculated from the equation:

$$
M A P=\frac{2}{3} D B P+\frac{1}{3} S B P
$$

and CVR was calculated from the equation:

$$
C V R=\frac{M A P}{C B F}
$$


Respiration was monitored using a Pneumotrace II respiratory belt (ADInstruments, Model \#MLT1132/D). If the raw breath signal exceeded $\pm 50 \mathrm{mV}$ during anytime period, causing motion artifact in the blood flow recordings, then the data was deleted over that interval. Any additional motion artifacts were also removed from the data trace. All measurements, besides BP, were continuously monitored using a PowerLab 26T system (Model \#ML4856) and LabChart 7 Pro software. The output of such measurements in LabChart is shown in Figure 5.1, the entire experimental set-up is shown in Figure 5.2, the different treatment parameters, i.e. frequency, pulse width, treatment duration, and intensity, are shown in Table 5.1, and electrode placement for both IFC and TENS on the forearm and back is shown in Figure 5.3.

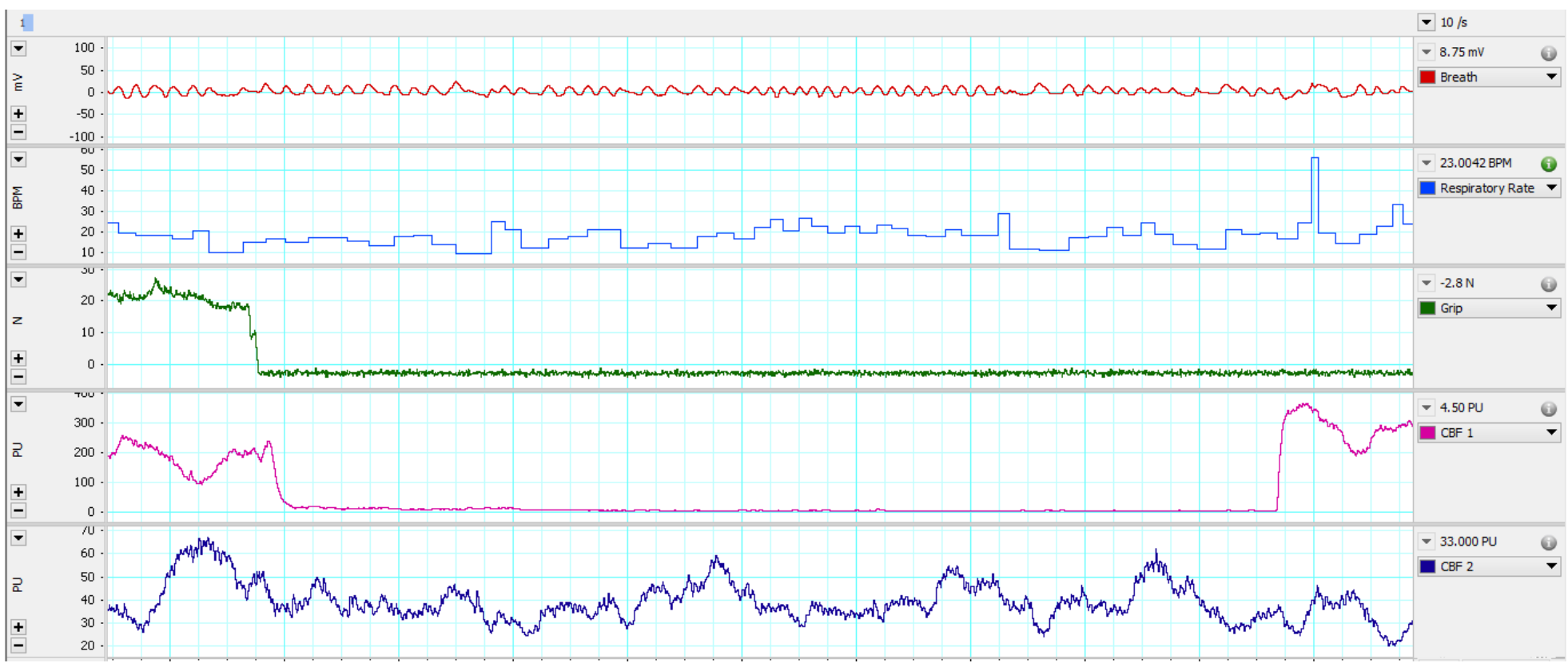

Figure 5.1: Representative data trace showing the raw breath signal in $m V$, the respiratory rate in BPM, the grip force in $N$, and the blood flow measurements at the two different locations in $P U$ 


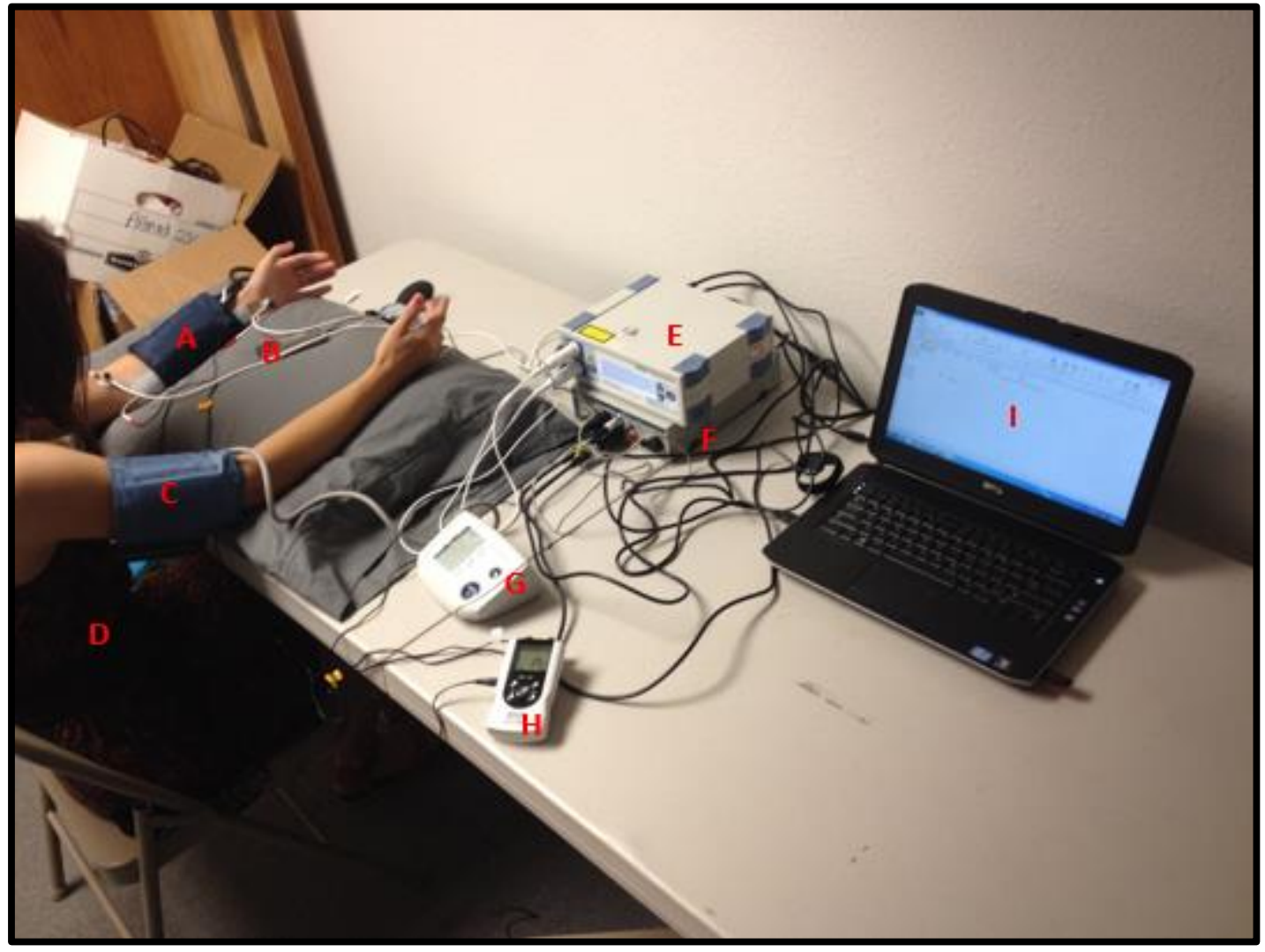

Figure 5.2: Experimental set-up for pre-pilot work A) Manual blood pressure cuff B) Hand dynamometer $C$ ) Digital blood pressure cuff D) Respiration belt E) LDF system $F$ ) PowerLab system G) Blood pressure monitor H) Stimulator I) Laptop with LabChart software 
Table 5.1: Treatment Parameters for TENS and IFC Testing*

\begin{tabular}{lllll}
\hline $\begin{array}{l}\text { Treatment } \\
\text { Method }\end{array}$ & Frequency $(\mathrm{Hz})$ & Pulse Width $(\mu \mathrm{s})$ & $\begin{array}{l}\text { Treatment } \\
\text { Duration }(\mathbf{m i n})\end{array}$ & $\begin{array}{l}\text { Intensity Range } \\
(\mathbf{m A})\end{array}$ \\
\hline $\begin{array}{l}\text { TENS on Back at } \\
\text { High Frequency }\end{array}$ & 100 & 200 & 15 & $12-13$ \\
$\begin{array}{l}\text { TENS on } \\
\text { Forearm at High } \\
\text { Frequency }\end{array}$ & 100 & 200 & 15 & $6-8$ \\
$\begin{array}{l}\text { TENS on Back at } \\
\text { Low Frequency }\end{array}$ & 4 & 200 & 15 & $11-14$ \\
$\begin{array}{l}\text { TENS on } \\
\begin{array}{l}\text { Forearm at Low } \\
\text { Frequency }\end{array}\end{array}$ & 4 & 200 & 15 & $6-8$ \\
$\begin{array}{l}\text { IFC on Back at } \\
\text { High Frequency }\end{array}$ & 100 (modulated) & 200 & 15 & $7-11$ \\
$\begin{array}{l}\text { IFC on Forearm } \\
\text { at High } \\
\text { Frequency }\end{array}$ & 100 (modulated) & 200 & & 5 \\
\hline
\end{tabular}

\footnotetext{
* Intensity for each subject was individually adjusted to the point just bel ow motor threshold i.e. no visible muscle contraction or sensations of pain
} 


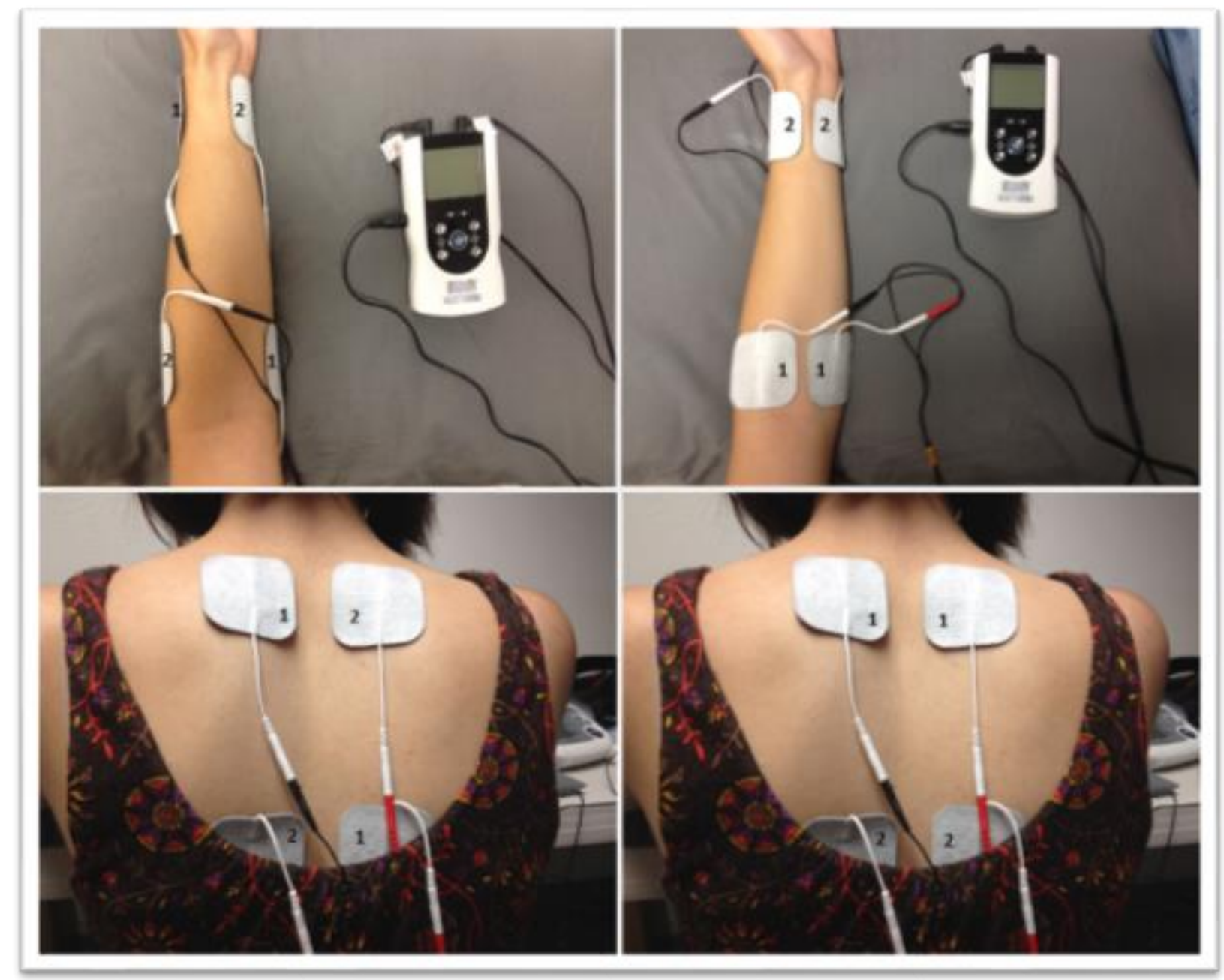

Figure 5.3: Electrode placement for: IFC on the forearm (upper left), TENS on the forearm (upper right), IFC on the back (lower left), and TENS on the back (lower right);

1) Channel 1 of the stimulator 2) Channel 2 of the stimulator

The hypothesis for all the treatment conditions was that stimulation would cause an increase in $\mathrm{CBF}$ with a concomitant decrease in BP, CVR, and pain intensity. Furthermore, it was expected that application of IFC on the back and on the forearm would produce greater favorable changes in these endpoints compared to TENS, because of its ability to stimulate deeper tissue, i.e. more muscle afferents. It was also expected that high frequency TENS would be more effective than low frequency TENS, because 
high frequency TENS produces greater inhibition of dorsal horn neuron activity than low frequency TENS [202]. Specifically, C-fibers are maximally suppressed at stimulation frequencies of $80-100 \mathrm{~Hz}$ [203]. Finally, it was expected that application of TENS on the back would cause similar decreases in BP as compared to application of TENS on the forearm, but with less of an increase in CBF (measured in the palm), since the stimulation current would most likely activate $\alpha_{2}$ receptors in the dorsal horn of the spinal cord more so than at the sympathetic nerve terminals of primary afferent neurons based on the electrode placement site.

Data for the hemodynamic parameters, pain intensity, and reperfusion time were all analyzed in JMP Pro 11 software. Repeated measures ANOVA and Dunnett's Test were used for comparisons among the different treatment conditions and comparing each treatment condition to the control, respectively. Statistical significance was accepted when $\mathrm{P}<0.05$. $\mathrm{P}$-values for all hemodynamic parameters and pain intensity are shown in

\section{Appendix G.}

\subsection{Results}

To test the proposed hypotheses for stimulation frequency and modality as well as electrode placement, six different treatment conditions and a control were all compared in terms of pain intensity, $\mathrm{CBF}$ in the palm and anterior brachial region, reperfusion time, SBP, DBP, HR, MAP, and CVR in the palm and anterior brachial region. Appendix $\mathbf{F}$ lists the averages obtained for control and treatment conditions. Figure 5.4 depicts the average pain intensity for baseline, exercise, occlusion and recovery, which is based on the Numerical Rating Scale (NRS). Figures 5.5, 5.6, and 5.8 through 5.13 depict the percent change for each hemodynamic parameter that was measured with regards to the specific treatment condition. Error bars from these figures have been removed for the 
sake of clarity. Figure $\mathbf{5 . 7}$ depicts the average reperfusion time for all treatment conditions.

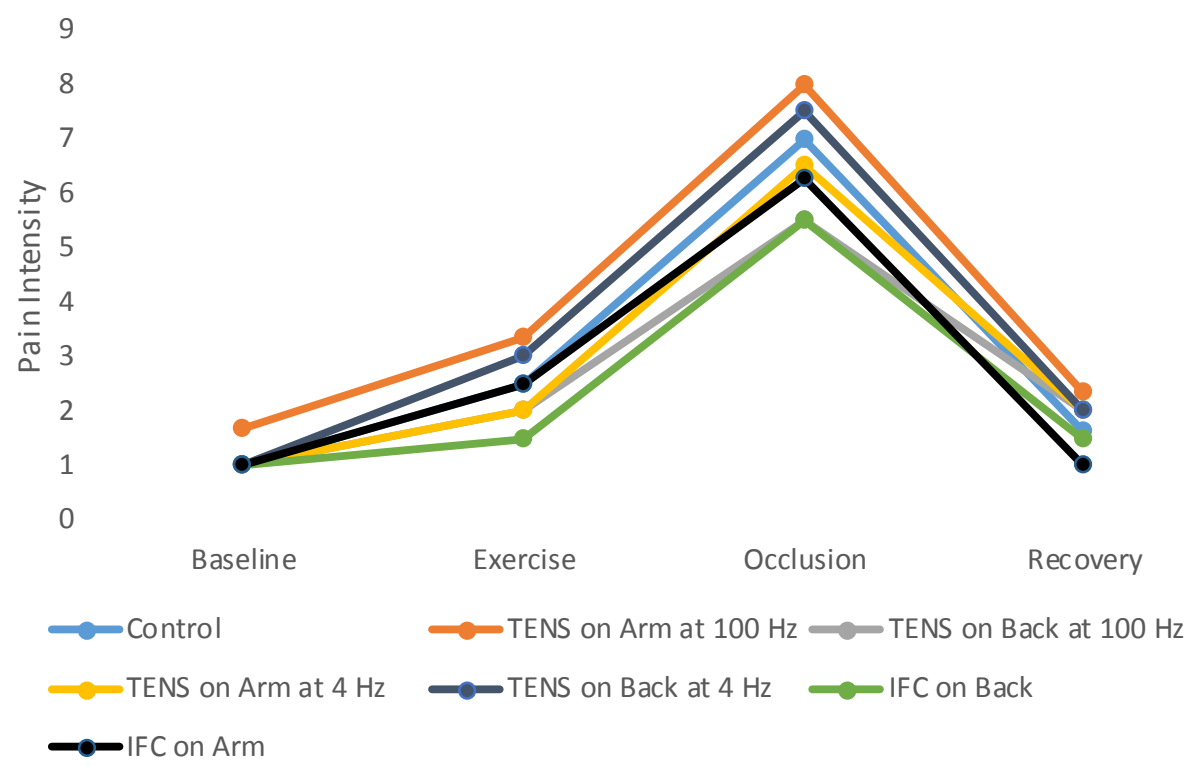

Figure 5.4: Pain intensity according to the NRS during each interval for all treatment conditions

Pain intensity was measured to determine if the ischemic pain induced by occlusion was reduced by TENS or IFC, which would indicate either a restoration of the oxygen supply in the ischemic region or pain modulation by activation of $A \beta$-fibers or a combination of both. TENS on the back at $4 \mathrm{~Hz}$ and TENS on the arm at $100 \mathrm{~Hz}$ exhibited higher pain intensity compared to control for baseline, exercise, occlusion, and recovery. All baseline pain intensity values were the same besides for TENS on the arm at $100 \mathrm{~Hz}$. Pain intensity for IFC on the arm was the same as control for exercise, but decreased during occlusion and recovery. No statistical differences were found among the treatment conditions when compared with the control condition. However, TENS on the arm at $4 \mathrm{~Hz}$ and TENS on the back at $100 \mathrm{~Hz}$ exhibited lower pain intensity during exercise and occlusion, but were higher during recovery compared to control. IFC on the 
back exhibited lower pain intensity during exercise, occlusion, and recovery compared to control.

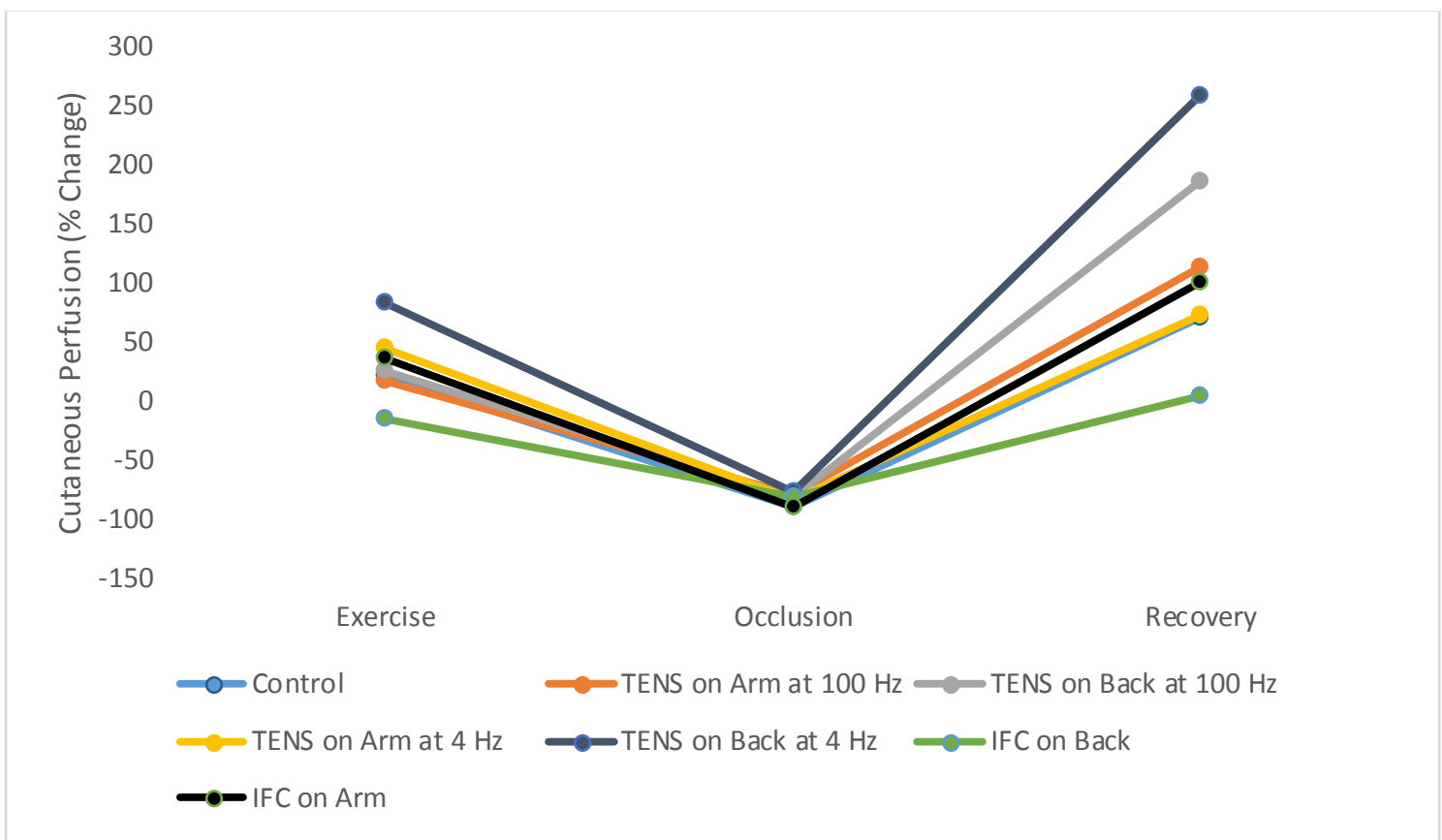

Figure 5.5: Blood flow in the left palm, measured as percent change from baseline reading, for all treatment conditions

CBF was measured in the left palm to determine if there was a local vasodilatory effect from TENS or IFC, which would be exhibited as a higher percentage increase in $\mathrm{CBF}$ during exercise, occlusion, and recovery as compared to control. No statistical differences were found among the treatment conditions when compared with the control condition. However, IFC on the arm, TENS on the back at $100 \mathrm{~Hz}$, and TENS on the back at $4 \mathrm{~Hz}$ all trended toward higher $\mathrm{CBF}$ for exercise, occlusion, and recovery compared to the control condition. TENS on the arm at $100 \mathrm{~Hz}$ trended toward lower CBF during exercise compared to control, but higher CBF during recovery. TENS on the arm at $4 \mathrm{~Hz}$ exhibited the opposite trend with higher $\mathrm{CBF}$ during exercise, but lower $\mathrm{CBF}$ during recovery. IFC on the back exhibited lower $\mathrm{CBF}$ during both exercise and recovery, but was still higher than control during occlusion. 


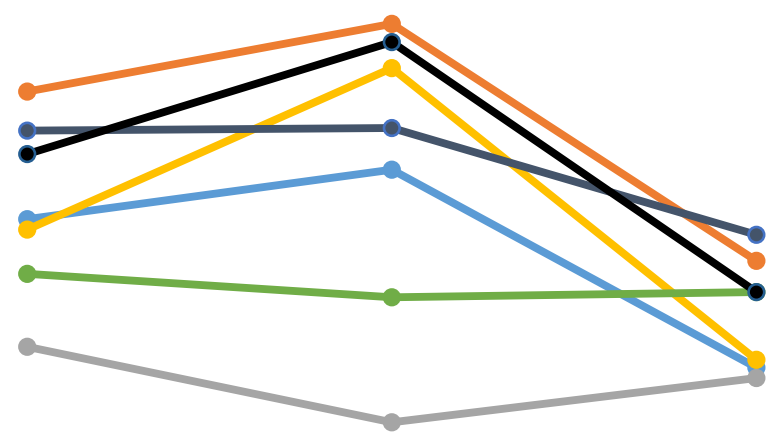

Exercise

Occlusion

Recovery

Control $\longrightarrow$ TENS on Arm at $100 \mathrm{~Hz} \longrightarrow$ TENS on Back at $100 \mathrm{~Hz}$

$\longrightarrow$ TENS on Arm at $4 \mathrm{~Hz} \longrightarrow$ TENS on Back at $4 \mathrm{~Hz} \quad \longrightarrow$ IFC on Back

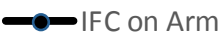

Figure 5.6: Blood flow in the left anterior brachial region, measured as percent change from baseline reading, for all treatment conditions

$\mathrm{CBF}$ was measured in the anterior brachial region to correlate the changes in perfusion occurring downstream of the occluded region, i.e. the palm, to changes upstream of this site. For example, if $\mathrm{CBF}$ in the left palm decreased during occlusion, then an increase in CBF in the left anterior brachial region would be expected, as blood flow is being redistributed to this ischemic region. No statistical differences were found among the treatment conditions when compared with the control condition. However, TENS on the arm at $100 \mathrm{~Hz}$, IFC on the arm, TENS on the arm at $4 \mathrm{~Hz}$, and TENS on the back at $4 \mathrm{~Hz}$ trended toward higher CBF values when compared to the control condition. IFC on the back exhibited lower CBF during exercise and occlusion, but higher CBF during recovery compared to control. TENS on the back at $100 \mathrm{~Hz}$ exhibited lower CBF for exercise, occlusion, and recovery compared to control. 


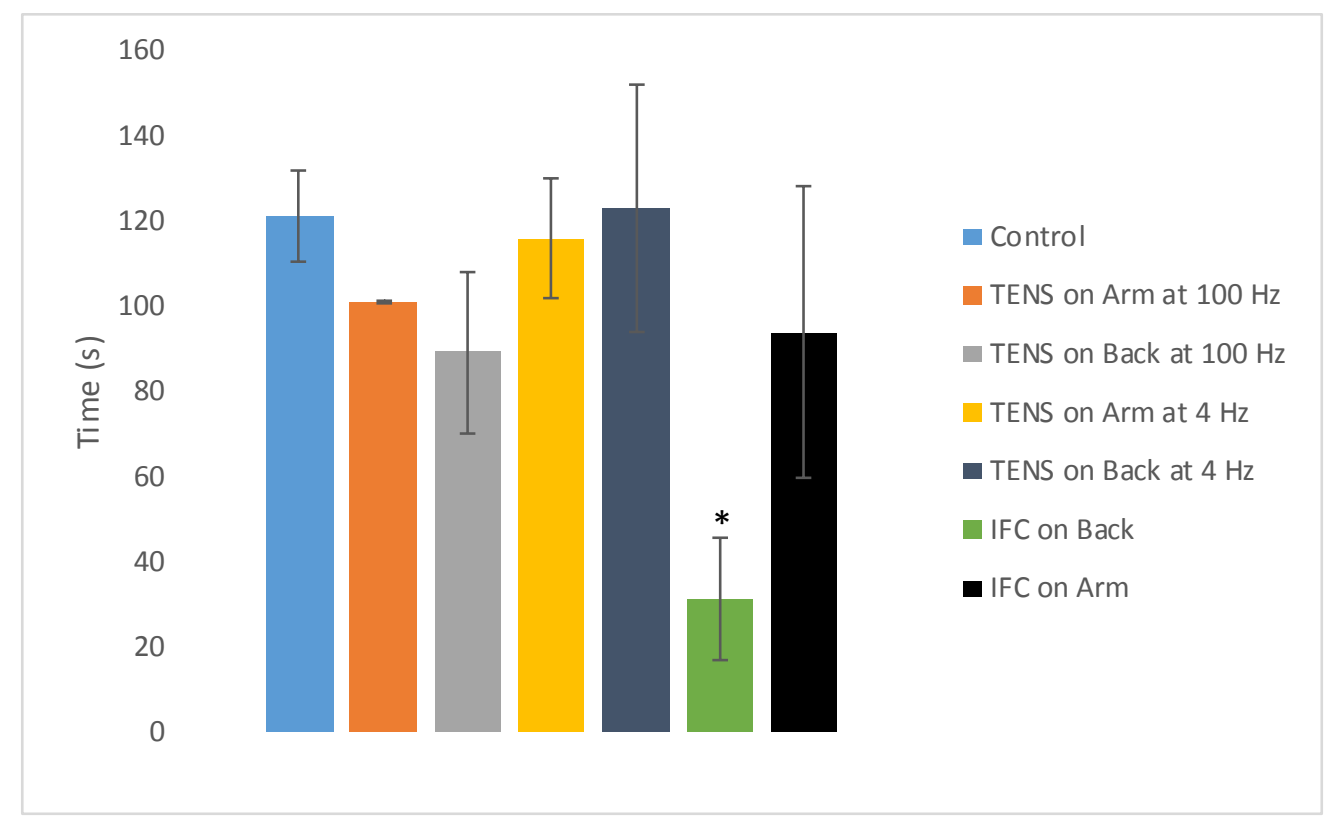

Figure 5.7: Average reperfusion time, which is the time from the start of hyperemia after occlusion to the first instance where blood flow reaches the average baseline value, for all treatment conditions; $* p<0.05$ compared to control

Reperfusion time was measured to determine, not only if blood flow increases as a result of TENS or IFC application, but also if blood flow redistribution to the ischemic region is improved after occlusion. TENS on the back at $4 \mathrm{~Hz}$ exhibited higher reperfusion time compared to control. All other treatment conditions exhibited lower reperfusion time compared to control with IFC on the back being significantly lower. However, it is important to note that reperfusion time may be dependent on the magnitude of the perfusion change from baseline during recovery e.g. TENS on the back at $4 \mathrm{~Hz}$ exhibited higher perfusion during recovery than all other treatment conditions, meaning that it is possible reperfusion time was higher for this treatment condition because perfusion in the palm was much higher during the hyperemia stage after occlusion and remained higher throughout, and thus taking longer to reach the average baseline value. The same applies to IFC on the back, which exhibited the lowest 
perfusion change in the palm during recovery as compared to the other treatment conditions, so it would take less time to reach the average baseline value.
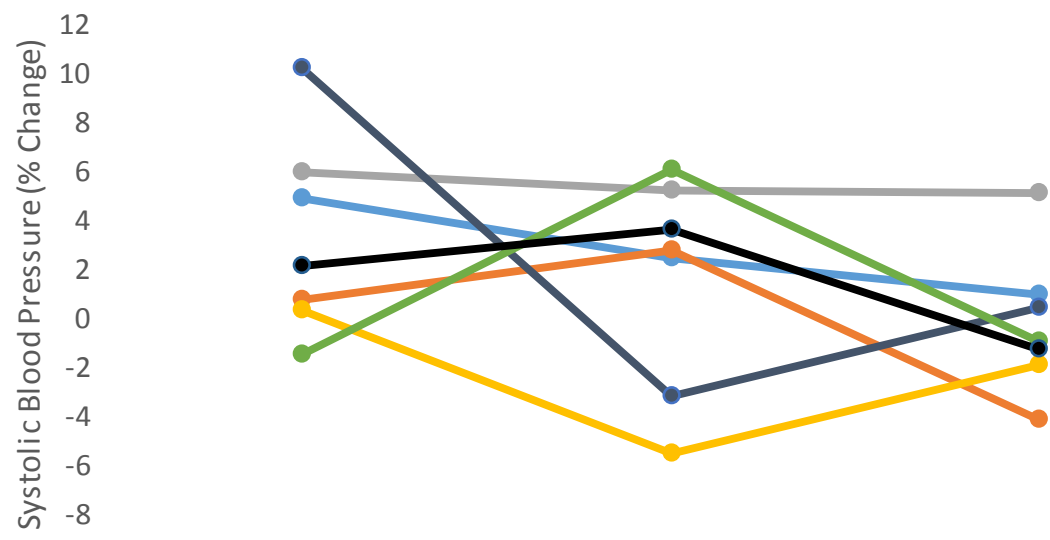

Exercise

Occlusion

Recovery

$\longrightarrow$ Control $\quad$ TENS on Arm at $100 \mathrm{~Hz} \longrightarrow$ TENS on Back at $100 \mathrm{~Hz}$

$\longrightarrow$ TENS on Arm at $4 \mathrm{~Hz} \longrightarrow$ TENS on Back at $4 \mathrm{~Hz} \longrightarrow$ IFC on Back

$\longrightarrow$ IFC on Arm

Figure 5.8: Systolic blood pressure, measured as percent change from baseline reading, for all treatment conditions

SBP was measured to determine if the metaboreflex was attenuated by TENS or IFC, i.e. reduced SBP would indicate a possible reduction in metaboreflex activation during a particular phase of the protocol. No statistical differences were found among the treatment conditions when compared with the control condition. However, TENS on the back at $100 \mathrm{~Hz}$ trended toward a higher SBP compared to control for exercise, occlusion, and recovery. IFC on the back, TENS on the arm at $100 \mathrm{~Hz}$, and IFC on the arm exhibited lower SBP during exercise and recovery, but were higher during occlusion. TENS on the back at $4 \mathrm{~Hz}$ exhibited the largest increase in SBP during exercise, which then decreased during occlusion and recovery compared to control. TENS on the arm at 4 Hz exhibited lower SBP for exercise, occlusion, and recovery compared to control. 

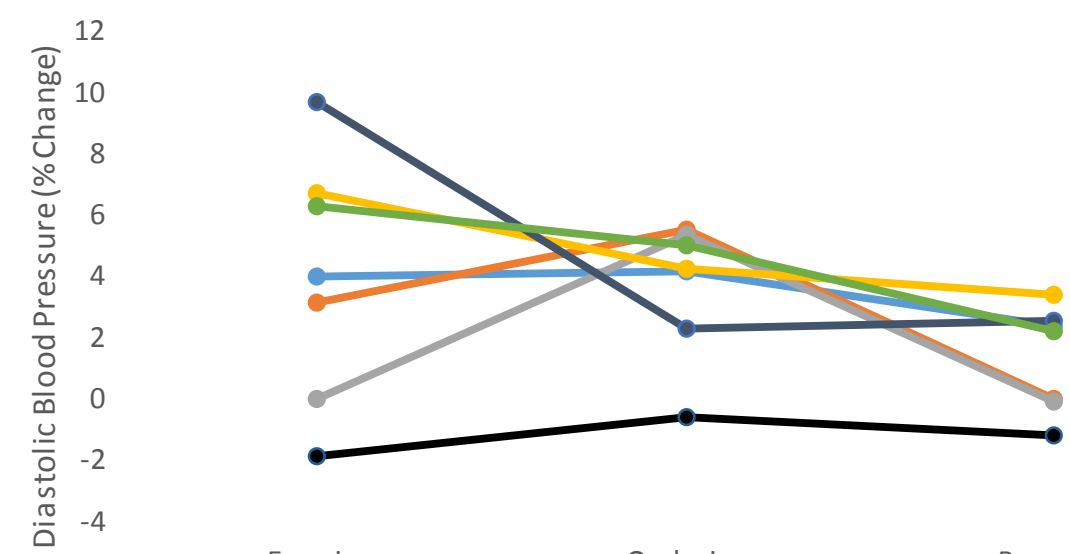

Exercise

Occlusion

Recovery

Control $\quad-$ TENS on Arm at $100 \mathrm{~Hz} \longrightarrow$ TENS on Back at $100 \mathrm{~Hz}$

$\longrightarrow$ TENS on Arm at $4 \mathrm{~Hz} \longrightarrow$ TENS on Back at $4 \mathrm{~Hz} \quad \longrightarrow$ IFC on Back

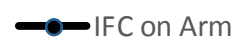

Figure 5.9: Diastolic blood pressure, measured as percent change from baseline reading, for all treatment conditions

DBP was measured to determine if the metaboreflex was attenuated by TENS or IFC, i.e. reduced DBP would indicate a possible reduction in metaboreflex activation during a particular phase of the protocol. No statistical differences were found among the treatment conditions when compared with the control condition. However, TENS on the arm at $4 \mathrm{~Hz}$ and IFC on the back trended toward a higher DBP compared to control for exercise, occlusion, and recovery. TENS on the arm at $100 \mathrm{~Hz}$ and TENS on the back at $100 \mathrm{~Hz}$ exhibited lower DBP during exercise and recovery, but were higher during occlusion. TENS on the back at $4 \mathrm{~Hz}$ exhibited the largest increase in DBP during exercise, which then decreased during occlusion and increased during recovery compared to control. IFC on the arm exhibited lower DBP for exercise, occlusion, and recovery compared to control. 


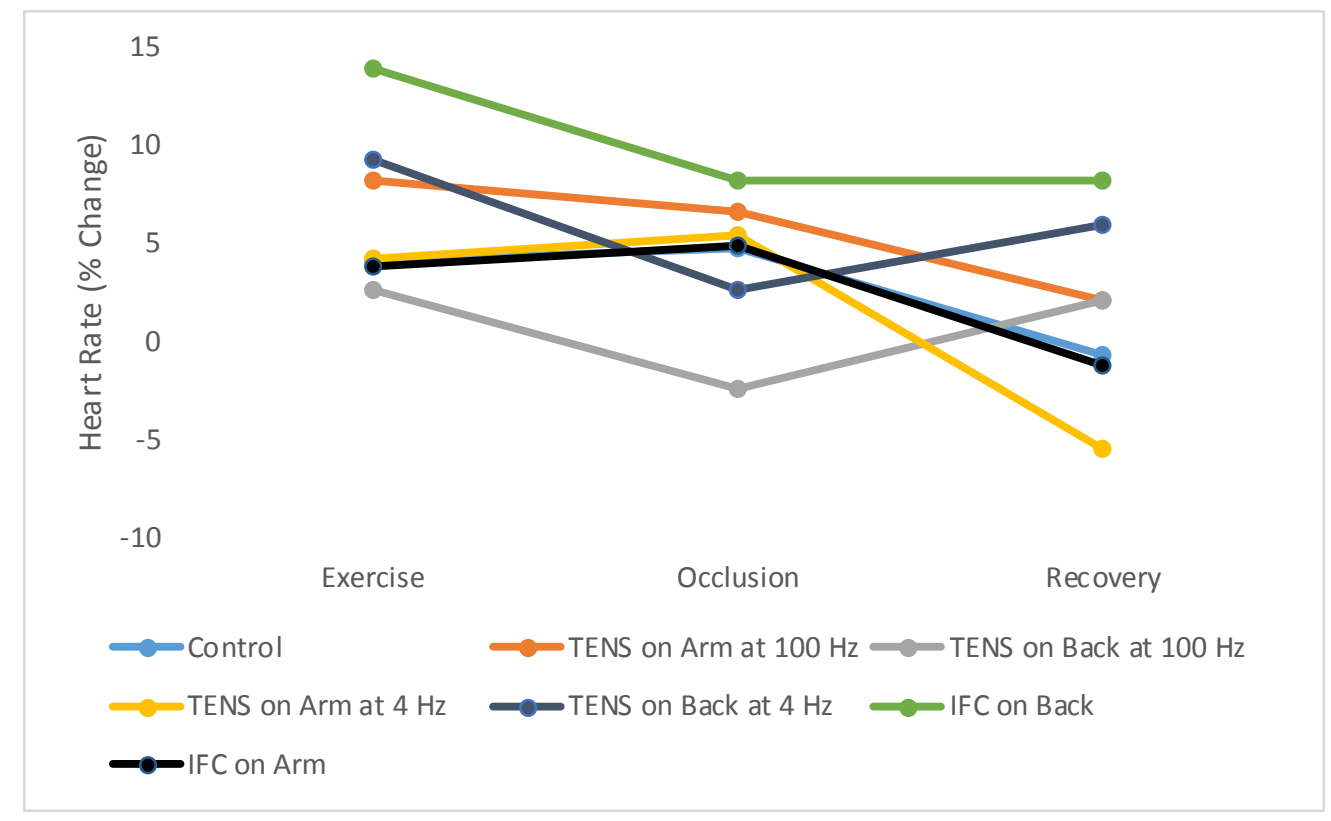

Figure 5.10: Heart rate, measured as percent change from baseline reading, for all treatment conditions

HR was measured to determine if TENS or IFC affected descending central controls from the brain, specifically the medulla oblongata, as any significant increase or decrease in HR would indicate activation of this region, most likely through vascular baroreceptor reflex arcs. No statistical differences were found among the treatment conditions when compared with the control condition. However, IFC on the back and TENS on the arm at $100 \mathrm{~Hz}$ trended toward a higher HR compared to control for exercise, occlusion, and recovery. TENS on the back at $4 \mathrm{~Hz}$ exhibited higher HR during exercise and recovery, but was lower during occlusion compared to control. TENS on the arm at $4 \mathrm{~Hz}$ exhibited higher $\mathrm{HR}$ during exercise and occlusion, but was lower during recovery. IFC on the arm nearly mirrored the trend for the control condition. TENS on the back at $100 \mathrm{~Hz}$ exhibited lower HR during exercise and occlusion, but was higher during recovery. 


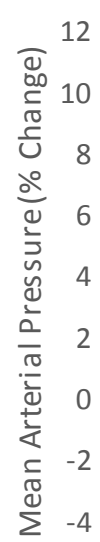

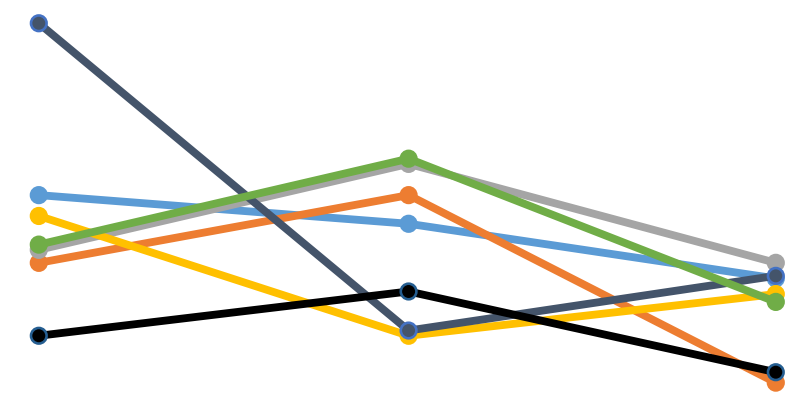

Exercise

Occlusion

Recovery

- Control $\quad$ TENS on Arm at $100 \mathrm{~Hz}=$ TENS on Back at $100 \mathrm{~Hz}$

$\longrightarrow$ TENS on Arm at $4 \mathrm{~Hz} \longrightarrow$ TENS on Back at $4 \mathrm{~Hz} \quad \longrightarrow$ IFC on Back

$\longrightarrow$ IFC on Arm

Figure 5.11: Estimated mean arterial pressure, measured as percent change from baseline reading, for all treatment conditions

MAP was estimated as discussed in Section 5.1 to determine if the metaboreflex was attenuated by TENS or IFC, i.e. reduced MAP would indicate a possible reduction in metaboreflex activation during a particular phase of the protocol. No statistical differences were found among the treatment conditions when compared with the control condition. However, IFC on the back and TENS on the arm at $100 \mathrm{~Hz}$ trended toward a lower MAP during exercise and recovery, but were higher during occlusion compared to control. TENS on the back at $100 \mathrm{~Hz}$ exhibited higher MAP during occlusion and recovery, but was lower during exercise. TENS on the back at $4 \mathrm{~Hz}$ exhibited the highest increase in MAP during exercise, which then decreased during occlusion and recovery compared to control. TENS on the arm at $4 \mathrm{~Hz}$ and IFC on the arm exhibited lower MAP during exercise, occlusion, and recovery compared to control. 


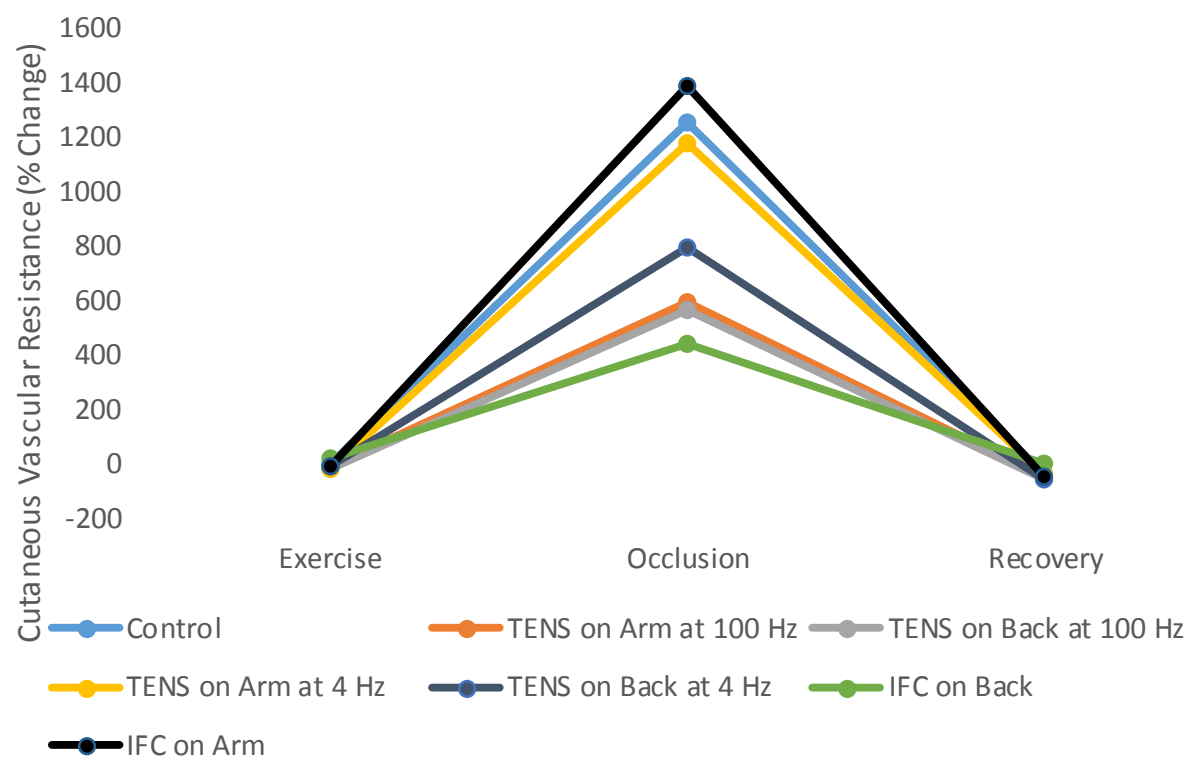

Figure 5.12: Estimated cutaneous vascular resistance in the left palm, measured as percent change from baseline reading, for all treatment conditions

CVR was estimated in the palm as discussed in Section 5.1 to determine if the metaboreflex was attenuated by TENS or IFC i.e. reduced CVR would indicate a possible reduction in metaboreflex activation during a particular phase of the protocol. No statistical differences were found among the treatment conditions when compared with the control condition. However, TENS on the back at $100 \mathrm{~Hz}$, TENS on the arm at 100 $\mathrm{Hz}$, TENS on the back at $4 \mathrm{~Hz}$, and TENS on the arm at $4 \mathrm{~Hz}$ all trended toward a lower CVR during exercise, occlusion, and recovery compared to control. IFC on the back exhibited higher CVR during exercise and recovery, but was lower during occlusion compared to control. IFC on the arm exhibited the opposite trend with lower CVR during exercise and recovery, but higher CVR during occlusion compared to control. 


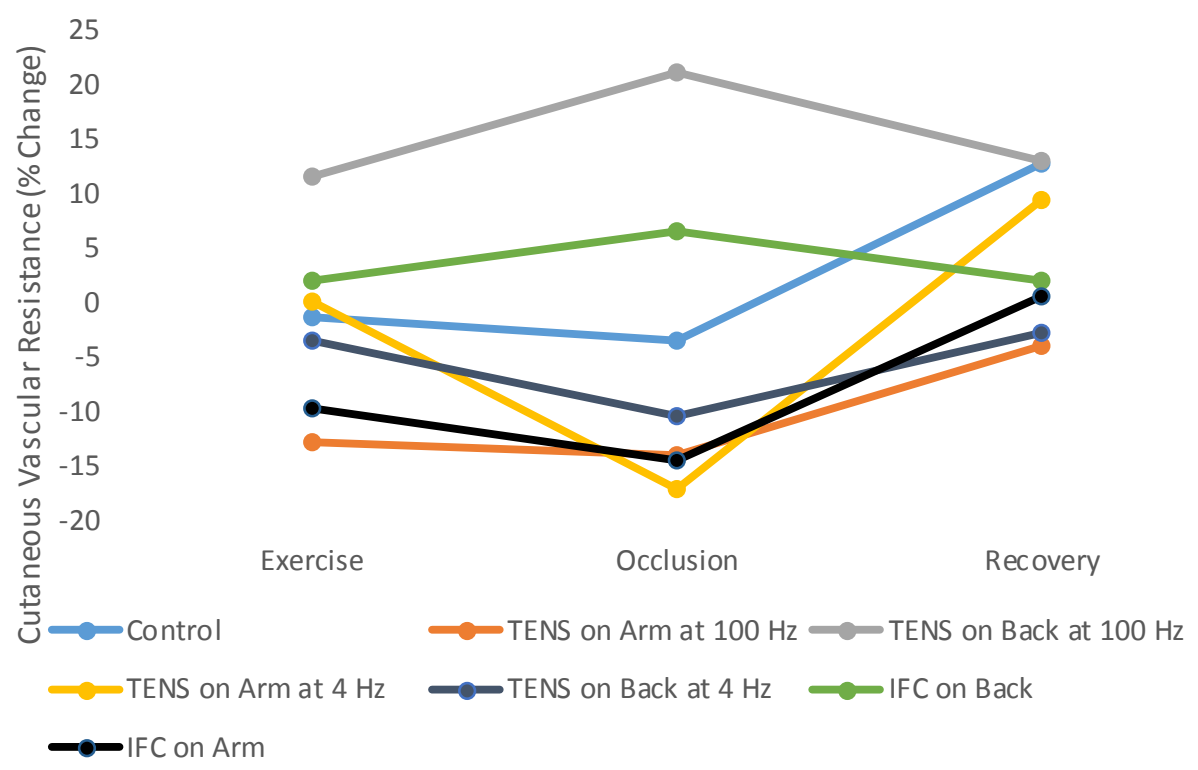

Figure 5.13: Estimated cutaneous vascular resistance in the left anterior brachial region, measured as percent change from baseline reading, for all treatment conditions

CVR was estimated in the anterior brachial region to correlate the changes in vascular resistance occurring downstream of the occluded region, i.e. the palm to changes upstream of this site. For example, if CVR in the left palm increased during occlusion, then a decrease in CVR in the left anterior brachial region would be expected, as blood flow is being redistributed to this ischemic region. No statistical differences were found among the treatment conditions when compared with the control condition. However, TENS on the back at $100 \mathrm{~Hz}$ trended toward a higher CVR compared to control for exercise, occlusion, and recovery. IFC on the back exhibited higher CVR during exercise and occlusion, but was lower during recovery compared to control. TENS on the arm at 4 $\mathrm{Hz}$ exhibited higher CVR during exercise, but was lower during occlusion and recovery. TENS on the back at $4 \mathrm{~Hz}$, IFC on the arm, and TENS on the arm at $100 \mathrm{~Hz}$ exhibited lower CVR during exercise, occlusion, and recovery compared to control. 


\subsection{Discussion}

The goal of the pre-pilot work was to optimize the design for the eventual pilot study. The ideal parameters, i.e. frequency, pulse width, duration of treatment, and location of application, for a given neurostimulation technique that elicit the greatest beneficial hemodynamic changes, i.e. decreased blood pressure, increased blood flow, and decreased vascular resistance, are not well-established. Similarly, there has been very little research comparing the different neurostimulation techniques to one another in terms of these changes. Thus, the primary focus of this research was to investigate what parameters and neurostimulation technique should be used in the pilot study. Six different treatment conditions were compared to a control condition where the electrodes were applied to the skin but the unit was not turned on. Specifically, TENS at $4 \mathrm{~Hz}$ and 100 $\mathrm{Hz}$, and IFC at $100 \mathrm{~Hz}$ were all compared. Two different locations for electrode placement were compared, the back at the $\mathrm{C} 7$ and $\mathrm{T} 4$ dermatomes and the forearm at the proximal and distal regions.

From the results obtained, a complete assessment of which treatment condition worked "best" is unattainable, as the treatment conditions did not exhibit statistically significant differences from the control condition, besides IFC on the back, which exhibited a significantly lower reperfusion time compared to control. The reason for this lack of statistical significance for the rest of the hemodynamic parameters is most likely due to the small sample sizes used for the different treatment groups, rather than a lack of effectiveness of the actual treatment. Nevertheless, the trends shown in Figures 5.4 through 5.13 suggest which treatment condition may be the most effective and which conditions should be ruled out based on their potential adverse effects. Application of TENS on the arm at $100 \mathrm{~Hz}$ trended towards increased pain intensity during exercise and 
occlusion. Although this condition trended towards increased $\mathrm{CBF}$ and decreased CVR, any treatment condition that increases pain intensity compared to control should not be utilized for the pilot study. The reason for this is that participants will be able to opt out of the experiment if they reach their personal pain tolerance threshold, so we want to ensure that we do not cause any additional/unnecessary pain besides the inducedischemic pain. For this same reasoning, application of TENS on the back at $4 \mathrm{~Hz}$ should not be further pursued as it too trended towards increased pain intensity. It was also the only treatment condition that trended towards a longer reperfusion time than control as well as a higher MAP during exercise. Excluding these two treatment conditions, TENS on the arm at $4 \mathrm{~Hz}$ trended towards favorable hemodynamic changes, such as lower reperfusion time, pain intensity, CVR in the anterior brachial region and in the palm, MAP, SBP, and higher CBF in the anterior brachial region compared to control. TENS on the back at $100 \mathrm{~Hz}$ also trended towards favorable hemodynamic changes, such as lower reperfusion time, pain intensity, CVR in the palm, HR, DBP, and higher CBF in the palm compared to control. This is in accordance with work by Vieira et al, in which decreases in MAP, increases in blood flow, and decreases in vascular resistance with application of TENS on the back at $80 \mathrm{~Hz}$ were found in their younger aged group [81], although MAP was higher than control during occlusion and recovery in our own study. These results cannot be directly compared, since both the TENS parameters and perfusion measurement instrumentation used in our study and in the study by Vieira et al were different, e.g. blood flow was measured in the calf using venous occlusion plethysmography rather than in the palm and anterior brachial region using LDF. Furthermore, MAP was continuously monitored using a Dinamap blood pressure monitor 
rather than estimated from SBP and DBP. From our own results, it seems that a low stimulation frequency is more effective when TENS is applied on the forearm, while a high stimulation frequency is more effective when TENS is applied on the back. It was expected that a high frequency would be more effective, regardless of electrode placement, but it is possible that a high frequency on the forearm activates $A \delta$-fibers responsible for the sharp pain sensation, which could also stimulate the SNS further. The high frequency on the back may be more effective than a low frequency, because it is capable of causing maximum suppression of the C-fibers, which allows for higher intensities to be used; thus, current travels farther along the dermatomes to the ischemic site, providing more local pain relief and vasodilation. Application of IFC on the arm presented the most consistent beneficial hemodynamic changes compared to the other treatment conditions, i.e. the data trended towards increased blood flow to the palm and anterior brachial region, decreased MAP, decreased CVR in the anterior brachial region, decreased pain intensity throughout the experiment, decreased reperfusion time, and it did not change HR. This was expected based on the hypothesis that IFC stimulates deeper muscle afferents, which further reduces noxious stimulus transmission and metaboreflex activation. The only concerning aspect of this treatment condition was that CVR in the palm increased slightly during occlusion compared to control, while all other treatment conditions decreased during this interval, Nevertheless, CVR trended towards lower values during exercise and recovery for IFC on the arm compared to control. Although not shown in Figure 5.12, the standard error during the occlusion phase was large, so there may be random effects from subject variation, or the standard error may result solely from experimental error. Application of IFC on the back also had promising results 
with the greatest reductions in pain and CVR in the palm, as well as a significant decrease in reperfusion time compared to control, although CBF trended towards lower values in the palm and anterior brachial regions as compared to control. This significant decrease in reperfusion time indicates either that blood flow redistribution to the palm after occlusion was improved compared to control and/or that it took less time to reach the average baseline perfusion value because the percent change during recovery was lower than the rest of the treatment conditions. In work by Santos et al, the effect of IFC on the back at $100 \mathrm{~Hz}$ was also investigated and they found statistically significant decreases in MAP, increases in blood flow, and decreases in vascular resistance. MAP trended towards lower values in our own study during exercise and recovery, but increased during occlusion compared to control. Although CVR in the palm trended towards lower values, $\mathrm{CBF}$ did as well, so our results do not show the same trends as Santos's study, although it should be noted that venous occlusion plethysmography was used to measure blood flow in the calf and the treatment duration was 30 minutes rather than 15 minutes [126]. Regardless, it seems that IFC did produce more favorable hemodynamic changes overall than TENS.

While conducting the pre-pilot work, a number of potential possibilities for experimental error were observed, all of which must be carefully considered and addressed before performing the pilot study. The most significant error we observed were fluctuations in blood flow readings not caused by the treatment condition itself during some of the experiments. For example, ambient temperature affects skin temperature and skin temperature can affect blood flow [204]. During our research, we noticed that fluctuations in room temperature could affect the skin temperature readings that we 
recorded from the LDF system, although to what extent was not determined in our research. Thus, blood flow may also have been affected by these fluctuations in room temperature. In order to mitigate this potential error, skin temperature was recorded before and after the treatment session to determine if any appreciable change had occurred. So long as the skin temperature remained within $\pm 1^{\circ} \mathrm{C}$, the results were kept for that individual session. If the temperature had fluctuated beyond this range, a new treatment session would have been conducted again and compared to the previous session to determine if there were significant differences between the two, but this did not occur. The blood flow readings can also be affected by any kind of motion artifact, such as from breathing, movement of the limbs, or vibrations from other equipment/other sources. Luckily, this motion artifact is relatively easy to identify in LabChart. For instance, major spikes in blood flow can be seen from both skin probes if the subject moves their arm. These spikes can be deleted from the data trace, so that they do not affect the results. The blood flow reading will change based on where the probe is positioned, so much so that even a millimeter difference in probe placement can affect the reading by as much as 200 perfusion units (PU). This is why percent changes from baseline must be taken for LDF measurements, not to mention there is inter-individual variation and day-to-day variation in these measurements as well. The reason for this day-to-day variation may be due to prior exercise, lack of sleep, hunger, dehydration, sickness, stress, and caffeine consumption. The blood pressure measurements that were taken for this study were not conducted in the most ideal manner. Most current research in this field uses continuous blood pressure monitors, such as Finometers, because they provide a real-time measurement that can be averaged over each interval of the experiment. MAP and CVR 
can then be accurately calculated from these measurements $[66,81,112,126,156]$. These systems are very expensive ( $\$ 25-30 \mathrm{k}$, based on quotes obtained from ADInstruments and Finapres), however, and could not be purchased for this study. We used a digital blood pressure monitor, as specified in Section 5.1, which is accurate to $\pm 3 \mathrm{mmHg}$. The estimation of MAP described in Section 5.1 is acceptable, so long as HR remains below 100 beats $^{\text {minute }}{ }^{-1}$ [205], and is more applicable for healthy, younger individuals [206]. Gripping of the hand dynamometer for the "exercise" portion of the treatment session did not cause HR to rise above this level. Lastly, the TENS parameters still have not been optimized based on the mixed results obtained, but IFC using the parameters specified in Table 5.1 seems to be more effective based on the trends observed for each hemodynamic parameter.

For the pilot study, it will be imperative to keep the room where the treatment sessions will be held as controlled as possible. Because temperature can affect CBF, the room should have a thermostat or other device capable of maintaining a constant temperature. The room should also be clear of any audio or visual distractions that may influence the participant's BP, HR, etc. The potential for motion artifact should be reduced by ensuring all cables are not overlapping with others or resting on the participant, if possible. Participant comfort should be a primary focus during the treatment session. In our pre-pilot work, the participant rested their arms on a pillow to ensure comfort and that pressure was evenly distributed across the forearm from the blood pressure cuff. Having the participant lay in a supine position may be even better for ensuring optimal comfort, rather than having them sit in a chair during the duration of the treatment, and was done in a few studies for this reason [81, 112, 126, 156, 207]. 
However, this may induce stronger parasympathetic activity, i.e. lower BP and HR [208]. Using the new MEDITEC budget for the next school year, it may be worthwhile to purchase a continuous blood pressure monitor, so that MAP and CVR can be calculated with confidence, rather than estimating both. Before the pilot study is conducted, further investigation is still needed into the relative effectiveness of IFC and TENS, and what set of parameters produces consistent, statistically significant hemodynamic changes. Specifically, low intensity (sensory threshold), high frequency $(100 \mathrm{~Hz})$ TENS and IFC should be compared to high intensity (motor threshold), low frequency $(4 \mathrm{~Hz})$ TENS and IFC. Treatment duration should also be compared at 15 minutes and 30 minutes, as well as determining how long the hemodynamic changes last. The electrode placement sites should be compared on the forearm and on the back as done in our pre-pilot experiments. Blood flow in the contralateral limb and/or the calf should also be measured to determine if neurostimulation causes systemic vasodilation or if it is only at the site of application. Many of these parameters have been investigated in terms of analgesic effects, but not hemodynamic effects [202, 209-211]; thus, future pre-pilot experiments should investigate all these different parameters (Figure 5.14). This work should build off the work conducted by our own group, when possible, so that results may be combined to increase the overall sample size. The research conducted by our own group has shown that both TENS and IFC may produce favorable changes on the cardiovascular system in ischemia-induced subjects. Whether these changes have a favorable impact on patients with actual ischemia, such as in the case of PAOD, is still yet to be seen. Thus, the pilot study will provide important information on the use of neurostimulation to treat ischemia, which may warrant further clinical investigation. 


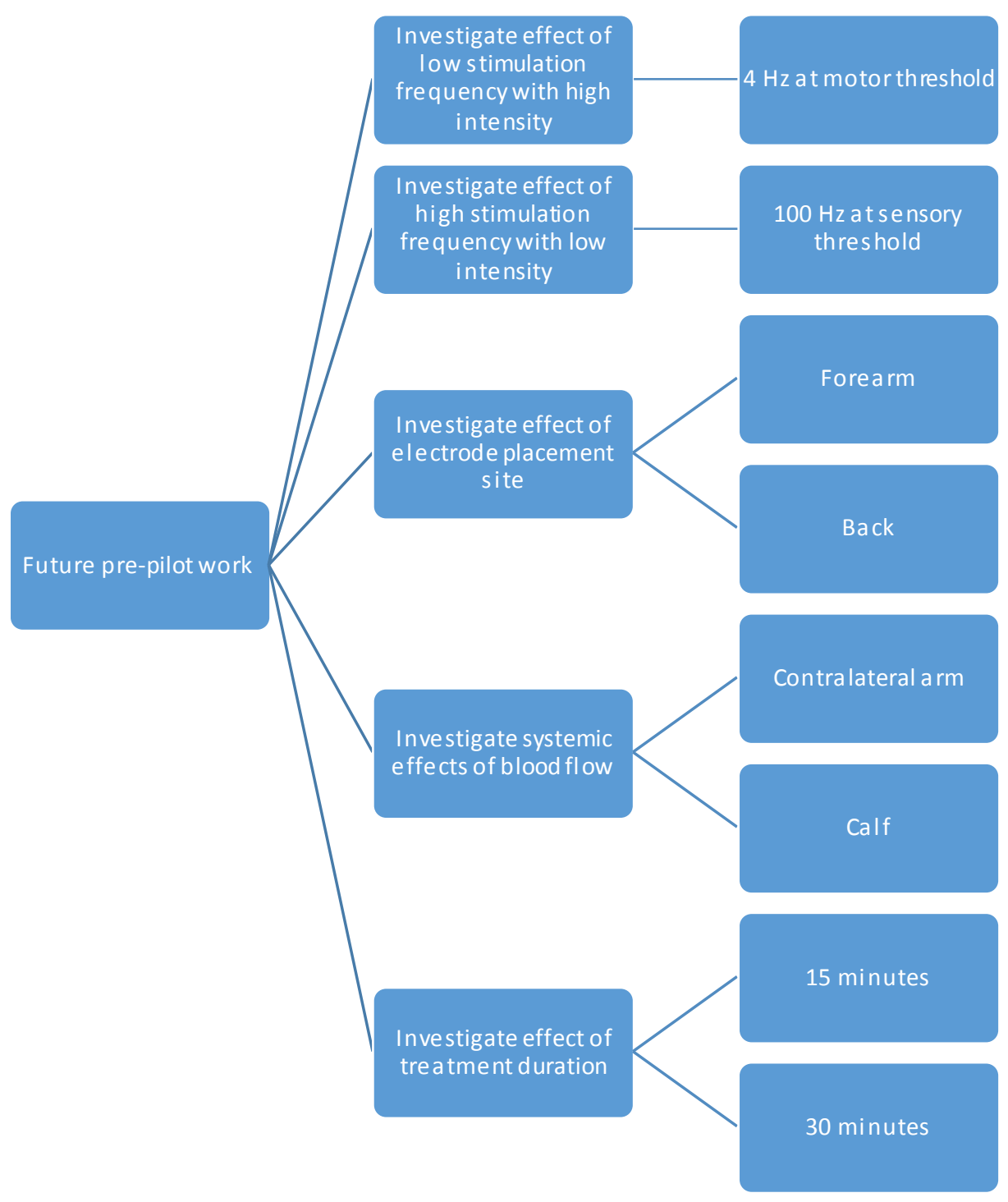

Figure 5.14: Diagram detailing the pre-pilot work that still needs to be conducted and what specific parameters should be analyzed before the pilot study 


\section{REFERENCES}

1. Hirsch, A.T., et al., Peripheral arterial disease detection, awareness, and treatment in primary care. JAMA, 2001. 286(11): p. 1317-24.

2. Go, A.S., et al., Heart disease and stroke statistics--2013 update: a report from the American Heart Association. Circulation, 2013. 127(1): p. e6-e245.

3. Milani, R.V. and C.J. Lavie, The role of exercise training in peripheral arterial disease. Vasc Med, 2007. 12(4): p. 351-8.

4. Criqui, M.H., et al., The prevalence of peripheral arterial disease in a defined population. Circulation, 1985. 71(3): p. 510-5.

5. Faxon, D.P., et al, Atherosclerotic Vascular Disease Conference: Executive summary: Atherosclerotic Vascular Disease Conference proceeding for healthcare professionals from a special writing group of the American Heart Association. Circulation, 2004. 109(21): p. 2595-604.

6. Cardinal, T. "Ischemic Disease Etiology." California Polytechnic State University. San Luis Obispo, CA. 9 January 2014. Lecture.

7. Weissberg, P.L., Atherogenesis: current understanding of the causes of atheroma. Heart, 2000. 83(2): p. 247-52.

8. New Medical Information and Health Information. "Atherosclerosis." 21 May 2014. Image. < http://www.nmihi.com/a/atherosclerosis.htm>.

9. WebMD. "Cholesterol Medications: Statins, Nicotinic Acid, Bile Acid Resins and Fibrates." 21 May 2014. Web. <http://www.webmd.com/cholesterolmanagement/guide/cholesterol-lowering-medication>.

10. Bruckert, E. and J. Ferrieres, Evidence supporting primary prevention of cardiovascular diseases with statins: Gaps between updated clinical results and actual practice. Arch Cardiovasc Dis, 2014. 107(3): p. 188-200.

11. Clement, D.L., Treatment of hypertension in patients with peripheral arterial disease: an update. Curr Hypertens Rep, 2009. 11(4): p. 271-6.

12. Tan, K.H., L. De Cossart, and P.R. Edwards, Exercise training and peripheral vascular disease. Br J Surg, 2000. 87(5): p. 553-62.

13. Bendermacher, B.L., et al, Supervised exercise therapy versus non-supervised exercise therapy for intermittent claudication. Cochrane Database Syst Rev, 2006(2): p. CD005263. 
14. Brandsma, J.W., et al., The effect of exercises on walking distance of patients with intermittent claudication: a study of randomized clinical trials. Phys Ther, 1998. 78(3): p. 278-86; discussion 286-8.

15. Ram, C.V., Antihypertensive drugs: an overview. Am J Cardiovasc Drugs, 2002. 2(2): p. 77-89.

16. Pedersen, M.E. and J.R. Cockcroft, The vasodilatory beta-blockers. Curr Hypertens Rep, 2007. 9(4): p. 269-77.

17. Schrier, R.W. and R.O. Estacio, Additional follow-up from the ABCD trial in patients with type 2 diabetes and hypertension. N Engl J Med, 2000. 343(26): p. 1969.

18. Schoolwerth, A.C., et al., Renal considerations in angiotensin converting enzyme inhibitor therapy: a statement for healthcare professionals from the Council on the Kidney in Cardiovascular Disease and the Council for High Blood Pressure Research of the American Heart Association. Circulation, 2001. 104(16): p. 198591.

19. University of Southern California Keck School of Medicine. "Stent." 21 May 2014. Image. < http://www.cts. usc.edu/zglossary-stent.html>.

20. Slovut, D.P. and E.C. Lipsitz, Surgical technique and peripheral artery disease. Circulation, 2012. 126(9): p. 1127-38.

21. Kugler, C.F. and G. Rudofsky, The challenges of treating peripheral arterial disease. Vasc Med, 2003. 8(2): p. 109-14.

22. Margolis, J., J.J. Barron, and W.D. Grochulski, Health care resources and costs for treating peripheral artery disease in a managed care population: results from analysis of administrative claims data. J Manag Care Pharm, 2005. 11(9): p. 72734.

23. Healthwise, Inc. "Learning About Femoropopliteal Bypass Surgery for Peripheral Arterial Disease." 7 July 2014. Image. < https $/ /$ myhealth.alberta.ca/health/AfterCareInformation/pages/conditions.asp $\mathrm{x}$ ?h wid=abk2323>.

24. Malas, M.B., et al., Comparison of surgical bypass with angioplasty and stenting of superficial femoral artery disease. J Vasc Surg, 2014. 59(1): p. 129-35.

25. Mahoney, E.M., et al., Vascular hospitalization rates and costs in patients with peripheral artery disease in the United States. Circ Cardiovasc Qual Outcomes, 2010. 3(6): p. 642-51. 
26. Medtronic, Inc. "Balloon Angioplasty and Stenting Therapy Option for Coronary Artery Disease." 22 September 2010.

$<$ http://www.medtronic.com/patients/coronary-artery-disease/therapy/balloonangioplasty-and-stenting/benefits-risks/>.

27. Michaels, A.D. and K. Chatterjee, Cardiology patient pages. Angioplasty versus bypass surgery for coronary artery disease. Circulation, 2002. 106(23): p. e18790.

28. Katsanos, K., et al., Bayesian network meta-analysis of nitinol stents, covered stents, drug-eluting stents, and drug-coated balloons in the femoropopliteal artery. J Vasc Surg, 2014. 59(4): p. 1123-1133 e8.

29. Kubler, P. and K. Reczuch, The use of drug-eluting stents in acute myocardial infarction - is the battle coming to an end? From despair to acceptance. Postepy Kardiol Interwencyjnej, 2013. 9(1): p. 50-54.

30. Pfisterer, M., et al., Late clinical events after clopidogrel discontinuation may limit the benefit of drug-eluting stents: an observational study of drug-eluting versus bare-metal stents. J Am Coll Cardiol, 2006. 48(12): p. 2584-91.

31. Lagerqvist, B., et al., Long-term outcomes with drug-eluting stents versus baremetal stents in Sweden. N Engl J Med, 2007. 356(10): p. 1009-19.

32. Augustinsson, L.E., et al., Epidural electrical stimulation in severe limb ischemia. Pain relief, increased blood flow, and a possible limb-saving effect. Ann Surg, 1985. 202(1): p. 104-10.

33. Chauhan, A., et al., Effect of transcutaneous electrical nerve stimulation on coronary blood flow. Circulation, 1994. 89(2): p. 694-702.

34. Dejongste, M.J., Efficacy, safety and mechanisms of spinal cord stimulation used as an additional therapy for patients suffering from chronic refractory angina pectoris. Neuromodulation, 1999. 2(3): p. 188-92.

35. Eliasson, T., L.E. Augustinsson, and C. Mannheimer, Spinal cord stimulation in severe angina pectoris--presentation of current studies, indications and clinical experience. Pain, 1996. 65(2-3): p. 169-79.

36. Mannheimer, C., H. Emanuelsson, and F. Waagstein, The effect of transcutaneous electrical nerve stimulation (TENS) on catecholamine metabolism during pacinginduced angina pectoris and the influence of naloxone. Pain, 1990. 41(1): p. 2734.

37. Tallis, R.C., et al., Spinal cord stimulation in peripheral vascular disease. J Neurol Neurosurg Psychiatry, 1983. 46(6): p. 478-84. 
38. DiLorenzo, D.J. and J.D. Bronzino. Neuroengineering. CRC Press, 2007. Print.

39. Parpura, V., et al., Neuromodulation: selected approaches and challenges. J Neurochem, 2013. 124(4): p. 436-53.

40. Al-Kaisy, A., et al., Sustained effectiveness of $10 \mathrm{kHz}$ high-frequency spinal cord stimulation for patients with chronic, low back pain: 24-month results of a prospective multicenter study. Pain Med, 2014. 15(3): p. 347-54.

41. Melzack, R. and P.D. Wall, Pain mechanisms: a new theory. Science, 1965. 150(3699): p. 971-9.

42. Goodman, M. "Pain, Its Pathways and the Theories behind Pain." 30 April 2014. PowerPoint Presentation.

43. Moayedi, M. and K.D. Davis, Theories of pain: from specificity to gate control. J Neurophysiol, 2013. 109(1): p. 5-12.

44. Sherrington, C.S., Qualitative difference of spinal reflex corresponding with qualitative difference of cutaneous stimulus. J Physiol, 1903. 30(1): p. 39-46.

45. Sinclair, D.C., Cutaneous sensation and the doctrine of specific energy. Brain, 1955. 78(4): p. 584-614.

46. Weddell, G., Somesthesis and the chemical senses. Annu Rev Psychol, 1955. 6: p. 119-36.

47. D'Mello, R. and A.H. Dickenson, Spinal cord mechanisms of pain. Br J Anaesth, 2008. 101(1): p. 8-16.

48. Suzuki, R., et al., Superficial NK1-expressing neurons control spinal excitability through activation of descending pathways. Nat Neurosci, 2002. 5(12): p. 131926.

49. Todd, A.J., Anatomy of primary afferents and projection neurones in the rat spinal dorsal horn with particular emphasis on substance $P$ and the neurokinin 1 receptor. Exp Physiol, 2002. 87(2): p. 245-9.

50. McGlone, F. and D. Reilly, The cutaneous sensory system. Neurosci Biobehav Rev, 2010. 34(2): p. 148-59.

51. Melzack, R. and P.D. Wall, On the nature of cutaneous sensory mechanisms. Brain, 1962. 85: p. 331-56. 
52. Caterina, M.J., et al., The capsaicin receptor: a heat-activated ion channel in the pain pathway. Nature, 1997. 389(6653): p. 816-24.

53. Anatomy Atlases. "Spinal Cord Cervical Level." 28 May 2013. Image. < http://www.anatomyatlases.org/MicroscopicAnatomy/Section17/Plate17317.shtm $1>$.

54. Chudler, E.H. "Primary Afferent Axons." 5 June 2014. Image.

$<$ https://faculty. washington.edu/chudler/cv.html $>$.

55. Kerr, R.C., D.J. Maxwell, and A.J. Todd, GluRl and GluR2/3 subunits of the AMPA-type glutamate receptor are associated with particular types of neurone in laminae I-III of the spinal dorsal horn of the rat. Eur J Neurosci, 1998. 10(1): p. 324-33.

56. Nagy, G.G., et al., Synaptic distribution of the NR1, NR2A and NR2B subunits of the $N$-methyl-d-aspartate receptor in the rat lumbar spinal cord revealed with an antigen-unmasking technique. Eur J Neurosci, 2004. 20(12): p. 3301-12.

57. Valerio, A., et al., Metabotropic glutamate receptor mRNA expression in rat spinal cord. Neuroreport, 1997. 8(12): p. 2695-9.

58. Devor, M., Review: Pain Mechanisms. The Neuroscientist, 1996. 2(4): p. 233244.

59. Levine, J. and Y. Taiwo, Textbook of Pain, P.D. Wall and R. Melzack, Editors. 1994, Churchill-Livingston: London.

60. Gracely, R.H., S.A. Lynch, and G.J. Bennett, Painful neuropathy: altered central processing maintained dynamically by peripheral input. Pain, 1992. 51(2): p. 17594.

61. Nordin, M., et al., Ectopic sensory discharges and paresthesiae in patients with disorders of peripheral nerves, dorsal roots and dorsal columns. Pain, 1984. 20(3): p. 231-45.

62. Marks, D.M., et al., Serotonin-norepinephrine reuptake inhibitors for pain control: premise and promise. Curr Neuropharmacol, 2009. 7(4): p. 331-6.

63. Cramp, A.F., et al., The effect of high-and low-frequency transcutaneous electrical nerve stimulation upon cutaneous blood flow and skin temperature in healthy subjects. Clin Physiol, 2000. 20(2): p. 150-7.

64. Kimura, Y. and S. Hara, The effect of electro-acupuncture stimulation on rhythm of autonomic nervous system in dogs. J Vet Med Sci, 2008. 70(4): p. 349-52. 
65. Lu, C.C., et al., Electroacupuncture induces differential effects between Yin and Yang: a study using cutaneous blood flow and temperature recordings of the hand's dorsum and palm. Am J Chin Med, 2009. 37(4): p. 639-45.

66. Sherry, J.E., et al., Effect of burst-mode transcutaneous electrical nerve stimulation on peripheral vascular resistance. Phys Ther, 2001. 81(6): p. 118391.

67. Ter Laan, M., et al., The influence of transcutaneous electrical neurostimulation (TENS) on human cerebral blood flow velocities. Acta Neurochir (Wien), 2010. 152(8): p. 1367-73; discussion 1373.

68. Zhou, F., et al., Electroacupuncture and Brain Protection against Cerebral Ischemia: Specific Effects of Acupoints. Evid Based Complement Alternat Med, 2013. 2013: p. 804397.

69. DeSantana, J.M., et al., Effectiveness of transcutaneous electrical nerve stimulation for treatment of hyperalgesia and pain. Curr Rheumatol Rep, 2008. 10(6): p. 492-9.

70. Facci, L.M., et al., Effects of transcutaneous electrical nerve stimulation (TENS) and interferential currents (IFC) in patients with nonspecific chronic low back pain: randomized clinical trial. Sao Paulo Med J, 2011. 129(4): p. 206-16.

71. Hurley, D.A., et al., Interferential therapy electrode placement technique in acute low back pain: a preliminary investigation. Arch Phys Med Rehabil, 2001. 82(4): p. 485-93.

72. Eckert, S. and D. Horstkotte, Management of angina pectoris: the role of spinal cord stimulation. Am J Cardiovasc Drugs, 2009. 9(1): p. 17-28.

73. Mekhail, N.A., et al., Clinical applications of neurostimulation: forty years later. Pain Pract, 2010. 10(2): p. 103-12.

74. MoonDragon's Health Therapy. "TENS Unit Therapy." 29 May 2014. Image. $<$ http://www.moondragon.org/health/therapy/tens.html>.

75. Intensity Select Combo Instruction Manual. Intensity Select Combo TENS/IF/MIC/EMS Stimulator. Current Solutions, LLC. Austin, TX, 2012.

76. Rokyta, R. and J. Fricova, Neurostimulation methods in the treatment of chronic pain. Physiol Res, 2012. 61 Suppl 2: p. S23-31.

77. Chung, J.M., et al., Prolonged inhibition of primate spinothalamic tract cells by peripheral nerve stimulation. Pain, 1984. 19(3): p. 259-75. 
78. Woolf, C.J., D. Mitchell, and G.D. Barrett, Antinociceptive effect of peripheral segmental electrical stimulation in the rat. Pain, 1980. 8(2): p. 237-52.

79. King, E.W., et al., Transcutaneous electrical nerve stimulation activates peripherally located alpha-2A adrenergic receptors. Pain, 2005. 115(3): p. 36473.

80. Sanderson, J.E., et al., The effect of transcutaneous electrical nerve stimulation (TENS) on autonomic cardiovascular reflexes. Clin Auton Res, 1995. 5(2): p. 814.

81. Vieira, P.J., et al., Effect of transcutaneous electrical nerve stimulation on muscle metaboreflex in healthy young and older subjects. Eur J Appl Physiol, 2012. 112(4): p. 1327-34.

82. Edvinsson, L., et al., Expression of calcitonin gene-related peptide1 receptor mRNA in human trigeminal ganglia and cerebral arteries. Neurosci Lett, 1997. 229(3): p. 209-11.

83. Khalil, Z. and M. Merhi, Effects of aging on neurogenic vasodilator responses evoked by transcutaneous electrical nerve stimulation: relevance to wound healing. J Gerontol A Biol Sci Med Sci, 2000. 55(6): p. B257-63.

84. Moriyama, T., [Microneurographic analysis of the effects of acupuncture stimulation on sympathetic muscle nerve activity in humans: excitation followed by inhibition]. Nihon Seirigaku Zasshi, 1987. 49(12): p. 711-21.

85. Nussbaum, E., P. Rush, and L. Disenhaus, The effects of interferential therapy on peripheral blood flow. Physiotherapy, 1990. 76(12): p. 803-807.

86. Sugiyama, Y., Y.X. Xue, and T. Mano, Transient increase in human muscle sympathetic nerve activity during manual acupuncture. Jpn J Physiol, 1995. 45(2): p. 337-45.

87. Kunnumpurath, S., R. Srinivasagopalan, and N. Vadivelu, Spinal cord stimulation: principles of past, present and future practice: a review. J Clin Monit Comput, 2009. 23(5): p. 333-9.

88. McAuley, J., et al., A questionnaire-based study on patients' experiences with rechargeable implanted programmable generators for spinal cord stimulation to treat chronic lumbar spondylosis pain. Neuromodulation, 2013. 16(2): p. 142-6.

89. Krames, E., Spinal Cord Stimulation: Indications, Mechanism of Action, and Efficacy. Curr Rev Pain, 1999. 3(6): p. 419-426. 
90. Carlsson, A.M., Assessment of chronic pain. I. Aspects of the reliability and validity of the visual analogue scale. Pain, 1983. 16(1): p. 87-101.

91. Harke, H., et al., Spinal cord stimulation in sympathetically maintained complex regional pain syndrome type I with severe disability. A prospective clinical study. Eur J Pain, 2005. 9(4): p. 363-73.

92. Manola, L., et al., Theoretical investigation into longitudinal cathodal field steering in spinal cord stimulation. Neuromodulation, 2007. 10(2): p. 120-32.

93. North, R.B., et al., Spinal cord stimulation versus repeated lumbosacral spine surgery for chronic pain: a randomized, controlled trial. Neurosurgery, 2005. 56(1): p. 98-106; discussion 106-7.

94. Bay State Pain Management. "Spinal Cord Stimulator Implant." 23 May 2014. Image.

<http://www.baystatepain.com/blog/treatment/spinal_cord_stimulator_implant/>.

95. Kumar, K., G. Hunter, and D. Demeria, Spinal cord stimulation in treatment of chronic benign pain: challenges in treatment planning and present status, a 22 year experience. Neurosurgery, 2006. 58(3): p. 481-96; discussion 481-96.

96. Croom, J.E., et al, Cutaneous vasodilation during dorsal column stimulation is mediated by dorsal roots and CGRP. Am J Physiol, 1997. 272(2 Pt 2): p. H950-7.

97. Gao, J., et al., Effects of spinal cord stimulation with "standard clinical" and higher frequencies on peripheral blood flow in rats. Brain Res, 2010. 1313: p. 5361.

98. Hilton, S.M. and J.M. Marshall, Dorsal root vasodilatation in cat skeletal muscle. J Physiol, 1980. 299: p. 277-88.

99. Naoum, J.J. and E.J. Arbid, Spinal cord stimulation for chronic limb ischemia. Methodist Debakey Cardiovasc J, 2013. 9(2): p. 99-102.

100. Ulett, G.A., S. Han, and J.S. Han, Electroacupuncture: mechanisms and clinical application. Biol Psychiatry, 1998. 44(2): p. 129-38.

101. Saletu, B., et al., Hypno-analgesia and acupuncture analgesia: a neurophysiological reality? Neuropsychobiology, 1975. 1(4): p. 218-42.

102. Barnes, P.M., B. Bloom, and R.L. Nahin, Complementary and alternative medicine use among adults and children: United States, 2007. Natl Health Stat Report, 2008(12): p. 1-23. 
103. Acupuncture Today. "Electroacupuncture."

<http://www.acupuncturetoday.com/abc/electroacupuncture.php>.

104. Physiotherapy Acupuncture Association of New Zealand. "Electro-Acupuncture." 12 May 2014. Image.

$<$ http://www.paanz.org.nz/mainmenu69/page90/Acupuncture+Methods++PAANZ.html>.

105. Casimiro, L., et al., Acupuncture and electroacupuncture for the treatment of rheumatoid arthritis. Cochrane Database Syst Rev, 2005(4): p. CD003788.

106. Ho, C.Y., et al., Clinical effectiveness of acupuncture for carpal tunnel syndrome. Am J Chin Med, 2014. 42(2): p. 303-14.

107. Mayer, D.J., Acupuncture: an evidence-based review of the clinical literature. Annu Rev Med, 2000. 51: p. 49-63.

108. White, A., et al., Acupuncture treatment for chronic knee pain: a systematic review. Rheumatology (Oxford), 2007. 46(3): p. 384-90.

109. National Institutes of Health. "Search Results for Electroacupuncture." Web. 21 April 2014.

$<\mathrm{http} / /$ clinicaltrials.gov/ct2/results?term=electroacupuncture\&recr=Open\&no_un $\mathrm{k}=\mathrm{Y}>$.

110. Han, H.J., et al, Clinical effect of additional electroacupuncture on thoracolumbar intervertebral disc herniation in 80 paraplegic dogs. Am J Chin Med, 2010. 38(6): p. 1015-25.

111. Hayashi, A.M., J.M. Matera, and A.C. Fonseca Pinto, Evaluation of electroacupuncture treatment for thoracolumbar intervertebral disk disease in dogs. J Am Vet Med Assoc, 2007. 231(6): p. 913-8.

112. Lin, C.F., et al, Depressor effect on blood pressure and flow elicited by electroacupuncture in normal subjects. Auton Neurosci, 2003. 107(1): p. 60-4.

113. Noguchi, E., et al., The effect of electro-acupuncture stimulation on the muscle blood flow of the hindlimb in anesthetized rats. J Auton Nerv Syst, 1999. 75(2-3): p. 78-86.

114. Li, W.J., et al, Electro-acupuncture upregulates CGRP expression after rat spinal cord transection. Neurochem Int, 2012. 61(8): p. 1397-403.

115. Li, Q.Q., et al, Acupuncture effect and central autonomic regulation. Evid Based Complement Alternat Med, 2013. 2013: p. 267959. 
116. Fang, J.Q., et al., Inhibitory effect of electroacupuncture on murine collagen arthritis and its possible mechanisms. In Vivo, 1999. 13(4): p. 311-8.

117. Lee, S.H. and B.C. Lee, Electroacupuncture relieves pain in men with chronic prostatitis/chronic pelvic pain syndrome: three-arm randomized trial. Urology, 2009. 73(5): p. 1036-41.

118. Knardahl, S., et al., Sympathetic nerve activity after acupuncture in humans. Pain, 1998. 75(1): p. 19-25.

119. Johnson, M.I. and G. Tabasam, An investigation into the analgesic effects of interferential currents and transcutaneous electrical nerve stimulation on experimentally induced ischemic pain in otherwise pain-free volunteers. Phys Ther, 2003. 83(3): p. 208-23.

120. Gracey, J.H., S.M. McDonough, and G.D. Baxter, Physiotherapy management of low back pain: a survey of current practice in northern Ireland. Spine (Phila $\mathrm{Pa}$ 1976), 2002. 27(4): p. 406-11.

121. Pope, G.D., S.P. Mockett, and J.P. Wright, A survey of electrotherapeutic modalities: ownership and use in the NHS in England. Physiotherapy, 1995. 81(2): p. 82-91.

122. Johnson, M.I. and G. Tabasam, A double blind placebo controlled investigation into the analgesic effects of interferential currents (IFC) and transcutaneous electrical nerve stimulation (TENS) on cold-induced pain in healthy subjects. Physiotherapy Theory and Practice 1999. 15(4): p. 217-233.

123. Tabasam, G. and M.I. Johnson, Electrotherapy for pain relief: does it work? A laboratory-based study to examine the analgesic effects of electrotherapy on coldinduced pain in healthy individuals. Clinical Effectiveness in Nursing 1999. 3(1): p. 14-24.

124. Johnson, M.I. and G. Tabasam, A single-blind placebo-controlled investigation into the analgesic effects of interferential currents on experimentally induced ischaemic pain in healthy subjects. Clin Physiol Funct Imaging, 2002. 22(3): p. 187-96.

125. Noble, J.G., et al., The effect of interferential therapy upon cutaneous blood flow in humans. Clin Physiol, 2000. 20(1): p. 2-7.

126. Santos, F.V., et al., Interferential electrical stimulation improves peripheral vasodilatation in healthy individuals. Braz J Phys Ther, 2013. 17(3): p. 281-8.

127. Leahy, MJ. Microcirculation Imaging. John Wiley \& Sons, 2012. Print. 
128. Zelis, R., D.T. Mason, and E. Braunwald, Partition of blood flow to the cutaneous and muscular beds of the forearm at rest and during leg exercise in normal subjects and in patients with heart failure. Circ Res, 1969. 24(6): p. 799-806.

129. Simmons, G.H., et al., Changes in the control of skin blood flow with exercise training: where do cutaneous vascular adaptations fit in? Exp Physiol, 2011. 96(9): p. 822-8.

130. Rendell, M. and O. Bamisedun, Diabetic cutaneous microangiopathy. Am J Med, 1992. 93(6): p. 611-8.

131. Park, J.W., et al., Sildenafil improves cutaneous microcirculation in patients with coronary artery disease: a monocentric, prospective, double-blind, placebocontrolled, randomized cross-over study. Clin Hemorheol Microcirc, 2004. 31(3): p. 173-83.

132. Brevetti, G., et al., Microcirculation and tissue metabolism in peripheral arterial disease. Clin Hemorheol Microcirc, 1999. 21(3-4): p. 245-54.

133. Reith, W., et al., Laser Doppler flowmetry of focal ischaemia and reperfusion in deep brain structures in rats. Acta Neurochir (Wien), 1994. 131(1-2): p. 151-6.

134. Machens, H.G., et al, Measurements of tissue blood flow by the hydrogen clearance technique (HCT): a comparative study including laser Doppler flowmetry $(L D F)$ and the Erlangen micro-lightguide spectrophotometer (EMPHO). Microsurgery, 1995. 16(12): p. 808-17.

135. Guy, R.H., E. Tur, and H.I. Maibach, Optical techniques for monitoring cutaneous microcirculation. Recent applications. Int J Dermatol, 1985. 24(2): p. 88-94.

136. Vaghela, D.J. and A.A. Sinha, Pulse oximetry and laser Doppler flowmetry for diagnosis of pulpal vitality. Journal of Interdisciplinary Dentistry 2011. 1(1).

137. Leutenegger, M., et al, Real-time full field laser Doppler imaging. Biomed Opt Express, 2011. 2(6): p. 1470-7.

138. Perimed AB. "PeriFlux System 5000 - Laser Doppler and Transcutaneous Oxygen." <http//www.perimed-instruments.com/products/instruments/laserdoppler-monitors/periflux-system-5000>.

139. Larsson, M. Integrated HSI and LSI setup. 3 June 2014. Image. $<$ http://www.imt.liu.se/bit/tabo/project_areas/ceniit_ml.html >. 
140. Forrester, K.R., et al, Comparison of laser speckle and laser Doppler perfusion imaging: measurement in human skin and rabbit articular tissue. Med Biol Eng Comput, 2002. 40(6): p. 687-97.

141. De Backer, D., K. Donadello, and D.O. Cortes, Monitoring the microcirculation. J Clin Monit Comput, 2012. 26(5): p. 361-6.

142. Draijer, M., et al., Twente Optical Perfusion Camera: system overview and performance for video rate laser Doppler perfusion imaging. Opt Express, 2009. 17(5): p. 3211-25.

143. Diamonda, J. and et.al., Medical Instrumentation \& Imaging. Technology and Health Care 2001. 9: p. 127-186.

144. Rajan, V., et al., Review of methodological developments in laser Doppler flowmetry. Lasers Med Sci, 2009. 24(2): p. 269-83.

145. Atochin, D.N., et al., Mouse model of microembolic stroke and reperfusion. Stroke, 2004. 35(9): p. 2177-82.

146. Dunn, A.K., et al., Simultaneous imaging of total cerebral hemoglobin concentration, oxygenation, and blood flow during functional activation. Opt Lett, 2003. 28(1): p. 28-30.

147. Kharlamov, A., et al., Heterogeneous response of cerebral blood flow to hypotension demonstrated by laser speckle imaging flowmetry in rats. Neurosci Lett, 2004. 368(2): p. 151-6.

148. Forrester, K.R., et al., A laser speckle imaging technique for measuring tissue perfusion. IEEE Trans Biomed Eng, 2004. 51(11): p. 2074-84.

149. Briers, J.D., Laser Doppler, speckle and related techniques for blood perfusion mapping and imaging. Physiol Meas, 2001. 22(4): p. R35-66.

150. Shung, K.K., Diagnostic ultrasound: Imaging and blood flow measurements. 2005: CRC Press.

151. Sun, J., et al., In vivo imaging of cerebral hemodynamics using high-frequency micro-ultrasound. Cold Spring Harb Protoc, 2010. 2010(9): p. pdb prot5495.

152. Golay, X. and M. Guenther, Arterial spin labelling: final steps to make it a clinical reality. MAGMA, 2012. 25(2): p. 79-82.

153. Jacobson, O., et al., Rat imaging and in vivo stability studies using [11C]dimethyl-diphenyl ammonium, a candidate agent for PET-myocardial perfusion imaging. Nucl Med Biol, 2013. 40(8): p. 967-73. 
154. Medical University of South Carolina. "Siemens Inveon Micro-CT/PET." 5 June 2014. Image.

$<$ http://academicdepartments.musc.edu/cbi/preclinical_imaging/siemens_inveon_ micro_ct_pet>.

155. Loaiza, L.A., et al., Electro-acupuncture stimulation to muscle afferents in anesthetized rats modulates the blood flow to the knee joint through autonomic reflexes and nitric oxide. Auton Neurosci, 2002. 97(2): p. 103-9.

156. Hollman, J.E. and B.J. Morgan, Effect of transcutaneous electrical nerve stimulation on the pressor response to static handgrip exercise. Phys Ther, 1997. 77(1): p. 28-36.

157. Radhakrishnan, R. and K.A. Sluka, Deep tissue afferents, but not cutaneous afferents, mediate transcutaneous electrical nerve stimulation-Induced antihyperalgesia. J Pain, 2005. 6(10): p. 673-80.

158. McLoughlin, P., R.A. Linton, and D.M. Band, Effects of potassium and lactic acid on chemoreceptor discharge in anaesthetized cats. Respir Physiol, 1995. 99(3): p. 303-12.

159. Prabhakar, N.R. and Y.J. Peng, Peripheral chemoreceptors in health and disease. J Appl Physiol (1985), 2004. 96(1): p. 359-66.

160. Mense, S. and Robert D. Gerwin. Muscle pain: understanding the mechanisms. Springer, 2010. Print.

161. Kon, H., et al., Muscle metaboreflex is blunted with reduced vascular resistance response of nonexercised limb in patients with chronic heart failure. J Card Fail, 2004. 10(6): p. 503-10.

162. Leuenberger, U.A., The muscle metaboreflex: reining in the heart? J Appl Physiol (1985), 2010. 109(2): p. 263-4.

163. Remensnyder, J.P., J.H. Mitchell, and S.J. Sarnoff, Functional sympatholysis during muscular activity. Observations on influence of carotid sinus on oxygen uptake. Circ Res, 1962. 11: p. 370-80.

164. Delliaux, S., et al., Reactive oxygen species activate the group IV muscle afferents in resting and exercising muscle in rats. Pflugers Arch, 2009. 459(1): p. 143-50.

165. Muller, M.D., et al., Oxidative stress contributes to the augmented exercise pressor reflex in peripheral arterial disease patients. J Physiol, 2012. 590( $\mathrm{Pt} 23)$ : p. 6237-46. 
166. Victor, R.G., et al., Effects of partial neuromuscular blockade on sympathetic nerve responses to static exercise in humans. Circ Res, 1989. 65(2): p. 468-76.

167. Sandberg, M.L., M.K. Sandberg, and J. Dahl, Blood flow changes in the trapezius muscle and overlying skin following transcutaneous electrical nerve stimulation. Phys Ther, 2007. 87(8): p. 1047-55.

168. Emanuelsson, H., et al., Catecholamine metabolism during pacing-induced angina pectoris and the effect of transcutaneous electrical nerve stimulation. Am Heart J, 1987. 114(6): p. 1360-6.

169. Kalra, A., M.O. Urban, and K.A. Sluka, Blockade of opioid receptors in rostral ventral medulla prevents antihyperalgesia produced by transcutaneous electrical nerve stimulation (TENS). J Pharmacol Exp Ther, 2001. 298(1): p. 257-63.

170. Hughes, G.S., Jr., et al., Response of plasma beta-endorphins to transcutaneous electrical nerve stimulation in healthy subjects. Phys Ther, 1984. 64(7): p. 10626.

171. Han, J.S., et al., Effect of low- and high-frequency TENS on Met-enkephalin-ArgPhe and dynorphin A immunoreactivity in human lumbar CSF. Pain, 1991. 47(3): p. 295-8.

172. Goodchild, C.S., et al., 5-HT spinal antinociception involves mu opioid receptors: cross tolerance and antagonist studies. Br J Anaesth, 1997. 78(5): p. 563-9.

173. Kishimoto, K., S. Koyama, and N. Akaike, Synergistic mu-opioid and 5-HT1A presynaptic inhibition of GABA release in rat periaqueductal gray neurons. Neuropharmacology, 2001. 41(5): p. 529-38.

174. Radhakrishnan, R., et al., Spinal 5-HT(2) and 5-HT(3) receptors mediate low, but not high, frequency TENS-induced antihyperalgesia in rats. Pain, 2003. 105(1-2): p. 205-13.

175. Sluka, K.A., T.L. Lisi, and K.N. Westlund, Increased release of serotonin in the spinal cord during low, but not high, frequency transcutaneous electric nerve stimulation in rats with joint inflammation. Arch Phys Med Rehabil, 2006. 87(8): p. 1137-40.

176. Kaada, B. and O. Eielsen, In search of mediators of skin vasodilation induced by transcutaneous nerve stimulation: II. Serotonin implicated. Gen Pharmacol, 1983. 14(6): p. 635-41.

177. Mylecharane, E.J., Mechanisms involved in serotonin-induced vasodilatation. Blood Vessels, 1990. 27(2-5): p. 116-26. 
178. von Kugelgen, I. and K. Starke, Release of noradrenaline and ATP by electrical stimulation and nicotine in guinea-pig vas deferens. Naunyn Schmiedebergs Arch Pharmacol, 1991. 344(4): p. 419-29.

179. Hein, L., J.D. Altman, and B.K. Kobilka, Two functionally distinct alpha2adrenergic receptors regulate sympathetic neurotransmission. Nature, 1999. 402(6758): p. 181-4.

180. Davis, K.D., et al, Topical application of clonidine relieves hyperalgesia in patients with sympathetically maintained pain. Pain, 1991. 47(3): p. 309-17.

181. Schwartz, D.D., Activation of alpha-2 adrenergic receptors inhibits norepinephrine release by a pertussis toxin-insensitive pathway independent of changes in cytosolic calcium in cultured rat sympathetic neurons. J Pharmacol Exp Ther, 1997. 282(1): p. 248-55.

182. Sommer, C., Serotonin in pain and analgesia: actions in the periphery. Mol Neurobiol, 2004. 30(2): p. 117-25.

183. Fairbanks, C.A., et al, alpha(2C)-Adrenergic receptors mediate spinal analgesia and adrenergic-opioid synergy. J Pharmacol Exp Ther, 2002. 300(1): p. 282-90.

184. Kaada, B. and O. Eielsen, In search of mediators of skin vasodilation induced by transcutaneous nerve stimulation: I. Failure to block the response by antagonists of endogenous vasodilators. Gen Pharmacol, 1983. 14(6): p. 623-33.

185. Cheng, J., et al., TENS stimulates constitutive nitric oxide release via opiate signaling in invertebrate neural tissues. Med Sci Monit, 2007. 13(8): p. BR163-7.

186. Kaada, B., Vasodilation induced by transcutaneous nerve stimulation in peripheral ischemia (Raynaud's phenomenon and diabetic polyneuropathy). Eur Heart J, 1982. 3(4): p. 303-14.

187. Ding, L., et al, Transcutaneous electrical nerve stimulation (TENS) improves the diabetic cytopathy $(D C P)$ via up-regulation of CGRP and cAMP. PLoS One, 2013. 8(2): p. e57477.

188. Struthers, A.D., et al, Human calcitonin gene related peptide: a potent endogenous vasodilator in man. Clin Sci (Lond), 1986. 70(4): p. 389-93.

189. Kaada, B., E. Olsen, and O. Eielsen, In search of mediators of skin vasodilation induced by transcutaneous nerve stimulation: III. Increase in plasma VIP in normal subjects and in Raynaud's disease. Gen Pharmacol, 1984. 15(2): p. 10713. 
190. Christensen, N.J., Sympathetic nervous activity and age. Eur J Clin Invest, 1982. 12(2): p. 91-2.

191. Ziegler, M.G., C.R. Lake, and I.J. Kopin, Plasma noradrenaline increases with age. Nature, 1976. 261(5558): p. 333-5.

192. Roseguini, B.T., et al., Muscle metaboreflex contribution to resting limb haemodynamic control is preserved in older subjects. Clin Physiol Funct Imaging, 2007. 27(5): p. 335-9.

193. Thijssen, D.H., et al., Sympathetic nervous system contributes to the age-related impairment of flow-mediated dilation of the superficial femoral artery. Am $\mathbf{J}$ Physiol Heart Circ Physiol, 2006. 291(6): p. H3122-9.

194. Houssiere, A., et al., Chemoreflex and metaboreflex responses to static hypoxic exercise in aging humans. Med Sci Sports Exerc, 2006. 38(2): p. 305-12.

195. Markel, T.A., et al., Aging and the exercise pressor reflex in humans. Circulation, 2003. 107(5): p. 675-8.

196. Wilson, L.B., et al., Effect of skeletal muscle fiber type on the pressor response evoked by static contraction in rabbits. J Appl Physiol (1985), 1995. 79(5): p. 1744-52.

197. Sullivan, V.K., et al., Myosin heavy chain composition in young and old rat skeletal muscle: effects of endurance exercise. J Appl Physiol (1985), 1995. 78(6): p. 2115-20.

198. Coutsos, M., et al., Muscle metaboreflex-induced coronary vasoconstriction limits ventricular contractility during dynamic exercise in heart failure. Am J Physiol Heart Circ Physiol, 2013. 304(7): p. H1029-37.

199. Westerhof, N. and M.F. O'Rourke, Haemodynamic basis for the development of left ventricular failure in systolic hypertension and for its logical therapy. $\mathrm{J}$ Hypertens, 1995. 13(9): p. 943-52.

200. Rondon, M.U., et al., Abnormal muscle metaboreflex control of sympathetic activity in never-treated hypertensive subjects. Am J Hypertens, 2006. 19(9): p. 951-7.

201. Grant, J.C. "Dermatomes of the Limbs." 13 April 2014. Image. <http://commons.wikimedia.org/wiki/File:Grant_1962_663.png>.

202. Gopalkrishnan, P. and K.A. Sluka, Effect of varying frequency, intensity, and pulse duration of transcutaneous electrical nerve stimulation on primary hyperalgesia in inflamed rats. Arch Phys Med Rehabil, 2000. 81(7): p. 984-90. 
203. Sjolund, B.H., Peripheral nerve stimulation suppression of $C$-fiber-evoked flexion reflex in rats. Part 1: Parameters of continuous stimulation. J Neurosurg, 1985. 63(4): p. 612-6.

204. Scudds, R.J., A. Helewa, and R.A. Scudds, The effects of transcutaneous electrical nerve stimulation on skin temperature in asymptomatic subjects. Phys Ther, 1995. 75(7): p. 621-8.

205. Rogers, G. and T. Oosthuyse, A comparison of the indirect estimate of mean arterial pressure calculated by the conventional equation and calculated to compensate for a change in heart rate. Int J Sports Med, 2000. 21(2): p. 90-5.

206. Meaney, E., et al., Formula and nomogram for the sphygmomanometric calculation of the mean arterial pressure. Heart, 2000. 84(1): p. 64.

207. Indergand, H.J. and B.J. Morgan, Effects of high-frequency transcutaneous electrical nerve stimulation on limb blood flow in healthy humans. Phys Ther, 1994. 74(4): p. 361-7.

208. van Dijk, A.E., et al., Measuring cardiac autonomic nervous system (ANS) activity in children. J Vis Exp, 2013(74): p. e50073.

209. Cheing, G.L. and W.W. Chan, Influence of choice of electrical stimulation site on peripheral neurophysiological and hypoalgesic effects. J Rehabil Med, 2009. 41(6): p. 412-7.

210. Brown, L., et al., An investigation into the effect of electrode placement of transcutaneous electrical nerve stimulation (TENS) on experimentally induced ischemic pain in healthy human participants. Clin J Pain, 2007. 23(9): p. 735-43.

211. Citak Karakaya, I., et al., Effects of different frequencies of conventional transcutaneous electrical nerve stimulation on pressure pain threshold and tolerance. J Back Musculoskelet Rehabil, 2014. 27(2): p. 197-201. 


\section{APPENDICES}

\section{Appendix A: Summary of Select Neurostimulation Studies on Hemodynamics}

Table A.1: Summary of TENS studies

\begin{tabular}{|c|c|c|c|c|c|}
\hline $\begin{array}{l}\text { Study } \\
\text { Author } \\
\text { Year }\end{array}$ & Purpose & $\begin{array}{l}\text { Model } \\
\text { Animal/Human } \\
\text { Healthy/Diseased }\end{array}$ & $\begin{array}{l}\text { Neurostimulation } \\
\text { Parameters Used } \\
\text { Intensity } \\
\text { Pulse width } \\
\text { Frequency } \\
\text { Duration } \\
\text { Location }\end{array}$ & Endpoints* & Possible Mechanism(s) of Action \\
\hline $\begin{array}{l}\text { Ter Laan [67] } \\
2010\end{array}$ & $\begin{array}{l}\text { Assessed the effect of } \\
\text { TENS on cerebral } \\
\text { blood flow and its } \\
\text { potential side-effects; } \\
\text { investigated the effects } \\
\text { of varying frequency } \\
\text { and hyperventilation; } \\
\text { accounted for } \\
\text { differences in age and } \\
\text { gender }\end{array}$ & $\begin{array}{l}\text { Human } \\
\text { Healthy }\end{array}$ & $\begin{array}{l}90 \% \text { of highest } \\
\text { tolerated current (about } \\
10 \text { to } 35 \mathrm{~mA} \text { ) } \\
200 \mu \mathrm{s} \\
2,20,50,100 \text { and } 120 \\
\mathrm{~Hz} \\
5 \text { minutes at each } \\
\text { frequency } \\
\text { Applied to the } \\
\text { dermatome at C2-C3 }\end{array}$ & $\begin{array}{l}\mathrm{MAP} ; \mathrm{HR} ; \mathrm{CBFV} \\
\mathrm{ETCO}_{2}\end{array}$ & $\begin{array}{l}\text { Either directly affects vascular } \\
\text { diameter or indirectly affects } \\
\text { sympathetic tone }\end{array}$ \\
\hline $\begin{array}{l}\text { Sanders on }[\mathbf{8 0}] \\
1995\end{array}$ & $\begin{array}{l}\text { Assessed the effect of } \\
\text { TENS on autonomic } \\
\text { cardiovascular reflexes } \\
\text { through noninvasive } \\
\text { tests i.e. tilt study, cold } \\
\text { face stimulus, } \\
\text { Valsalva's maneuver, } \\
\text { handgrip test, and } \\
\text { supine resting }\end{array}$ & $\begin{array}{l}\text { Human } \\
\text { Healthy }\end{array}$ & $\begin{array}{l}\text { Motor intensity } \\
200 \mu \mathrm{s} \\
150 \mathrm{~Hz} \\
\sim 35 \text { minutes } \\
\text { Applied to center of } \\
\text { chest and back }\end{array}$ & $\begin{array}{l}\text { SBP; DBP; MAP; } \\
\text { HR }\end{array}$ & $\begin{array}{l}\text { Mild effect on autonomic reflexes; } \\
\text { more effective during exercise when } \\
\text { sympathetic tone is more strongly } \\
\text { stimulated; possibly blocking or } \\
\text { interfering with vascular reflex } \\
\text { response within spinal cord }\end{array}$ \\
\hline
\end{tabular}

${ }^{*}$ MAP = Mean Arterial Pressure; HR = Heart Rate; CBFV = Cerebral Blood Flow Velocity; ETCO $_{2}=$ End-Tidal Carbon Dioxide Concentration; SBP = Systolic Blood Pressure; DBP = Diastolic Blood Pressure 


\begin{tabular}{|c|c|c|c|c|c|}
\hline $\begin{array}{l}\text { Study } \\
\text { Author } \\
\text { Year }\end{array}$ & Purpose & $\begin{array}{l}\text { Model } \\
\text { Animal/Human } \\
\text { Healthy/Dis eased }\end{array}$ & $\begin{array}{l}\text { Neurostimulation } \\
\text { Parameters Used } \\
\text { Intensity } \\
\text { Pulse width } \\
\text { Frequency } \\
\text { Duration } \\
\text { Location }\end{array}$ & Endpoints* & Possible Mechanism(s) of Action \\
\hline $\begin{array}{l}\text { Chauhan [33] } \\
1994\end{array}$ & $\begin{array}{l}\text { Assessed whether } \\
\text { TENS can relieve } \\
\text { ischemia associated } \\
\text { with angina pectoris } \\
\text { by increasing coronary } \\
\text { blood flow; accounted } \\
\text { for gender differences } \\
\text { and different disease } \\
\text { states }\end{array}$ & $\begin{array}{l}\text { Human } \\
\text { Diseased (Syndrome } \\
\text { X and CAD) and } \\
\text { "Healthy" (heart } \\
\text { transplant patients) }\end{array}$ & $\begin{array}{l}10-60 \mathrm{~mA} \\
300 \mu \mathrm{s} \\
150 \mathrm{~Hz} \\
5 \text { minutes } \\
\text { Chest near pain location }\end{array}$ & $\begin{array}{l}\text { CBFV; HR; MAP; } \\
\text { SBP; coronary } \\
\text { artery diameter; } \\
\text { epinephrine/norepi } \\
\text { nephine levels }\end{array}$ & $\begin{array}{l}\text { May affect coronary microvascular } \\
\text { tone as a result of changes in neural } \\
\text { tone resulting in increased coronary } \\
\text { blood flow; decreased sympathetic } \\
\text { activity within the heart }\end{array}$ \\
\hline $\begin{array}{l}\text { Mannheimer [36] } \\
1990\end{array}$ & $\begin{array}{l}\text { Assessed effect of } \\
\text { TENS on the } \\
\text { sympathetic nervous } \\
\text { system; administered } \\
\text { naloxone to determine } \\
\text { if natural opioid } \\
\text { release could be a } \\
\text { possible mechanism of } \\
\text { action }\end{array}$ & $\begin{array}{l}\text { Human } \\
\text { Diseased } \\
\text { Study I: Pacing- } \\
\text { induced angina } \\
\text { pectoris (Class III or } \\
\text { IV) } \\
\text { Study II: Pacing- } \\
\text { induced angina } \\
\text { pectoris (Class III or } \\
\text { IV) and CAD }\end{array}$ & $\begin{array}{l}30-50 \mathrm{~mA} \\
200 \mu \mathrm{s} \\
70 \mathrm{~Hz} \\
15 \text { minutes } \\
\text { Painful area of chest }\end{array}$ & $\begin{array}{l}\text { Left ventricular } \\
\text { afterload; SBP; } \\
\text { DBP; myocardial } \\
\text { lactate metabolism; } \\
\text { systemic and } \\
\text { pulmonary } \\
\text { resistance; oxygen } \\
\text { saturation; stroke } \\
\text { volume index; } \\
\text { cardiac index; HR; } \\
\text { concentrations of } \\
\text { epinephrine and } \\
\text { norpepinephrine }\end{array}$ & $\begin{array}{l}\text { Study I: Decrease in sympathetic } \\
\text { activity due to drop in arterial levels } \\
\text { of epinephrine and norepineprhine; } \\
\text { Study II: No change in SBP or levels } \\
\text { of epinephrine and norepinephine; not } \\
\text { mediated by beta-endorphins; may } \\
\text { activate delta or kappa receptor } \\
\text { agonists }\end{array}$ \\
\hline
\end{tabular}

${ }^{*}$ MAP = Mean Arterial Pressure; HR = Heart Rate; CBFV = Coronary Blood Flow Velocity; SBP = Systolic Blood Pressure; DBP = Dias tolic Blood Pressure 


\begin{tabular}{|c|c|c|c|c|c|}
\hline $\begin{array}{l}\text { Study } \\
\text { Author } \\
\text { Year }\end{array}$ & Purpose & $\begin{array}{l}\text { Model } \\
\text { Animal/Human } \\
\text { Healthy/Diseased }\end{array}$ & $\begin{array}{l}\text { Neurostimulation } \\
\text { Parameters Used } \\
\text { Intensity } \\
\text { Pulse width } \\
\text { Frequency } \\
\text { Duration } \\
\text { Location }\end{array}$ & Endpoints* & Possible Mechanism(s) of Action \\
\hline $\begin{array}{l}\text { Sherry [66] } \\
2001\end{array}$ & $\begin{array}{l}\text { Assessed the effect of } \\
\text { burst-mode TENS on } \\
\text { calf blood flow, } \\
\text { arterial pressure, and } \\
\text { skin temperature }\end{array}$ & $\begin{array}{l}\text { Human } \\
\text { Healthy }\end{array}$ & $\begin{array}{l}\text { Motor intensity } \\
250 \mu \text { s } \\
\text { Burst frequency: } 2 \\
\text { bursts per second } \\
\text { Carrier frequency: } 85 \\
\mathrm{~Hz} \\
5 \text { minutes } \\
\text { Peroneal and tibial } \\
\text { nerves }\end{array}$ & $\begin{array}{l}\mathrm{CBF} ; \mathrm{MAP} ; \text { skin } \\
\text { temperature; } \\
\mathrm{ETCO}_{2} ; \mathrm{BP} ; \mathrm{CVR}\end{array}$ & $\begin{array}{l}\text { Depends on stimulation intensity } \\
\text { whereby a higher intensity can cause } \\
\text { muscle contraction and a transient, } \\
\text { local increase in blood flow via } \\
\text { accumulation of metabolic vasodilator } \\
\text { substances and/or release of "relaxing } \\
\text { factors" from endothelium }\end{array}$ \\
\hline $\begin{array}{l}\text { Cramp [63] } \\
2000\end{array}$ & $\begin{array}{l}\text { Assessed the effect of } \\
\text { both high and low } \\
\text { frequency TENS on } \\
\text { local cutaneous blood } \\
\text { flow and skin } \\
\text { temperature }\end{array}$ & $\begin{array}{l}\text { Human } \\
\text { Healthy }\end{array}$ & $\begin{array}{l}\text { Sensory intensity } \\
200 \mu \mathrm{s} \\
\text { Low }(4 \mathrm{~Hz}) \text { and high } \\
(110 \mathrm{~Hz}) \\
15 \text { minutes } \\
\text { Median nerve of } \\
\text { forearm }\end{array}$ & $\begin{array}{l}\text { Forearm blood } \\
\text { perfusion; skin } \\
\text { temperature }\end{array}$ & $\begin{array}{l}\text { Low frequency stimulation elicits a } \\
\text { local increase in cutaneous blood flow } \\
\text { as a result of vasodilation but does not } \\
\text { affect skin temperature; may partially } \\
\text { inhibit the sympathetic nervous } \\
\text { system }\end{array}$ \\
\hline
\end{tabular}

${ }^{*}$ MAP = Mean Arterial Pressure; $\mathrm{BP}=$ Blood Pressure; $\mathrm{CBF}=$ Calf Blood Flow; CVR = Calf Vascular Resistance; ETCO $_{2}=$ End - Tidal Carbon Dioxide Concentration 


\begin{tabular}{|c|c|c|c|c|c|}
\hline $\begin{array}{l}\text { Study } \\
\text { Author } \\
\text { Year }\end{array}$ & Purpose & $\begin{array}{l}\text { Model } \\
\text { Animal/Human } \\
\text { Healthy/Diseased }\end{array}$ & $\begin{array}{l}\text { Neurostimulation } \\
\text { Parameters Used } \\
\text { Intensity } \\
\text { Pulse width } \\
\text { Frequency } \\
\text { Duration } \\
\text { Location }\end{array}$ & Endpoints* & Possible Mechanism(s) of Action \\
\hline $\begin{array}{l}\text { Vieira [81] } \\
2012\end{array}$ & $\begin{array}{l}\text { Assessed the effect of } \\
\text { TENS on } \\
\text { metaboreflex } \\
\text { activation and HRV in } \\
\text { both young and older } \\
\text { subjects }\end{array}$ & $\begin{array}{l}\text { Human } \\
\text { Healthy }\end{array}$ & $\begin{array}{l}\text { Sensory intensity } \\
150 \mu \mathrm{s} \\
80 \mathrm{~Hz} \\
30 \text { minutes } \\
\text { C7 and T4 vertebral } \\
\text { levels }\end{array}$ & $\begin{array}{l}\text { HR; MAP; CBF; } \\
\text { CVR; HRV }\end{array}$ & $\begin{array}{l}\text { Blunted muscle metaboreflex, reduced } \\
\text { sympathetic activity, and } \\
\text { improvement of the sympatho-vagal } \\
\text { balance with application of TENS, } \\
\text { especially in younger individuals; } \\
\text { metaboreflex may be attenuated in } \\
\text { older subjects }\end{array}$ \\
\hline $\begin{array}{l}\text { Indergand [207] } \\
1994\end{array}$ & $\begin{array}{l}\text { Assessed the effect of } \\
\text { TENS on limb blood } \\
\text { flow; compared both } \\
\text { sensory and motor } \\
\text { intensities }\end{array}$ & $\begin{array}{l}\text { Human } \\
\text { Healthy }\end{array}$ & $\begin{array}{l}\text { Both sensory and motor } \\
\text { intensity } \\
150 \mu \mathrm{s} \\
110 \mathrm{~Hz} \\
20 \mathrm{minutes} \\
\text { Left common peroneal } \\
\text { nerve and left tibial } \\
\text { nerve }\end{array}$ & $\begin{array}{l}\text { CBF; MAP; CVR; } \\
\text { skin temperature }\end{array}$ & $\begin{array}{l}\text { Both sensory and motor intensity } \\
\text { levels of TENS failed to elicit any } \\
\text { changes in CBF, MAP, or CVR; skin } \\
\text { temperature decreased during both } \\
\text { control and TENS }\end{array}$ \\
\hline
\end{tabular}

${ }^{*}$ MAP = Mean Arterial Pressure; HR = Heart Rate; CBF = Calf Blood Flow; CVR = Calf Vascular Resistance; HRV = Heart Rate Variability 
Table A.2: Summary of SCS studies

\begin{tabular}{|c|c|c|c|c|c|}
\hline $\begin{array}{l}\text { Study } \\
\text { Author } \\
\text { Year }\end{array}$ & Purpose P** $^{* *}$ & $\begin{array}{l}\text { Model } \\
\text { Animal/Human } \\
\text { Healthy/Diseased }\end{array}$ & $\begin{array}{l}\text { Neurostimulation } \\
\text { Parameters Used } \\
\text { Intensity } \\
\text { Pulse width } \\
\text { Frequency } \\
\text { Duration } \\
\text { Location }\end{array}$ & Endpoints* & Possible Mechanism(s) of Action** \\
\hline $\begin{array}{l}\text { Tallis [37] } \\
1983\end{array}$ & $\begin{array}{l}\text { Assessed whether } \\
\text { SCS could } \\
\text { potentially } \\
\text { improve clinical } \\
\text { outcomes for } \\
\text { PAOD patients; } \\
\text { compared to } \\
\text { placebo and } \\
\text { TENS as well }\end{array}$ & $\begin{array}{l}\text { Human } \\
\text { PAOD }\end{array}$ & $\begin{array}{l}8 \mathrm{~mA} \\
200 \mu \mathrm{s} \\
33 \mathrm{~Hz} \\
\text { Varied on the order of } \\
\text { months } \\
\text { Not indicated }\end{array}$ & $\begin{array}{l}\text { Claudication distance; } \\
\text { exercise tolerance using } \\
\text { bicycle ergometer; } \\
\text { CBF; MBF }\end{array}$ & $\begin{array}{l}\text { Inhibits vasoconstriction; antidromic } \\
\text { stimulation of sensory neurons may } \\
\text { cause release of prostaglandins and } \\
\text { prostacyclins in muscle }\end{array}$ \\
\hline $\begin{array}{l}\text { Gao [97] } \\
2010\end{array}$ & $\begin{array}{l}\text { Assessed the } \\
\text { effect of SCS on } \\
\text { peripheral } \\
\text { vasodilation at } \\
\text { different } \\
\text { frequencies; used } \\
\text { RTX and CGRP8- } \\
37 \text { to try to } \\
\text { elucidate } \\
\text { mechanisms }\end{array}$ & $\begin{array}{l}\text { Rats } \\
\text { Healthy }\end{array}$ & $\begin{array}{l}30 \%, 60 \% \text {, and } 90 \% \text { of } \\
\text { motor intensity } \\
200 \mu \text { s } \\
50,200 \text {, and } 500 \mathrm{~Hz} \\
2 \text { minutes } \\
\mathrm{L} 2-\mathrm{L} 3 \text { vertebral levels }\end{array}$ & CBF; MAP; CVR & $\begin{array}{l}\text { CGRP }_{8-37} \text { blocks vasodilation } \\
\text { induced by SCS; } \\
\text { SCS activates TRPV1-containing } \\
\text { sensory neurons to release } \\
\text { vasodilators; indirectly induces } \\
\text { release of NO; both antidromic and } \\
\text { sympathetic inhibition mechanisms } \\
\text { at work; higher frequencies i.e. } 500 \\
\text { Hz cause more vasodilation }\end{array}$ \\
\hline
\end{tabular}

${ }^{*}$ MAP = Mean Arterial Pressure; CBF = Cutaneous Blood Flow; CVR = Cutaneous Vascular Resistance; CGRP = Calcitonin Gene-Related Peptide; TRPV1 = Transient Receptor Potential Vanilloid-1;NO = Nitric Oxide; RTX = Resiniferatoxin 


\begin{tabular}{|c|c|c|c|c|c|}
\hline $\begin{array}{l}\text { Study } \\
\text { Author } \\
\text { Year }\end{array}$ & Purpose $^{\dagger \dagger}$ & $\begin{array}{l}\text { Model } \\
\text { Animal/Human } \\
\text { Healthy/Diseased }\end{array}$ & $\begin{array}{l}\text { Neurostimulation } \\
\text { Parameters Used } \\
\text { Intensity } \\
\text { Pulse width } \\
\text { Frequency } \\
\text { Duration } \\
\text { Location }\end{array}$ & Endpoints* & Possible Mechanism(s) of Action \\
\hline $\begin{array}{l}\text { Augustinsson [32] } \\
1985\end{array}$ & $\begin{array}{l}\text { Assessed the } \\
\text { potential for SCS } \\
\text { as a treatment for } \\
\text { PAOD and } \\
\text { whether it reduced } \\
\text { the number of } \\
\text { amputations }\end{array}$ & $\begin{array}{l}\text { Human } \\
\text { PAOD/diabetic; } \\
\text { Buerger's disease; } \\
\text { vasospastic } \\
\text { disorders }\end{array}$ & $\begin{array}{l}\text { Varied } \\
200 \mu \mathrm{s} \\
100 \mathrm{~Hz} \\
\sim 15 \text { months } \\
\text { T10 vertebral level for } \\
\text { affected legs, T3 and } \\
\text { C5 for affected arms }\end{array}$ & $\begin{array}{l}\text { SBP; skin temperature; } \\
\text { systolic toe pressure; pain } \\
\text { relief (qualitative); number } \\
\text { of amputations; healing of } \\
\text { ulcers; thumb pressure }\end{array}$ & $\begin{array}{l}\text { Suppresses vasospasmin addition to } \\
\text { pain; stimulation may cause } \\
\text { prostaglandin release having a local } \\
\text { dilatory effect on the vasculature or it } \\
\text { may simply block the noxious signal } \\
\text { which would decrease sympathetic } \\
\text { tone; may release segmental spinal } \\
\text { reflexes causing sympatholysis } \\
\text { within vessels in the extremities }\end{array}$ \\
\hline $\begin{array}{l}\text { Croom [96] } \\
1997\end{array}$ & $\begin{array}{l}\text { Assessed the } \\
\text { effect of SCS on } \\
\text { cutaneous } \\
\text { vasodilation, } \\
\text { specifically in } \\
\text { regards to the } \\
\text { release of CGRP } \\
\text { and substance P; } \\
\text { investigated } \\
\text { whether } \\
\text { rhizotomy of the } \\
\text { dorsal roots would } \\
\text { attenuate the } \\
\text { induced } \\
\text { vasodilation }\end{array}$ & $\begin{array}{l}\text { Rats } \\
\text { Healthy }\end{array}$ & $\begin{array}{l}0.2 \text { or } 0.6 \mathrm{~mA} \\
200 \mu \mathrm{s} \\
50 \mathrm{~Hz} \\
1 \text { minute } \\
\mathrm{L} 1-\mathrm{L} 2 \text { vertebral levels }\end{array}$ & CBF; CVR; MAP & $\begin{array}{l}\text { Vasodilation caused by release of } \\
\text { CGRP into the periphery via } \\
\text { antidromic activation of sensory } \\
\text { afferents in the dorsal roots, } \\
\text { specifically L3 - L5 dorsal roots are } \\
\text { necessary for increased cutaneous } \\
\text { hindpaw blood flow; substance P } \\
\text { does not play a major role in the } \\
\text { vasodilatory response }\end{array}$ \\
\hline
\end{tabular}

${ }^{*}$ MAP = Mean Arterial Pressure; CBF = Cutaneous Blood Flow; CVR = Cutaneous Vascular Resistance; CGRP = Calcitonin Gene-Related Peptide; SBP = Systolic Blood Pressure 
Table A.3: Summary of EA studies

\begin{tabular}{|c|c|c|c|c|c|}
\hline $\begin{array}{l}\text { Study } \\
\text { Author } \\
\text { Year }\end{array}$ & Purpose & $\begin{array}{l}\text { Model* } \\
\text { Animal/Human } \\
\text { Healthy/Diseased }\end{array}$ & $\begin{array}{l}\text { Neurostimulation } \\
\text { Parameters Used } \\
\text { Intensity } \\
\text { Pulse width } \\
\text { Frequency } \\
\text { Duration } \\
\text { Location }\end{array}$ & Endpoints* & Possible Mechanism(s) of Action \\
\hline $\begin{array}{l}\text { Lin [112] } \\
2003\end{array}$ & $\begin{array}{l}\text { Assessed whether } \\
\text { EA has a depressor } \\
\text { effect on the } \\
\text { cardiovascular } \\
\text { system }\end{array}$ & $\begin{array}{l}\text { Human } \\
\text { Healthy }\end{array}$ & $\begin{array}{l}5 \mathrm{x} \text { above sensory intensity } \\
50 \mu \mathrm{s} \\
2 \mathrm{~Hz} \\
3 \mathrm{minutes} \\
\text { "Hoku" point (LI-4) i.e. } \\
\text { between index finger and } \\
\text { thumb }\end{array}$ & BP, PVT, FBF, HR & $\begin{array}{l}\text { Increased PVT explained by decreased } \\
\text { response of sympathetic nerve system, } \\
\text { which caused dilation of arterioles; BP } \\
\text { and FBF decreased while HR increased }\end{array}$ \\
\hline $\begin{array}{l}\text { Zhou [68] } \\
2013\end{array}$ & $\begin{array}{l}\text { Assessed whether } \\
\text { EA-induced } \\
\text { cerebral protection } \\
\text { against is chemia } \\
\text { was dependent on } \\
\text { stimulation of } \\
\text { certain acupoints }\end{array}$ & $\begin{array}{l}\text { Rats } \\
\text { Induced cerebral } \\
\text { ischemia via } \\
\text { MCAO }\end{array}$ & $\begin{array}{l}1 \mathrm{~mA} \\
500 \mu \mathrm{s} \\
5 \mathrm{~Hz} \text { or } 20 \mathrm{~Hz} \\
30 \text { minutes } \\
4 \text { different acupoints:DU- } \\
26 \& \text { DU-20, left LI-11 \& } \\
\text { PC-6, right LI-11 \& PC-6, } \\
\text { and left GB-34 \& SP-6 i.e. } \\
\text { head, face, anterior limbs }\end{array}$ & $\begin{array}{l}\text { Infarct volume; death } \\
\text { rate; neurological } \\
\text { deficits; CBF }\end{array}$ & $\begin{array}{l}\text { Location of stimulation can have a } \\
\text { protective effect against cerebral } \\
\text { ischemia possibly via regulation of } \\
\text { neurotransmitter release, causing an } \\
\text { increase in blood flow, but only in } \\
\text { ischemic conditions }\end{array}$ \\
\hline
\end{tabular}

${ }^{*} \mathrm{CBF}=$ Cerebral Blood Flow; $\mathrm{BP}=\mathrm{Blood}$ Pressure; PVT = Paravertebral Temperature; FBF = Finger Blood Flow; HR = Heart Rate; MCAO = Middle Cerebral Artery Occlusion 


\begin{tabular}{|c|c|c|c|c|c|}
\hline $\begin{array}{l}\text { Study } \\
\text { Author } \\
\text { Year }\end{array}$ & Purpose & $\begin{array}{l}\text { Model }^{*} \\
\text { Animal/Human } \\
\text { Healthy/Diseased }\end{array}$ & $\begin{array}{l}\text { Neurostimulation } \\
\text { Parameters Used } \\
\text { Intensity } \\
\text { Pulse width } \\
\text { Frequency } \\
\text { Duration } \\
\text { Location }\end{array}$ & Endpoints $^{*}$ & Possible Mechanism(s) of Action \\
\hline $\begin{array}{l}\text { Noguchi } \\
{[\mathbf{1 1 3}]} \\
1999\end{array}$ & $\begin{array}{l}\text { Assessed whether } \\
\text { EA stimulation } \\
\text { could induce } \\
\text { changes in muscle } \\
\text { blood flow and } \\
\text { determined which } \\
\text { somatic afferent } \\
\text { fibers were } \\
\text { responsible for } \\
\text { these changes }\end{array}$ & $\begin{array}{l}\text { Rats } \\
\text { Healthy }\end{array}$ & $\begin{array}{l}0.1-10 \mathrm{~mA} \\
500 \mu \mathrm{s} \\
1-20 \mathrm{~Hz} \\
30 \text { seconds } \\
\text { Left and right hindpaws }\end{array}$ & MBF; MAP; RBF & $\begin{array}{l}\text { Stimulation of group III and IV } \\
\text { afferent fibers in saphenous and tibial } \\
\text { nerves produces an increase in MBF in } \\
\text { conjunction with an increase in } \\
\text { systemic MAP; splanchnic nerve } \\
\text { severance decreases MBF suggesting } \\
\text { group III and IV afferent fibers } \\
\text { primarily excite a vasoconstrictive } \\
\text { response; the pressor response still } \\
\text { dominates in muscles causing more } \\
\text { vasodilation than vasoconstriction; } \\
\text { stimulation of group I and II afferent } \\
\text { fibers seems to be ineffective }\end{array}$ \\
\hline $\begin{array}{l}\text { Kimura [64] } \\
2008\end{array}$ & $\begin{array}{l}\text { Assessed the effect } \\
\text { of EA on the } \\
\text { rhythmicity of the } \\
\text { autonomic nervous } \\
\text { system }\end{array}$ & Canine Healthy & $\begin{array}{l}5 \mathrm{~V} \\
250 \mu \mathrm{s} \\
2 \mathrm{~Hz} \\
15 \text { minutes } \\
\text { "Xuan Shu" (GV-5) and } \\
\text { "Bai Hui" (GV-20) i.e. T13- } \\
\text { L1 and L7-S1 spinal } \\
\text { segment levels }\end{array}$ & $\begin{array}{l}\text { HR; CVRR; LF/HF; } \\
\text { HRV }\end{array}$ & $\begin{array}{l}\text { Activates sympathetic nervous } \\
\text { activities as evidenced by increase in } \\
\text { LF/HF ratio }\end{array}$ \\
\hline
\end{tabular}

${ }^{*} \mathrm{MAP}=$ Mean Arterial Pressure; HR = Heart Rate; RBF = Renal Blood Flow; MBF = Muscle Blood Flow; CVRR = Coefficient of Variati on in R-R Intervals; LF/HF = Low-Frequency/High Frequency (components of HRV); HRV = Heart Rate Variability 
Table A.4: Summary of IFC studies

\begin{tabular}{|c|c|c|c|c|c|}
\hline $\begin{array}{l}\text { Study } \\
\text { Author } \\
\text { Year }\end{array}$ & Purpose & $\begin{array}{l}\text { Model } \\
\text { Animal/Human } \\
\text { Healthy/Diseased }\end{array}$ & $\begin{array}{l}\text { Neurostimulation } \\
\text { Parameters Used } \\
\text { Intensity } \\
\text { Pulse width } \\
\text { Frequency } \\
\text { Duration } \\
\text { Location }\end{array}$ & Endpoints* & Possible Mechanism(s) of Action \\
\hline $\begin{array}{l}\text { Johns on [119] } \\
2003\end{array}$ & $\begin{array}{l}\text { Assessed the analgesic } \\
\text { effects of both IFC } \\
\text { and TENS on induced } \\
\text { ischemic pain }\end{array}$ & $\begin{array}{l}\text { Human } \\
\text { Healthy }\end{array}$ & $\begin{array}{l}\text { Sensory intensity } \\
200 \mu \mathrm{s} \\
100 \mathrm{~Hz} \\
22 \text { minutes } \\
\text { Anterior and posterior } \\
\text { aspects of forearm }\end{array}$ & $\begin{array}{l}\text { Amount of pain } \\
\text { experienced (VAS \& } \\
\text { MPQ scores) }\end{array}$ & $\begin{array}{l}\text { Selective activation of A-beta } \\
\text { nerve fibers }\end{array}$ \\
\hline $\begin{array}{l}\text { Noble }[\mathbf{1 2 5}] \\
2000\end{array}$ & $\begin{array}{l}\text { Assessed the effect of } \\
\text { varying frequency of } \\
\text { IFC on CBF }\end{array}$ & $\begin{array}{l}\text { Human } \\
\text { Healthy }\end{array}$ & $\begin{array}{l}\text { Sensory intensity } \\
125 \mu \mathrm{s} \\
10-100,80-100, \text { and } 10-20 \\
\mathrm{~Hz} \\
15 \text { minutes } \\
\text { Medial and lateral aspects of } \\
\text { the thigh }\end{array}$ & Skin temperature; CBF & $\begin{array}{l}\text { Low frequency }(10-20 \mathrm{~Hz}) \text { causes } \\
\text { increases in CBF and skin } \\
\text { temperature through inhibition of } \\
\text { the sympathetic nervous system }\end{array}$ \\
\hline $\begin{array}{l}\text { Santos [126] } \\
2013\end{array}$ & $\begin{array}{l}\text { Assessed the effect of } \\
\text { IFC on muscle } \\
\text { metaboreflex } \\
\text { activation and } \\
\text { peripheral vasodilation }\end{array}$ & $\begin{array}{l}\text { Human } \\
\text { Healthy }\end{array}$ & $\begin{array}{l}\text { Sensory intensity } \\
\text { Not indicated } \\
100 \mathrm{~Hz} \\
30 \text { minutes } \\
\text { C7 and T4 spinal segments }\end{array}$ & $\begin{array}{l}\text { MAP; HR; CBF; CVR; } \\
\text { metaboreflex activity }\end{array}$ & $\begin{array}{l}\text { Decrease in MAP and metaboreflex } \\
\text { activity indicates reduction in } \\
\text { sympathetic tone; reduced CVR } \\
\text { and increased CBF }\end{array}$ \\
\hline
\end{tabular}

${ }^{*} \mathrm{MAP}=$ Mean Arterial Pressure; HR = Heart Rate; RBF = Renal Blood Flow; MBF = Muscle Blood Flow; CVRR = Coefficient of Variati on in R-R Intervals; LF/HF = Low-Frequency/High Frequency (components of HRV); HRV = Heart Rate Variability 


\section{Appendix B: Informed Consent Form}

INFORMED CONSENT TO PARTICIPATE IN A RESEARCH PROJECT: "Determining Limb Blood Flow Changes in Response to Electrical Neurostimulation".

A research project on peripheral blood flow and ischemic pain is being conducted by Sean Youra and Stacey Fishman in the Department of Biomedical Engineering at Cal Poly, San Luis Obispo. The purpose of the study is to measure changes in blood flow, heart rate, and blood pressure due to the application of electrical neurostimulation.

You are being asked to take part in this study by first filling out a short medical history questionnaire. Questions marked with an asterisk (*) are required, but any others you do not wish to answer may be omitted. These questions are directly related to your safety. During each treatment session, you will be hooked up to a neurostimulation device that will be attached to your upper back with electrodes, a blood flow measurement system using skin probes on the upper arms, a respiration belt wrapped around your midsection, and a blood pressure cuff applied to each arm. Appropriate clothing should be worn to ensure proper placement of the electrodes, and a researcher from the same gender will be there to place the electrodes on your upper back. You will be asked to squeeze a handgrip force measurement device for a short period of time. You will experience electrical stimulation from the attached electrodes, which you may feel as a warm, tingling sensation on your back. Your participation will take approximately 1 hour in two separate sessions on two different days, which includes a 30-minute break in-between each session, for a total of approximately 2 hours. In some of these sessions, the neurostimulation device will be hooked up to you, but no current will be applied, as in you will not feelany sensation on your back. This will be randomized. Please be aware that you are not required to participate in this research and you may discontinue your participation at any time without penalty.

The possible risks associated with participation in this study include pain due to temporarily induced ischemia i.e. insufficient blood flow to the tissue, skin irritation from the application of skin probes and electrodes, and possible discomfort and/or stress from gripping the hand force measurement device. If your personal pain tolerance threshold is reached at any point, you may discontinue your participation immediately. If you should experience residual pain or tingling after the duration of the experiment or an allergic reaction at the site of the probes or electrodes, please be aware that you may contact Cal Poly Health and Counseling Services, located in building 27, at (805) 756-1211 for assistance.

Your confidentiality will be protected by recording your medical history, age, gender, height and weight on a document with a corresponding code. This document will be kept as a hard copy only and separate from the corresponding list of codes. Your information will only be accessible to the researchers in this study. If the results of the study are published, any identifying information will be omitted. There are no direct benefits to you associated with this study. Depending on the outcome of the study, this could become an additional treatment method for individuals with ischemic pain. 
If you have questions regarding this study or would like to be informed of the results when the study is completed, please feelfree to contact Sean Youra at (949) 697-5789, Stacey Fishman at (860) 338-4085, or Dr. Trevor Cardinal at (805) 756-6244. If you have concerns regarding the manner in which the study is conducted, you may contact Dr. Steve Davis, Chair of the Cal Poly Human Subjects Committee, at (805) 756-2754, sdavis@ calpoly.edu, or Dr. Dean Wendt, Interim Dean of Research, at (805) 756-1508, dwendt@ calpoly.edu.

If you agree to voluntarily participate in this research project as described, please indicate your agreement by signing below. Please keep one copy of this form for your reference, and thank you for your participation in this research.

Signature of Volunteer

Date

Signature of Researcher

Date 


\section{Appendix C: Medical History And Screening Form}

* Required

\section{General Information}

\section{Participant:}

Name

Contact phone numbers

Age

Height

Weight

\section{Sex:}

$\square$ Male $\square$ Female

\section{Women only ans wer the following:}

Yes No

$\square \square$ *Are you currently pregnant?

$\square \quad \square \quad$ Are you currently breast-feeding?

\section{Men and women ans wer the following:}

List any prescription medications you are now taking:

${ }^{*}$ Do you have any implantable electrical devices (pacemaker, spinal cord stimulator, etc.)? If so, please list them below:

${ }^{*}$ In the past two months, have you experienced a major injury or significant trauma to your arms or upper back? If so, please describe: 


\section{Past Medical History}

* Required

\section{Have you ever had any of the following:}

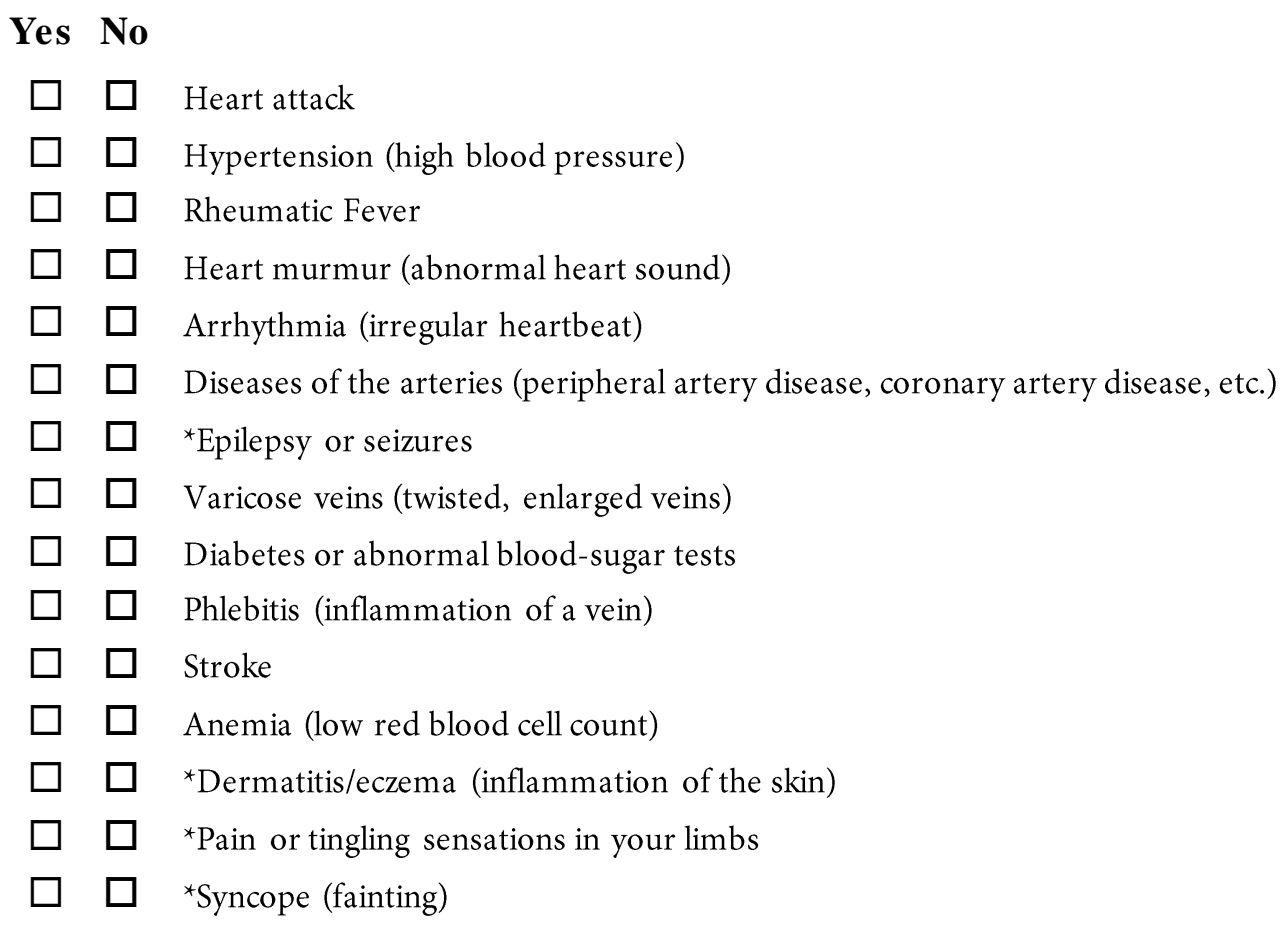

\section{Smoking}

Have you ever smoked cigarettes, cigars or a pipe?

$\square$ Yes $\square$ No

If you have stopped smoking, when was it?

If you now smoke, how long ago did you start?

\section{Drinking}

Do you ever drink alcoholic beverages?

$\square$ Yes $\square$ No

At any time in the past, were you a heavy drinker (consumption of six ounces of hard liquor per day or more)?

$\square$ Yes $\quad \square$ No 
Appendix D: Numeric Pain Rating Scale

\section{0-10 Numeric Pain Rating Scale}

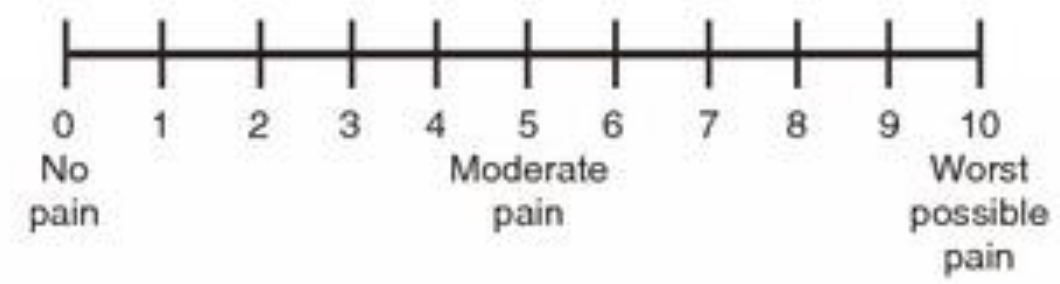




\section{Appendix E: Protocol For The Pilot Study}

* Setup

Turn on the laptop.

Connect the power supply to PowerLab.

Connect the USB cable from PowerLab to the laptop.

Connect the respiration belt to Input 1 on the front panel of PowerLab.

Connect the Hand Dynamometer to Input 2 on the front panel of PowerLab.

Connect the power supply to the Laser Doppler Flow (LDF) system and turn it on.

Connect the skin probes to Channels 1 and 2 on the LDF system.

Connect the BNC cables from the LDF system to Inputs 3 and 4 on the front panel of PowerLab.

Turn on the PowerLab system.

Open LabChart on the laptop and open the customized settings file.

The raw breath signal in millivolts $(\mathrm{mV})$, the respiratory rate in breaths per minute (BPM), the handgrip force in Newtons $(\mathrm{N}), \mathrm{CBF} 1$ in perfusion units (PU), and CBF 2 in PU should all be displayed in LabChart at this point.

Application

Seat the participant in a chair with both arms supinated and gently resting on the pillow. Ensure that they are comfortable and properly positioned before continuing.

Instruct the participant to loosely grip the Hand Dynamometer in the fist of their left hand.

Instruct the participant to squeeze the Hand Dynamometer as hard as possible for a second or two, and then relax their grip.*

Determine Maximum Voluntary Contraction (MVC) by recording the average of three handgrip trials and calculate 25\% of MVC.

Apply the TENS electrodes to the C7 and T4 vertebrae locations, approximately $3 \mathrm{~cm}$ to the left and right of the vertebral column (Figure 4.4). ${ }^{\dagger}$

\footnotetext{
* Adapted from BMED 460 - "Muscle Stimulation Fatigue Student Protocol” by Trevor Cardinal

${ }^{+}$Adapted from "Effect of transcutaneous electrical nerve stimulation on muscle metaboreflex in healthy young and older subjects." by Vieira, et. al.
} 


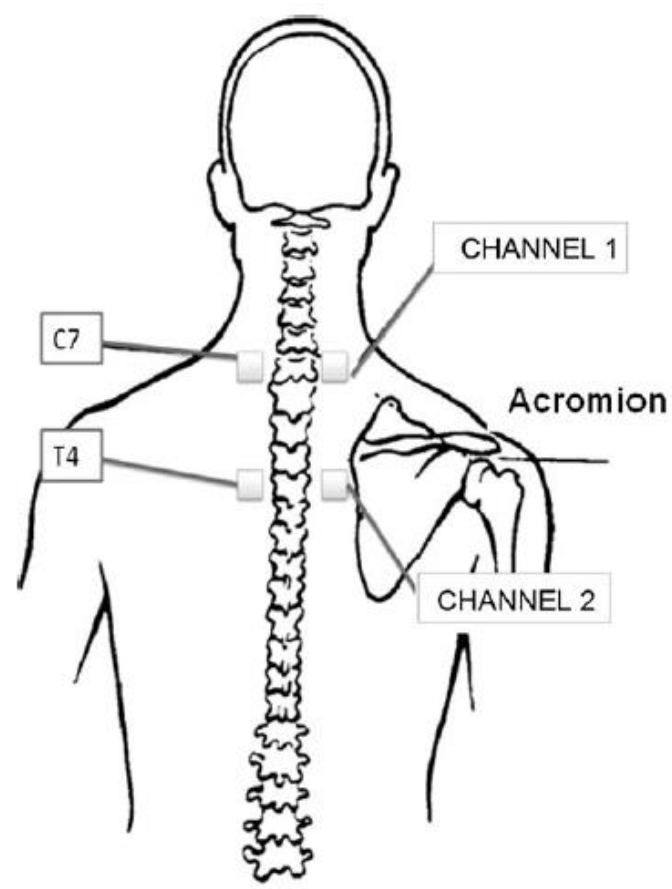

Figure D.1: TENS Electrode Placement at the C7 and T4 Regions*

Wrap the respiration belt around the participant's chest, just below the xiphoid process.

Attach the skin probe connected to Channel 1 of the LDF system to the left arm, $2 \mathrm{~cm}$ below the crease of the wrist.

Attach the skin probe connected to Channel 2 of the LDF system to the right arm, $2 \mathrm{~cm}$ below the crease of the wrist.

Wrap the cuff connected to the manual sphygmomanometer around the participant's left forearm, $2 \mathrm{~cm}$ below the crease of the elbow.

Wrap the cuff connected to the blood pressure monitor around the participant's right arm.

Set the stimulation frequency to $100 \mathrm{~Hz}$, pulse duration to $200 \mu \mathrm{s}$, and slowly adjust the intensity to just above sensory threshold (no pain or muscle contraction) by asking the participant when he/she begins to feel a strong, but comfortable tingling sensation.

* Treatment

Begin treatment according to assigned group code. ${ }^{\dagger}$

Every minute, assess the intensity of the participant's pain via the NPRS. In addition, halfway through each interval of the treatment i.e. "baseline",

\footnotetext{
* Adapted from "Effect of transcutaneous electrical nerve stimulation on muscle metaboreflex in heal thy young and older subjects." by Vieira, et. al.

${ }^{+}$Group codes: Control/PECO- (CP-), Control/PECO+ (CP+), TENS/PECO- (TP-), TENS/PECO+ (TP+)
} 
"exercise", "occlusion", and "recovery", record the participant's blood pressure and heart rate from the monitor.

Begin recording baseline blood flow for 3 minutes.

Place the hand dynamometer in the participant's left hand. Instruct the participant to perform a static handgrip exercise for 3 minutes at $25 \%$ MVC.

Five seconds before exercise completion, inflate the sphygmomanometer cuff to $180 \mathrm{mmHg}^{*}$

- Maintain cuff inflation at $180 \mathrm{mmHg}$ for 3 minutes, while still recording blood flow.

Deflate the cuff immediately and record for 3 minutes.

Stop recording.

Insert comments for "baseline", "exercise", "occlusion", and "recovery" at the end of each interval.

Detach all equipment from the participant and wait at least 30 minutes before beginning the next treatment.

* Only if PECO+ group 


\section{Appendix F: Averages From Pre-Pilot Work}

Table F.1: Average percent change for all hemodynamic parameters for each treatment condition

\begin{tabular}{lrrr}
\hline & Exercise & Occlusion & Recovery \\
\hline Control $(\mathrm{n}=20)$ & & -90.1396 & \\
\hline CBF 1 & 20.61408 & 10.56105 & -7.5512 \\
CBF 2 & 6.181795 & 2.513589 & 1.065731 \\
SBP & 4.922132 & 4.212532 & 2.391328 \\
DBP & 4.045545 & 4.732632 & -0.72447 \\
HR & 4.116884 & 3.420077 & 1.658637 \\
MAP & 4.343151 & 1258.739 & -36.7768 \\
CVR 1 & 1.979512 & -3.54692 & 12.89023 \\
CVR 2 & -1.34234 & & \\
\hline TENS Application & & & \\
on the Back at High & & & 185.0897 \\
Frequency (n=6) & & -81.5803 & -8.40812 \\
CBF 1 & & -12.4239 & 5.120653 \\
CBF 2 & & 5.324572 & -0.03608 \\
SBP & -5.5738 & 5.411255 & 2.195767 \\
DBP & 6.04962 & -2.43386 & 2.147184 \\
HR & 0.036075 & 5.37299 & -54.2402 \\
MAP & 2.698413 & 570.4271 & 13.07613 \\
CVR 1 & 2.595939 & 21.19491 & \\
CVR 2 & -18.2172 & & \\
\hline TENS Application & 11.68384 & & \\
\hline
\end{tabular}

TENS Application on the Forearm at High Frequency ( $\mathrm{n}$ $=2$ )

\begin{tabular}{lrrr}
\hline CBF 1 & 16.45631 & -80.0942 & 114.3978 \\
CBF 2 & 17.8305 & 24.17139 & 2.384457 \\
SBP & 0.81187 & 2.874207 & -4.04069 \\
DBP & 3.159981 & 5.538713 & 0.034981 \\
HR & 8.249337 & 6.618037 & 2.122016 \\
MAP & 2.145089 & 4.337402 & -1.7909 \\
CVR 1 & -5.08757 & 597.8964 & -45.3314 \\
CVR 2 & -12.8027 & -13.8696 & -3.84971 \\
\hline TENS Application & & & \\
on the Back at Low & & & \\
Frequency (n=2) & & & \\
\hline CBF 1 & & -77.4402 & 259.6295 \\
CBF 2 & 14.16821 & 14.37029 & 4.612285 \\
SBP & 14.21466 & -3.0833 & 0.531915 \\
DBP & 10.29571 & 2.34357 & 2.574463 \\
HR & 9.732163 & 2.675439 & 5.921053 \\
\hline
\end{tabular}




\begin{tabular}{|c|c|c|c|}
\hline MAP & 9.975071 & -0.03917 & 1.698718 \\
\hline CVR 1 & -10.7307 & 802.1998 & -52.9969 \\
\hline CVR 2 & -3.47213 & -10.4482 & -2.73357 \\
\hline \multicolumn{4}{|c|}{$\begin{array}{l}\text { TENS Application } \\
\text { on the Forearm at } \\
\text { Low Frequency (n } \\
=2 \text { ) }\end{array}$} \\
\hline CBF 1 & 44.57743 & -82.7889 & 72.09013 \\
\hline CBF 2 & 5.046217 & 19.99818 & -6.70987 \\
\hline SBP & 0.423812 & -5.45535 & -1.87759 \\
\hline DBP & 6.737288 & 4.265537 & 3.418079 \\
\hline HR & 4.312039 & 5.454545 & -5.42998 \\
\hline MAP & 3.67893 & -0.19509 & 1.161278 \\
\hline CVR 1 & -16.3281 & 1184.719 & -34.5453 \\
\hline CVR 2 & 0.07898 & -16.9482 & 9.427779 \\
\hline \multicolumn{4}{|c|}{$\begin{array}{l}\text { IFC Application on } \\
\text { the Back }(n=2)\end{array}$} \\
\hline CBF 1 & -15.2391 & -80.6055 & 3.330334 \\
\hline CBF 2 & 1.131429 & -1.04201 & -0.52675 \\
\hline SBP & -1.40911 & 6.140351 & -0.90519 \\
\hline DBP & 6.299841 & 5.023923 & 2.232855 \\
\hline HR & 13.95161 & 8.225806 & 8.252688 \\
\hline MAP & 2.753674 & 5.581614 & 0.869684 \\
\hline CVR 1 & 25.3756 & 445.1115 & 0.364934 \\
\hline CVR 2 & 1.982277 & 6.688098 & 2.013535 \\
\hline \multicolumn{4}{|c|}{$\begin{array}{l}\text { IFC Application on } \\
\text { the Forearm }(n=4)\end{array}$} \\
\hline CBF 1 & 68.73909 & -89.7606 & 117.8071 \\
\hline CBF 2 & 20.54841 & 37.41265 & 5.370384 \\
\hline SBP & 3.632479 & 6.452991 & 3.076923 \\
\hline DBP & -4.3794 & 1.947623 & -2.26673 \\
\hline HR & 2.255727 & 8.625526 & -1.6129 \\
\hline MAP & -0.92894 & 4.044313 & 0 \\
\hline CVR 1 & -10.8726 & 1518.964 & -43.7508 \\
\hline CVR 2 & -16.7931 & -20.5259 & -2.40704 \\
\hline
\end{tabular}




\section{Appendix G: Statistical Analysis}

Table G.1: Two-way Repeated Measures ANOVA P-values for Hemodynamic Endpoints

\begin{tabular}{lllll}
\hline & Baseline & Exercise & Occlusion & Recovery \\
\hline CBF 1 & - & 0.5962 & 0.0525 & 0.2257 \\
CBF 2 & - & 0.4950 & 0.4691 & 0.9333 \\
SBP & - & 0.5827 & 0.7223 & 0.8479 \\
DBP & - & 0.4988 & 0.9417 & 0.8843 \\
HR & - & 0.4601 & 0.9878 & 0.2911 \\
MAP & - & 0.2122 & 0.8725 & 0.7789 \\
CVR 1 & - & 0.8997 & 0.3380 & 0.3474 \\
CVR 2 & - & 0.3535 & 0.2601 & 0.6502 \\
Pain Intensity & 0.0817 & 0.0654 & 0.2176 & 0.3325 \\
\hline
\end{tabular}

\begin{tabular}{ll}
\hline & P-value \\
\hline Reperfusion Time & $0.039^{*}$ \\
\hline
\end{tabular}

* Dunnett's Test Comparison: IFC on Back significantly different from control 